\title{
WestVirginiaUniversity
}

THE RESEARCH REPOSITORY @ WVU

Graduate Theses, Dissertations, and Problem Reports

2011

\section{Class III correction using an inter-arch spring loaded module}

\author{
Robert VanLaecken \\ West Virginia University
}

Follow this and additional works at: https://researchrepository.wvu.edu/etd

\section{Recommended Citation}

VanLaecken, Robert, "Class III correction using an inter-arch spring loaded module" (2011). Graduate Theses, Dissertations, and Problem Reports. 3439.

https://researchrepository.wvu.edu/etd/3439

This Thesis is protected by copyright and/or related rights. It has been brought to you by the The Research Repository @ WVU with permission from the rights-holder(s). You are free to use this Thesis in any way that is permitted by the copyright and related rights legislation that applies to your use. For other uses you must obtain permission from the rights-holder(s) directly, unless additional rights are indicated by a Creative Commons license in the record and/ or on the work itself. This Thesis has been accepted for inclusion in WVU Graduate Theses, Dissertations, and Problem Reports collection by an authorized administrator of The Research Repository @ WVU. For more information, please contact researchrepository@mail.wvu.edu. 


\title{
Class III correction using an inter-arch spring loaded module
}

Robert VanLaecken, DDS

\section{A THESIS}

\author{
Submitted to: \\ The School of Dentistry \\ at West Virginia University \\ in partial fulfillment of the requirements \\ for the degree of \\ Master of Science \\ In \\ Orthodontics
}

Peter Ngan, D.M.D., Chair

Chris Martin, D.D.S., M.S.

Thomas Razmus, D.D.S., M.S.

Department of Orthodontics

Morgantown, West Virginia

2011 


\title{
Abstract \\ Class III correction using an inter-arch spring loaded module
}

\author{
Robert VanLaecken, D.D.S., D.M.D.
}

\begin{abstract}
Objectives: To determine the skeletal and dental changes seen in the sagittal, vertical, and angular directions in a group of patients who had undergone treatment with an inter-arch spring loaded module, the CS2000® appliance. Methods: The treatment group consisted of 30 patients treated in the private practice office of Dr. Michael Williams in Gulfport, MS, (15 males, 15 females) with an average pre-treatment age of 9.6 and post-treatment age of 10.9 . The average treatment time for the pooled group studied was 1.3 years. Lateral cephalometric films were collected from pre-treatment records before treatment began and from post-treatment records after CS2000® appliance removal. The two radiographs were then compared to allow a final calculation of average total effect seen by the CS2000® appliance in addition to normal growth of each patient during the treatment time prescribed. Results: Significant sagittal, vertical, and angular changes were seen between the pre-treatment and post-treatment. The maxillary base was found to move $1.5 \mathrm{~mm}$ forward, while the mandibular base moved $1.5 \mathrm{~mm}$ posterior. ANB and Wits measurements improved a significant level throughout treatment as well. The maxillary incisor moved forward $2.6 \mathrm{~mm}$ while the mandibular incisor only move 0.6 $\mathrm{mm}$ forward. The maxillary molar moved $1.2 \mathrm{~mm}$ forward while the mandibular molar moved $0.6 \mathrm{~mm}$ posterior. These sagittal, vertical, and angular changes contributed to the overjet and molar relationship correction. The average overjet correction found a skeletal contribution of 60 $\%$ and a $40 \%$ dental contribution. The molar relationship correction found a $62 \%$ skeletal influence a $38 \%$ dental contribution. Conclusions: The CS 2000 appliance produces its correction by protraction of the maxillary base, proclination of the maxillary incisors, extrusion of the maxillary molars and mandibular incisors which rotates the occlusal plane in a counterclockwise direction, retraction of the mandibular base (partially coming from a downward and back rotation) mesialization of the maxillary molars, and distalization of the mandibular molars.
\end{abstract}




\section{DEDICATION}

To my wife, Kristin, for always believing in me and being the foundation behind our family. You truly are the most beautiful creature God has ever made, and we are all so lucky to have you in our lives. None of this would have been possible without you. I am so excited to begin the next adventure of our lives and can't wait to grow old loving you each and every day. Thanks beautiful, we made it.

To my 3 girls, Maia, Sophia, and Ella, for always keeping me grounded and reminding me what the most important things in life are about. I am so glad that God chose you to come into our lives. The favorite parts of my life are watching you grow each and every day. Life would not be near as beautiful without you in it. Thank you for all you teach me and making the cloudy days fill with sunshine. I love each of you so much.

To my parents, Ron and Rosemary, for teaching me all about what it means to be a good spouse, parent and person. Your continued wisdom, guidance, and sacrifices through the years have helped shaped me into the person I am today. I feel so lucky to be called your son. Thank you so much for all you have done and continue to do for our family. I love you so much and know three little girls who can't wait to have a home close to your own.

To my brother and sister in-law, Ryan and Jen, for showing me what the perfect family looks like. You have been mentors to me since the beginning. I have loved how our relationship has grown over the years and am excited for it to continue to grow as we team up together. Thank you so much for showing me the correct path and guiding me through the tougher times in life. I love you both and am excited to start our adventure together.

To my sister and brother in-law, Rhonda and Mike, for you continued love and support of my family. You are the perfect examples on how to be successful and raise such a beautiful family. Thanks for being there when times were tough and sharing with us so many wonderful moments. I love you both and look forward to being closer to home and spending more time with you.

To my parents in-law, Mark and Elizabeth, for always being a continued source of support for our family. Thank you both for all you have done for us. We look forward to being close to home to see you more often. I love you and am excited for you to be there as our family continues to grow.

To our, Friends and Family, for touching our lives in so many wonderful ways. We feel so blessed to have you and cannot wait to share so many wonderful memories in the years to come. Thank you for your continued love and support.

To GOD, for the rich blessings you continue to bestow on me and my family. I cannot begin to thank you enough for all you have done for us, much more than is deserved. I love you and thank you for all the events that were initially perceived as bad, only to find out later, it was all part of your awesome plan. 


\section{ACKNOWLEDEMENTS}

Dr. Peter Ngan - Thank you so much for all your help and guidance throughout the last three years. I feel truly blessed to have had the opportunity to learn from the best. Everything great about this program stems from you awesome leadership. Thank you for all you do.

Dr. Chris Martin - Thank you for each and every day you spent with us in the clinic. I will miss our daily banter and yes, will still be there to mow your grass...next time. . Thank you for your humor and keeping things light around the clinic. You will be missed.

Dr. Thomas Razmus - Thank you for serving on my research committee and your help over the last three years.

Dr. Michael Williams - Thank you for the use of your records in my research project.

Dr. Erdogan Gunel - Thank you for your timely calculations of my statistics. Your work is greatly appreciated.

Drs. Hazey, Tremont, McFarland, Dempsey, Kirsch, Gilmore, Sebbahi, Jarrett, Foley, Boyles - Thank you for your continued dedication to our program. I have learned so much from each of you and appreciate the time you sacrifice to make our program so great.

Carrie, Karen, Leona, Joyce, Hillary, Marsha - Thanks to each of you for putting up with me and making the last three years of clinic so wonderful. I really enjoyed our time together. You are all much appreciated.

Maggie and Erica - Thank you for you kindness and support to me during our residency. The memories we shared together will always be remembered. Good luck to both of you in whatever life brings you. I know you will both do great.

Holly, Ronnie, Jung Mee, Chad, Doyoung, and Alice as well as former residents Dean, Kolin, Mike, Mike, Rajia, and Thuy - Thank you so much for your friendship and all the good times we shared together. You all have made our time here in West Virginia such a wonderful experience. I wish you all the best. 


\section{TABLE OF CONTENTS}

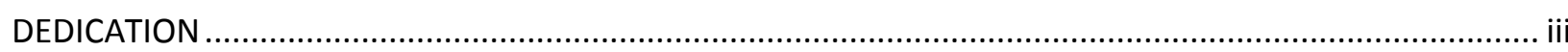

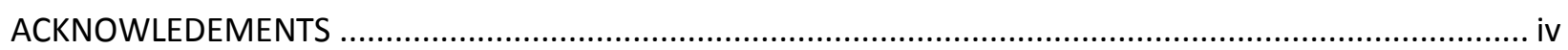

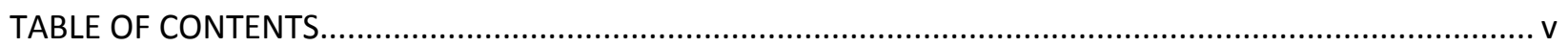

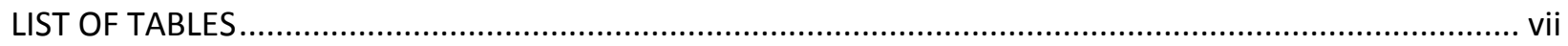

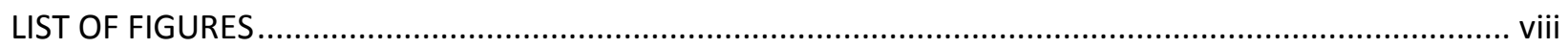

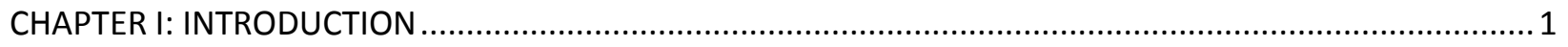

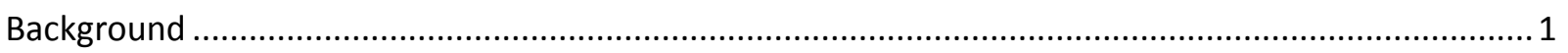

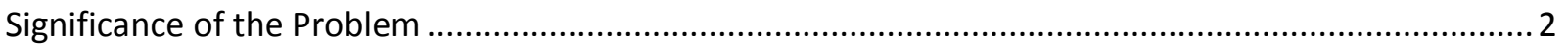

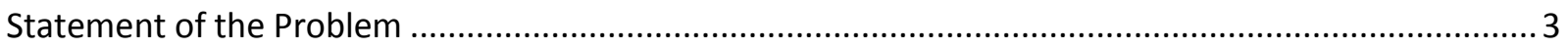

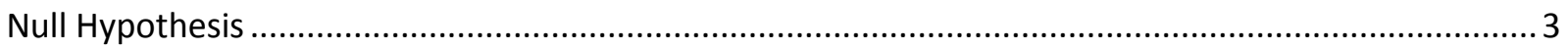

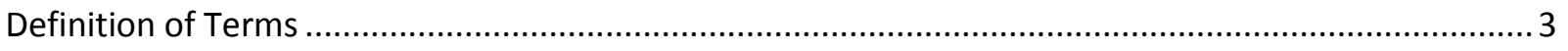

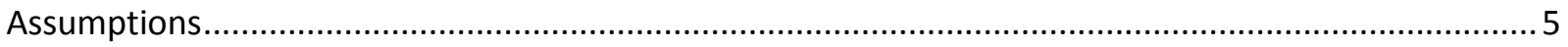

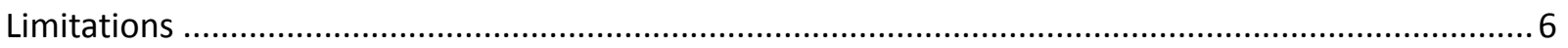

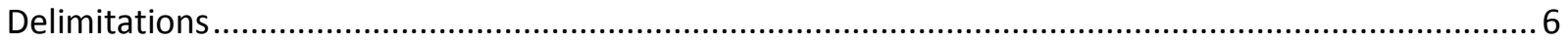

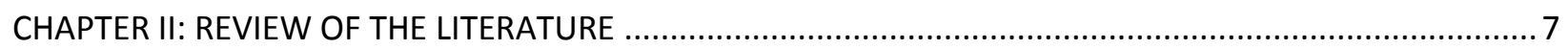

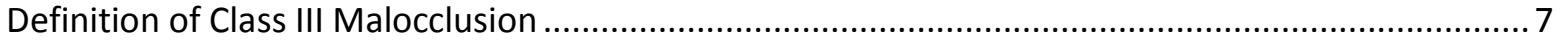

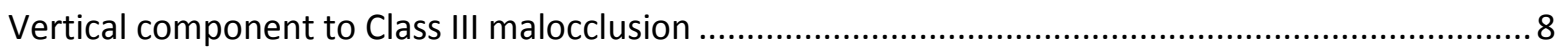

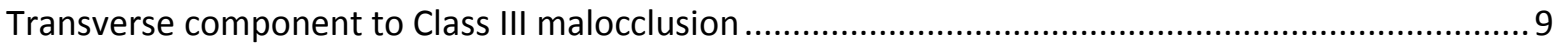

Normal growth patterns of the maxilla and mandible .................................................................... 10

The role of the maxilla and mandible in the causation of Class III facial types ................................ 11

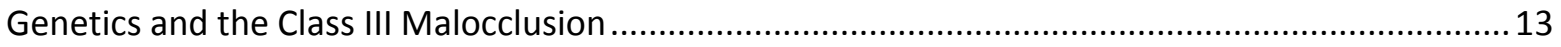

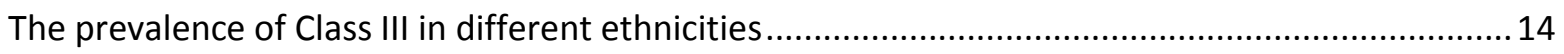

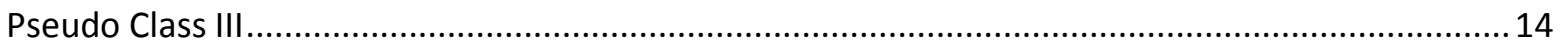

Growth Prediction and its role in treatment of Class III individuals ............................................... 15

Timing of treatment of the Class III malocclusion .......................................................................... 19

Appliances in the treatment of the Class III malocclusion ................................................................20

The use of the facemask in the treatment of Class III malocclusion ................................................. 21

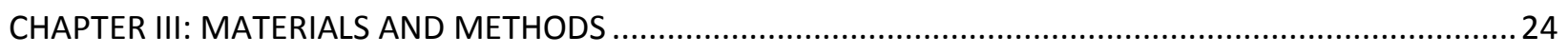

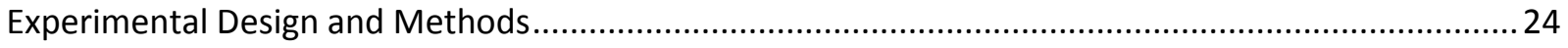

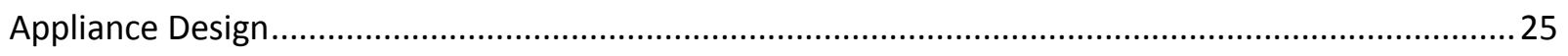

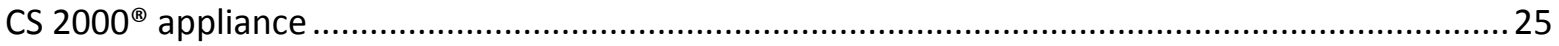

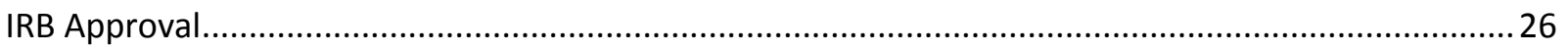

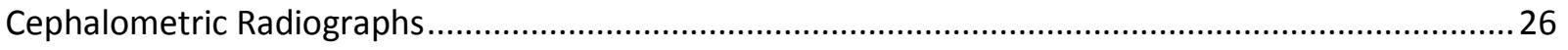

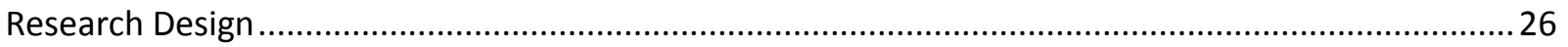

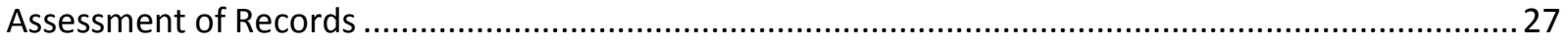

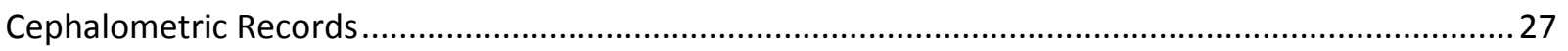

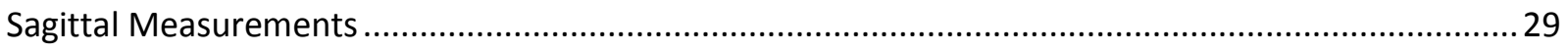

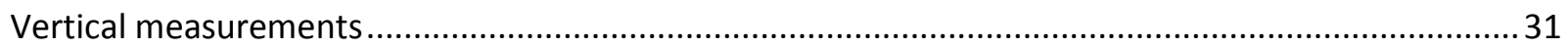




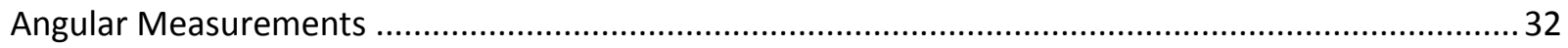

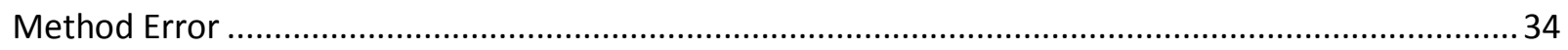

Dental and Skeletal contributions to overjet and molar relationship corrections ...............................36

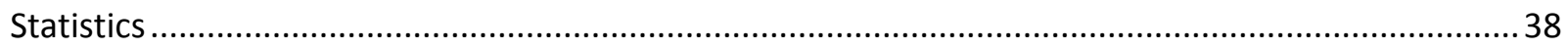

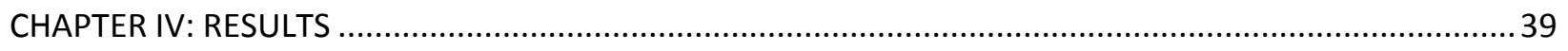

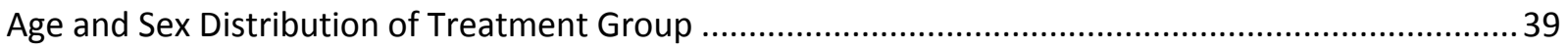

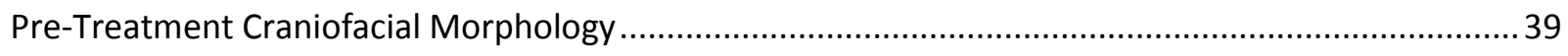

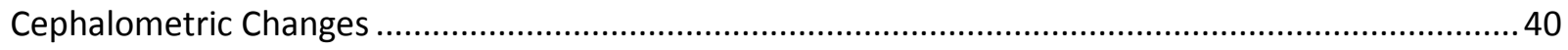

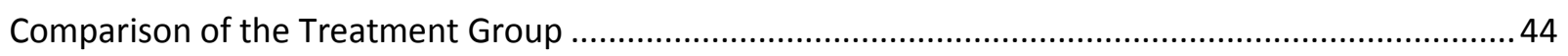

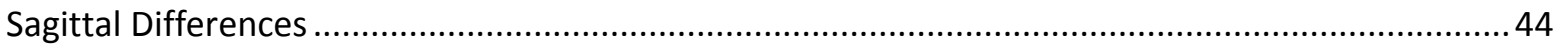

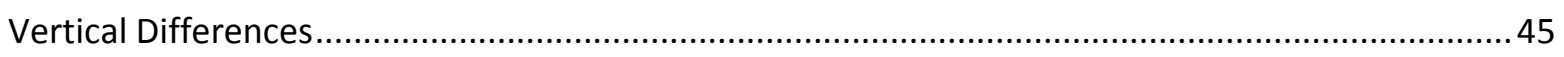

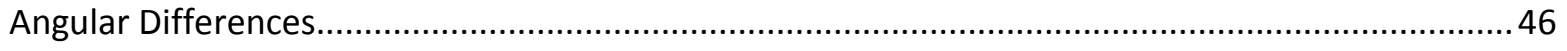

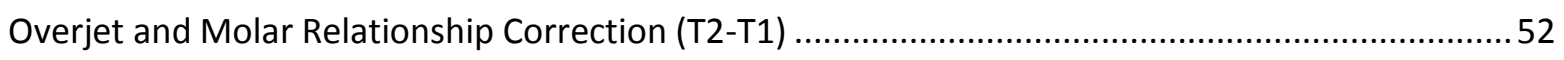

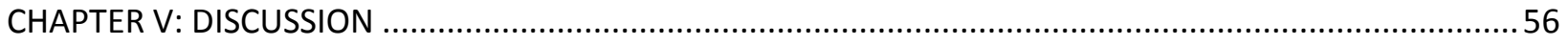

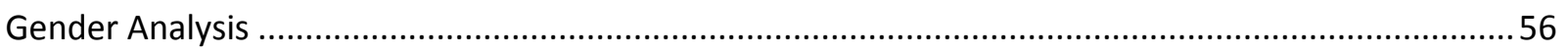

Pre-Treatment Craniofacial Morphology ........................................................................................ 56

Comparison of the Pre-Treatment and Post-Treatment groups (T2-T1) ..........................................57

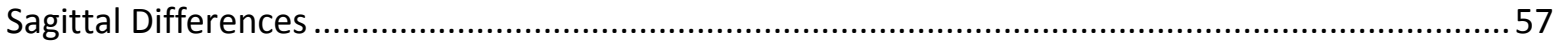

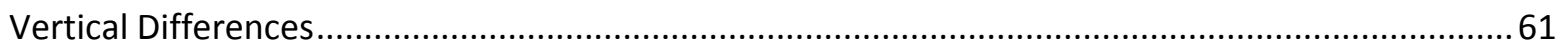

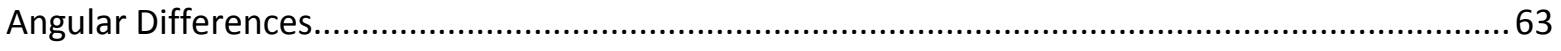

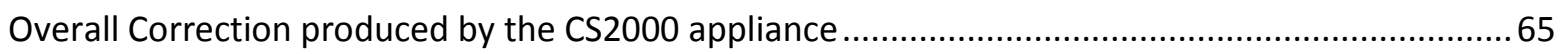

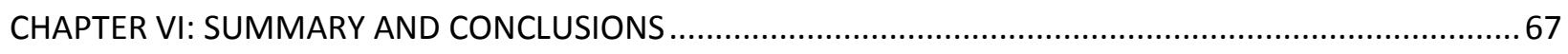

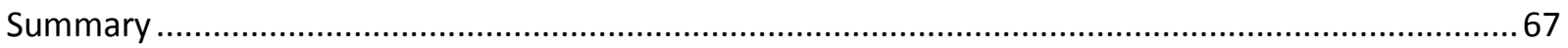

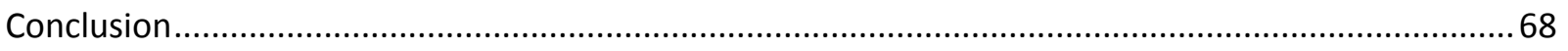

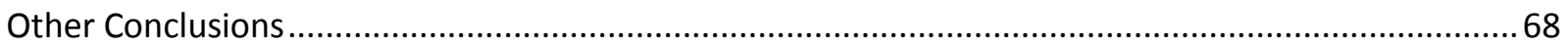

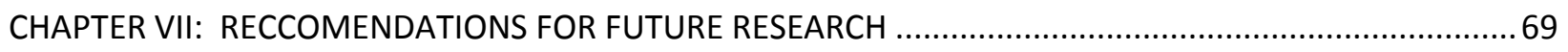

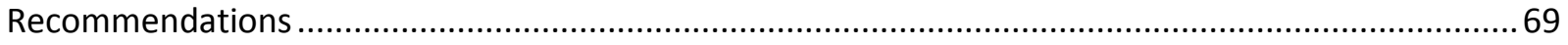

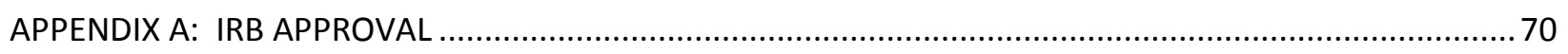

APPENDIX B: PRE AND POST-TREATMENT VARIABLE MEASUREMENTS FOR EACH INDIVIDUAL PATIENT 


\section{LIST OF TABLES}

Table 1. Prevalence of Class III in different ethnicities......................................................... 14

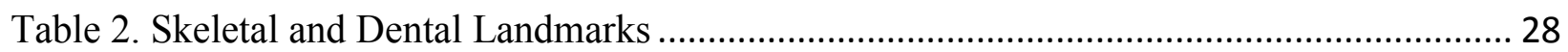

Table 3. Definition of Reference Lines............................................................................... 29

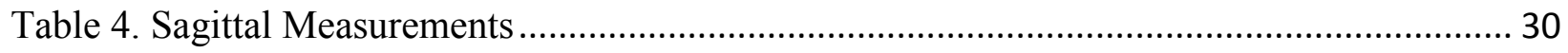

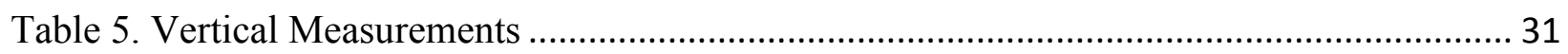

Table 6. Angular Measurements ........................................................................................... 33

Table 7. Correlation Coefficients for individual variable at T1 and T2 from the first and second

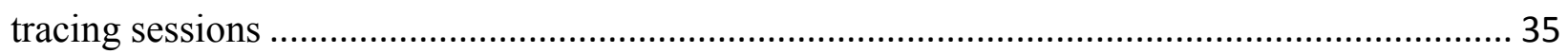

Table 8. Mean, SD, Min, and Max differences for the two tracing sessions ((T2-T1 from tracing session 2) - (T2-T1 from tracing session 1)) ....................................................................... 36

Table 9. Calculation of overjet and molar relationship changes .......................................... 37

Table 10. Ages of patients at Pre-Treatment and Post-Treatment .......................................... 39

Table 11. Pre-Treatment craniofacial morphology ............................................................. 40

Table 12. Individual comparison of sagittal changes from Pre-Treatment to Post-Treatment (T2-

T1) for female, male and pooled groups ............................................................................. 41

Table 13. Individual comparison of vertical changes from Pre-Treatment to Post-Treatment (T2-

T1) for female, male and pooled groups

Table 14. Individual comparison of angular changes, OLp-Co, and Wits from Pre-Treatment to Post-Treatment (T2-T1) for female, male and pooled groups ............................................. 43

Table 15. Quantification of Pre and Post-Treatment measurements in pooled group (T2-T1) .... 49

Table 16. Quantification of Pre and Post-Treatment measurements in female group (T2-T1) .... 50

Table 17. Quantification of Pre and Post-Treatment measurements in female group (T2-T1) .... 51

Table 18. Sagittal Pre-Treatment ................................................................................... 72

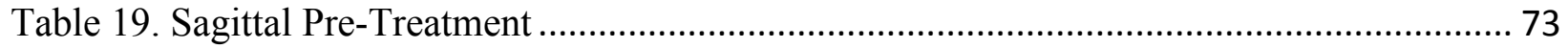

Table 20. Sagittal Post-Treatment........................................................................................... 74

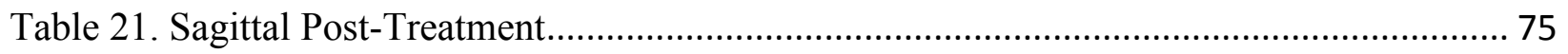

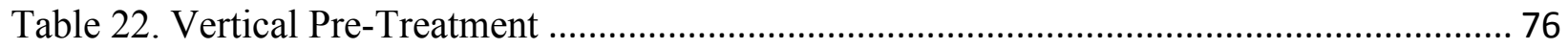

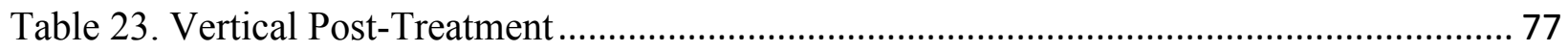

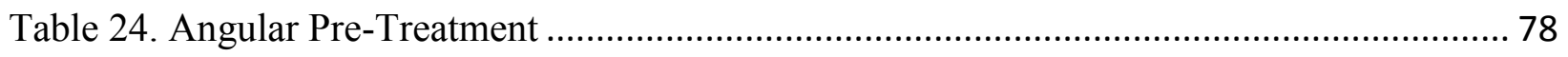

Table 25. Angular Post-Treatment...................................................................................... 79 


\section{LIST OF FIGURES}

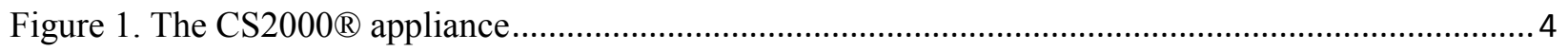

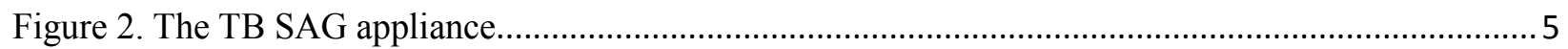

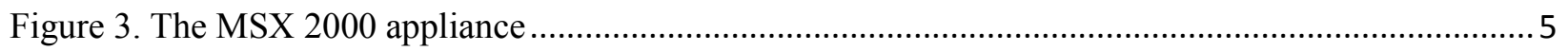

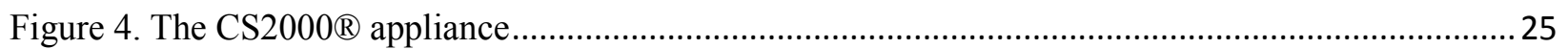

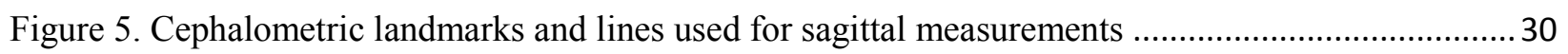

Figure 6. Cephalometric landmarks and lines for vertical measurements ................................................ 32

Figure 7. Cephalometric landmarks and lines for angular measurements ............................................. 33

Figure 8. Diagram of vertical and angular changes (T2-T1) ........................................................... 48

Figure 9. Skeletal and Dental Contributions to Overjet Correction (T2-T1) .......................................... 53

Figure 10. Skeletal and Dental Contributions to Molar relationship Correction (T2-T1) .......................54

Figure 11. Pitchfork Analysis of Overjet and Molar Relationship Correction .......................................55 


\section{CHAPTER I: INTRODUCTION}

\section{Background}

As orthodontists, our main goals are to improve the esthetics of the smile and face, and the function of the masticatory complex. This becomes extremely apparent in the correction of the Class III patient. Class III malocclusion is caused by a deficient maxilla, an overgrowth of the mandible, or a combination of the two. ${ }^{1}$ The incidence of this malocclusion in the patient population has been shown to be $5 \%$ in the Caucasian population, ${ }^{2} 8.7 \%$ in the black population, ${ }^{3} 12.6 \%$ in the Chinese population, ${ }^{4}$ and $9.1 \%$ in the Latino population. ${ }^{5}$ While these only provide a small part of the orthodontic patient pool, the treatment difficulty of these patients often exceed that of other malocclusions due to the limitation of treatment options and the well-established genetic component in the growth of the Class III individual. ${ }^{6}$ The treatment of this condition ranges from camouflage treatment to surgery. Dependent on the age of the individual and how they view their profile, different treatment options will be chosen. ${ }^{7}$ In the young patient (primary to mixed dentition) facemask therapy (reverse-pull head gear) has long been the staple in the treatment of individuals with a deficient maxilla. The various protocols associated with this treatment have been researched to great lengths. How many hours per day should the appliance be worn? Should expansion accompany the protraction of the maxilla? ${ }^{8}$ Is the result stable ${ }^{9}$ While these questions can all be debated, whether or not patient compliance is needed in this treatment is unarguable. In fact, if the patient doesn't wear these removable appliances, namely the facemask, then orthopedic protraction of the maxilla is sure to fail.

The advantage of using an inter-arch spring loaded module is that it is a fixed appliance and it takes the compliance issue out of the equation. The CS2000® (Dynaflex, St. Ann, Missouri) 
appliance has been used by Dr. Mike Williams (Gulfport, Mississippi) to treat patients with Class III malocclusions with clinical success. It has an upper and lower member and a closed coil inter-arch spring in the same vector as Class III elastics. However, how this appliance is producing this effect has not been studied. It is not known whether the correction of the malocclusion is skeletal or dental. If the appliance provides a skeletal effect along with dento-alveolar correction, it could be used as an alternate appliance to the compliance dependent facemask. If the appliance is simply dento-alveolar (tooth tipping and alveolar remodeling) relapse is more likely. However, when an appliance is able to provide orthopedic change (basal bone remodeling) the results tend to be more stable. The aim of this study is to assess the skeletal and dentoalveolar changes taking place with the use of the CS2000® appliance. These results will then be indirectly compared to documented research on the facemask appliance.

\section{Significance of the Problem}

Removable appliances, namely the facemask, have long been advocated in the correction of Class III individuals. These appliances have been shown to be successful to varying degrees. The main issue, however, is patient compliance and its necessity for the success of treatment. The appliance tested in this study (CS2000®) is fixed, and takes the compliance issue out of the equation. However, whether or not this appliance provides the same orthopedic effects as the facemask is still in question. If the appliance is simply dento-alveolar (tooth tipping and alveolar remodeling) relapse is more likely. However, when an appliance is able to provide orthopedic change (basal bone remodeling) the results tend to be more stable. 


\section{Statement of the Problem}

What type of skeletal and/or dento-alveolar effects can be achieved in the treatment of Class III malocclusions with the CS2000® appliance?

\section{Null Hypothesis}

1. The $\mathrm{CS} 2000 ®$ appliance provides no significant sagittal changes between $\mathrm{T} 1$ (pre-treatment) and T2 (post-treatment) as measured by lateral cephalometric radiographs.

2. The $\mathrm{CS} 2000 ®$ appliance provides no significant vertical changes between $\mathrm{T} 1$ (pre-treatment) and T2 (post-treatment) as measured by lateral cephalometric radiographs.

3. The CS2000® appliance provides no significant angular changes between $\mathrm{T} 1$ (pre-treatment) and T2 (post-treatment) as measured by lateral cephalometric radiographs.

\section{Definition of Terms}

1. Prognathic: Forward relationship of the mandible relative to the craniofacial skeleton.

2. Procline: To flare teeth (mainly incisors) into a more facial position (to increase inclination/torque)

3. Retrusion: Teeth and/or jaw posterior to their normal positions.

4. Retrocline: To place teeth (mainly incisors) into a more palatal / lingual position (to decrease inclination/torque) 
5. Facial concavity: A term applied to the analysis of a profile. The shape is described as an inwardly rounded curve from the forehead to the lips to the chin. A concave facial profile is often associated with a Class III malocclusion.

6. Overbite: Vertical overlapping of upper teeth over lower teeth, usually measured perpendicular to occlusal plane.

7. Overjet: Horizontal projection of upper teeth beyond the lower teeth, usually measured parallel to the occlusal plane.

8. Underbite/ negative overjet: Situation in which maxillary anterior teeth are lingual to the mandibular incisors

9. Rapid maxillary (palatal) expansion: Orthopedic widening of the two halves of the maxilla using the high load system.

10. Protraction facemask: An extra-oral protraction appliance used to exert a forward vector of force on the maxilla; for example, in maxillary deficiency problems.

11. Growth spurt: A rapid increase in height and weight, which typically occurs during puberty.

12. Cephalometrics: The use of lateral cephalometric radiographs to diagnose treatment and study treatment outcomes and/or growth of an individual.

13. CS2000® appliance: Fixed Class II correction appliance consisting of an upper member, the TB SAG, and a lower member, the MSX 2000, and interarch NiTi springs from upper first molars to lower first bicuspids

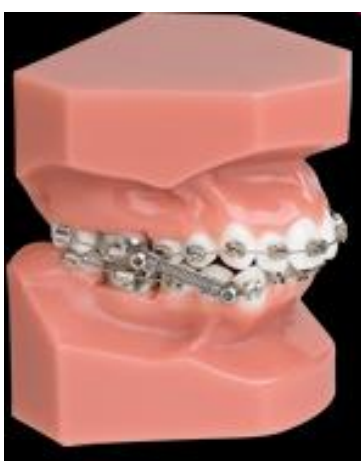

Figure 1. The CS2000® appliance 
14. TB SAG (Tooth Born Sagittal Appliance): Upper member of the CS2000® appliance. It consists of NiTi expansion springs for transverse correction as well as NiTi springs in an anterior-posterior direction that places a protraction force on the pre-maxilla. It also provides an attachment at the first molars for NiTi springs.

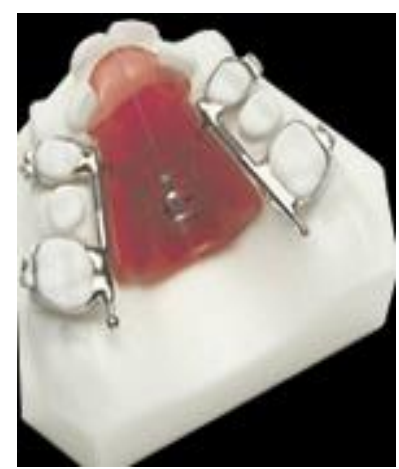

Figure 2. The TB SAG appliance

15. MSX 2000: Lower member of the CS2000® appliance that provides mandibular arch transverse correction with NiTi springs. It also provides an attachment at the first bicuspids for NiTi springs.

All pictures were gathered from the Dynaflex web site http://www.dynaflex.com/store/index.html ${ }^{10}$

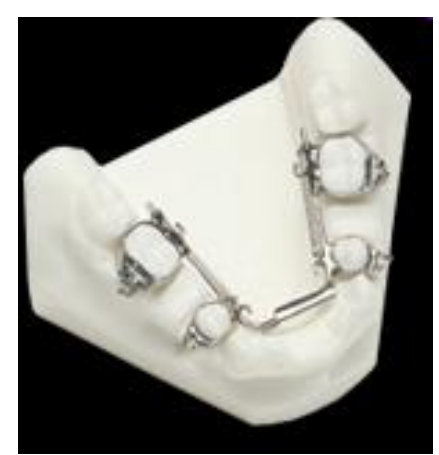

Figure 3. The MSX 2000 appliance

\section{Assumptions}

1. The CS2000® appliance does provide clinical correction of the treated sample

2. Growth is constant (i.e., there is no growth spurt)

3. The upper and lower members of the CS2000® appliance are providing the correct transverse correction for the particular patient

4. Lateral cephalograms for each of the patients were taken with the subjects in centric occlusion

5. Cephalometric radiographs taken with different machines at different times can be compared by adjusting the magnification. 


\section{Limitations}

1. Age differences amongst patients -- Growth spurts occur at different times amongst patients

2. Gender, ethnicity, and health history differences amongst patients

3. The amount of treatment time between patients in the treatment group varies, and thus allows for greater error in estimation of average treatment effects.

4. Lack of a control group to factor out growth from the effects in the treatment group. Thus the resultant numbers include effects produced by the appliance itself and the amount the particular patient has grown during the treatment period.

\section{Delimitations}

1) The study will be retrospective.

2) The experimental group will consist of 30 patients treated by Dr. Mike Williams using the CS2000® appliance

3) There will be no control group. This study is purely observational and the treatment effects listed have not factored out growth

4) Patients of both genders from the early mixed dentition through the early permanent dentition (ages 6 through 15)

5) Patients from the experimental group will have treatment times between 8 months and 2 years

6) Those patients whose records were not of diagnostic quality and/or did not show a regular treatment interval will be excluded. 


\section{CHAPTER II: REVIEW OF THE LITERATURE}

\section{Definition of Class III Malocclusion}

The first concept of occlusion and its relationship to the function and esthetics of the oral cavity occurred in the late part of the $19^{\text {th }}$ century. While this concept started as a means to make good prosthetic replacements, Edward Angle in 1890, applied this concept to the natural dentition, and thus the specialty of orthodontics is born. ${ }^{11}$ In this relationship, Angle postulated if the mesiobuccal cusp of the maxillary first molar occluded with the buccal groove of the lower first molar, and the teeth were arranged on a smoothly curving line of occlusion, then a good occlusion could result. He went on to call this relationship as Class I. He also defined Class II occlusion as the mesiobuccal cusp of the maxillary first molar being mesial to the mandibular first molar's buccal groove. Class III occlusion is when this same mesiobuccal cusp is distal to the buccal groove. ${ }^{12}$ As time went on this system had many additions and eventually became used to describe other things than the relationship of the maxillary and mandibular first molars. The concept of Class III jaw relationship is now used to describe a deficient maxilla or a protrusive mandible. A Class III grower is one who has one or both of these characteristics. ${ }^{11}$ Interestingly enough, in 1819 Delaware had described this malocclusion as an \#nderbite" or edge to edge" relationship, which is frequently seen in these individuals and is formally known as anterior crossbite. ${ }^{13}$

The skeletal component of this malocclusion, as defined by Sugawara and Mitani and can be attributed to a forward position of the mandible in relationship to the face and/ or maxilla. This can result from an overgrowth of the mandible, deficient growth of the maxilla, or a combination of the two. ${ }^{14}$ As described earlier, this relationship can result in a Class III molar 
relationship, but does not have to in all cases. Therefore, it should be concluded, that a Class III jaw relationship does not necessarily mean a Class III molar relationship and vice versa. ${ }^{13}$ Typically, if the teeth are camouflaging for a Class III jaw relationship, the maxillary incisors will be proclined and the mandibular incisors will be retroclined. If the position of these teeth are corrected, an anterior crossbite or \#nderbite" will result, thus de-camouflaging the jaw relationship. ${ }^{13,15,16}$ In his study, Battagel tried to identify the etiological factors in a class III individual. He found that when these Class III children were compared to control groups, facial morphologies were different in all areas examined. The cranial base angle was more acute, the maxilla shorter and more retrusive, but the mandible was longer and more prominent. This could be attributed to the more forward position of the glenoid fossa. ${ }^{17}$

\section{Vertical component to Class III malocclusion}

A component of the Class III malocclusion not accounted for by Angle's classification system is the vertical component. Class III individuals can be hyperdivergent and have excessive vertical facial heights or hypodivergent, having decreased lower facial heights. The treatment of these differing vertical growth patterns can be very different. In a study examining growth in Class III individuals, Reyes looked at the significance of the vertical component in Class III malocclusions. 949 cephalometric radiographs were compared to norms established by the Michigan Growth Study annually from ages 6-16. While noting mandibular length increases were larger during this interval than the norm, Reyes also stressed that lower anterior facial height was significantly larger during the later developmental stages. ${ }^{18}$ In his article, Sato looks at other components of this malocclusion. He notes Class III individuals usually have steep 
mandibular plane angles, obtuse gonial angles, overdeveloped mandibles, underdeveloped maxillas, and small cranial base angles which displace the glenoid fossa anteriorly causing a forward positioning of the mandible. These factors contribute to the development of skeletal malocclusion as well as facial deformities. Because of its effect on the occlusal plane, this posterior discrepancy is an important factor in the development of a skeletal Class III malocclusion. ${ }^{19}$

\section{Transverse component to Class III malocclusion}

A major component in many Class III individuals is the transverse parameter. It is often found that both sagittal and transverse components are present in these patients. In Chen's research comparing these two parameters, it was found that the intermolar relationship and maxillary skeletal base widths were decreased in Class III individuals as compared to Class I individuals, and that this deficiency worsened with age. ${ }^{20}$ Franchi, Baccetti found similar results in there study comparing Class II and III individuals to Class I norms. ${ }^{21}$ Comparing the transverse and vertical components of Class III malocclusion, patients with higher mandibular plane angles have narrower transverse measurements, both skeletally and dentally, than those of patients with lower mandibular plane angles. ${ }^{22}$ This thus connects all three dimensions, sagittal, vertical and transverse, as playing vital roles in the development of Class III malocclusions. Mandibular intercanine and intermolar alveolar widths were found to be significantly larger in Class III individuals as well. This same research also agrees with the findings of Chen, Franchi, and Baccetti when comparing maxillary measurements. ${ }^{23}$ 


\section{Normal growth patterns of the maxilla and mandible}

In order to assess the etiology of Class III malocclusions, normal facial growth lends review. The bones of the craniofacial skeleton, with exception of the cranial base, nasal septum, and condyle of the mandible, all begin with mesenchymal bone formation in the early fetal development. The morphology of the face develops as these bones are formed in reaction to the soft tissue growth around them, which are genetically controlled. As tension develops between the sutures, with the advancing soft tissues, bony apposition takes place. In addition to sutural growth, continued bony remodeling consisting of both apposition and resorption is happening concurrently. ${ }^{11}$ Differing combinations of growth at the sutures and bony remodeling, give the facial skeleton its shape. These processes are extremely variable in each patient and give each face its unique characteristics. The process of sutural growth takes place into early adulthood and bony remodeling takes place until the sixth through eighth decades. ${ }^{24}$

This developing craniofacial skeleton can be thought of as a series of parts relating to and affecting each other. How well these parts relate to each other is the predictor of the skeletal relationship of the jaws. However, Profit reminds us that occlusal disharmony must not be thought of as a discrete entity, but instead a proportion in a continuous process of growth. As one portion of the face grows, it then effects the growth of all parts around it. ${ }^{25}$ In our specialty, a main concern is the maxillo-mandibular relationship and its effect on the facial structures. Two of the major factors in this maxillo-mandibular relationship are the growth of both these bones and how they relate to each other in all three planes of space (sagittal, vertical, and transverse). In his implant study on normal and abnormal growth, Bjork ${ }^{26}$ breaks $^{2}$ down the growth rotation of the mandible into three components. Total rotation of the 
mandible equals the sum of matrix rotation and intramatrix rotation. Matrix rotation is defined as the rotation of a tangential line on the inferior surface of the mandible. Intramatrix rotation is the rotation of bony of the mandible inside itself. Notice that both these factors, (which equals total rotation) along with the condylar growth pattern, result in the final position of the

mandible. As the other parts of the face are growing toward their adult positions, in accordance with the soft tissues, the mandible is responding by growing up and back to remain harmonious with the growth of the maxilla and cranial base. Bjork states that there is no said pattern leading to facial harmony. Rather there are an infinite number of combinations of condylar growth, matrix and intramatrix rotations that lead toward normal occlusal schemes and facial balance. What is important is how each part responds to the other in concert. ${ }^{26}$

\section{The role of the maxilla and mandible in the causation of Class III facial types}

Bjork states that the most common growth patterns seen in normal maxillo-mandibular relation are forward growth patterns of the condyle, and forward total rotations of the mandible. More importantly, if one of the growth patterns shows a tendency for backward growth, the other components compensate, and thus restore the pattern and harmony in relation to the downward and forward growing maxilla. ${ }^{26}$ What causes the poor relationship of the mandible to the maxilla is much debated, but is definitely multi-factorial, and involves both a genetic and an environmental component. Bjork states in one of his paper's that seven signs exist in predicting extreme mandibular growth cases (Class III): inclination of the condylar head, curvature of the mandibular canal, the shape of the lower border of the mandible, the interincisal angle, the intermolar angle, the width of the symphysis, and the anterior lower facial height. However, 
these signs may only be $70 \%$ accurate in the prediction of excessive mandibular growth. ${ }^{26}$ As stated earlier, Class III relationships can be caused by sagittal mandibular prognathism, maxillary deficiency, and differing combinations of these.

In an attempt to evaluate how Class III patients grow, Miyajima ${ }^{27}$ looked at 1376 untreated Class III Japanese females. These patients were categorized according to developmental status and then compared. In this study, it was found that the maxillas of these patients were in a retruded position when compared to the cranial base, and this did not worsen with time. However, a mandible that was protrusive in the early developmental groups worsened with age, and the maxillo-mandibular jaw discrepancy became worse. This study also noted that dental compensations for the malpositioned jaws were apparent in most cases and became worse as the skeletal malposition worsened. ${ }^{27}$ In agreement Ellis found Class III individuals showed a retrusive maxilla, protrusive maxillary incisors, prognathic mandible, and retrusive mandibular incisors, and increased lower facial height. ${ }^{28}$ In contrast, Mitani, in his research of prognathic Japanese males and females, found that morphological characteristics of mandibular prognathism are established before the pubertal growth spurt and are maintained, then after growth was similar to that of the Class I control group. ${ }^{14}$

In another study, Baccetti ${ }^{29}$ looked at the growth of Caucasian Class III individuals of differing skeletal maturations. He found significant growth changes of the mandible until 18 years of age. Peak mandibular growth occurred between CVM stages 3 and 4, while smaller changes occurred until CVM 6 in some patients. Compared to Class I growers, female Class III individuals had 2 times the mandibular growth, while male Class III individuals have three times 
larger than the individuals of the control. He also noted the increase in the vertical dimension in the later stages of development. ${ }^{29}$ Similar results were shown in a study by Reyes. ${ }^{18}$

\section{Genetics and the Class III Malocclusion}

The role of genetics versus the environment in the causation of the Class III malocclusion has been much debated. Studies have been done regarding both viewpoints as correct. Jacobsen $^{15}$ and Litton ${ }^{30}$ and McGuigan, ${ }^{31}$ detail two different families with Class III characteristics. In one family 33 of the 40 members whom records were taken on showed a prognathic mandible. In Litton's ${ }^{30}$ paper he detailed other genetic Class III patterns in the families of 51 individuals. These and other studies done on the role of genetics' in Class III malocclusion have concluded that mandibular growth and it's final size are affected by hereditary. ${ }^{15,30,31}$ However, environmental factors have also been identified that add to the Class III facial type. Habits, mouth breathing, or mandibular posturing due to airway maintenance, and tongue size have been attributed. ${ }^{32}$ This issue is further studied in a paper by Chang ${ }^{33}$. He notes the recent findings of a gene associated with mandibular prognathism. However, notes that further research needs to be carried out to identify the interactions between these genes and the environment in the development of Class III growth ${ }^{33}$ In accordance with Chang's research, Bui ${ }^{6}$ found five genetic subphenotypes that affect the sagittal and vertical dimensions of the maxilla and mandible. He also notes the exact causative gene causing Class III growth is unknown, and further research is warranted. ${ }^{6}$ 


\section{The prevalence of Class III in different ethnicities}

Prevalence of Class III malocclusion differs among different ethnicities. Recent research by Silva and Kang looks at the prevalence of Class III malocclusion among the Latino population. It also shows figures for other ethnicities as well. ${ }^{5}$ See below table (Table 1)

\begin{tabular}{|c|c|c|c|c|c|c|}
\hline \multicolumn{7}{|c|}{ Prevalence of malocclusion among different ethnic groups } \\
\hline Author & Ethnicity & Sample & Class I & Class I & Class II & Class III \\
\hline Horowitz $^{2}$ & White & 718 & 6.8 & 65.2 & 22.5 & 5.5 \\
\hline $\begin{array}{l}\text { Garner and } \\
\text { Butt }^{3}\end{array}$ & Black & 445 & 31.3 & 44.0 & 16.0 & 8.7 \\
\hline Lew et $\mathrm{al}^{4}$ & Chinese & 1050 & 7.1 & 58.8 & 21.5 & 12.6 \\
\hline $\begin{array}{l}\text { Silva and } \\
\text { Kang }^{5}\end{array}$ & Latino & 507 & 6.5 & 62.9 & 21.5 & 9.1 \\
\hline
\end{tabular}

Table 1. Prevalence of Class III in different ethnicities

\section{Pseudo Class III}

In order to correctly assess and treat a Class III malocclusion one must look at both the skeletal and dental components. In the primary dentition, anterior crossbite can result from abnormal lingual inclination of the maxillary incisors, and excessive labial inclination of the mandibular incisors. Also, it could be from functional occlusal interferences, or skeletal discrepancies of the maxilla and/ or mandible. ${ }^{34,35}$ In order to assess if this issue is a true skeletal Class III relationship, $\operatorname{Ngan}^{36}$ has set forth a diagnostic criteria. First, check if a Class III molar relationship is accompanied by an anterior crossbite. If so a functional assessment is warranted. If the Class III molar is accompanied by an end to end or positive overjet, a skeletal Class III jaw 
relationship with dental compensation (proclined maxillary incisors and retroclined mandibular incisors) is suspected. In the functional assessment the practitioner is looking for a slide between centric relation and centric occlusion. In the patient who has an anterior slide from centric relation to centric occlusion, a Class III molar relationship with an anterior crossbite may be resulting from the slide. If this discrepancy is removed, a normal Class I relationship may become apparent. This situation, in which the patient has Class I relationship in centric relation and Class III in centric occlusion, is known as pseudo Class III. ${ }^{36}$ The third and final assessment has to do with the profile. A skeletal Class III relationship can become apparent when one sees a straight or concave profile. ${ }^{37}$ This — psedo Class III" relationship is also spoken of in a paper by Rabie. ${ }^{38}$ He notes that a significant portion of the pseudo Class III patients in his study showed no family history and had Class I habitual occlusion. He characterizes these patients as having retroclined upper incisors, with upper lip retrusion and decreased midfacial length. ${ }^{38}$ In his study, Le,Gall ${ }^{39}$ also looks at the pseudo class III. In what he calls the functional mandibular prognathism" he notes the importance of diagnosis. He states that the treatment of this condition is important in that it allows the jaws to be in a more harmonious position for growth. Left untreated this functional Class III relationship may become a skeletal problem. ${ }^{39}$

\section{Growth Prediction and its role in treatment of Class III individuals}

If one could predict which patients will develop Class III facial patterns, preventive treatment could then be rendered to limit the complexity of treatment later in life. Several attempts have been made to do exactly this. Bjork ${ }^{26}$ states in one of his paper's that seven signs exist in predicting extreme mandibular growth cases (Class III): inclination of the condylar 
head, curvature of the mandibular canal, the shape of the lower border of the mandible, the interincisal angle, the intermolar angle, the width of the symphysis, and the anterior lower facial height. However, these signs may only be $70 \%$ accurate in the prediction of excessive mandibular growth. ${ }^{26}$ In his paper, Franchi ${ }^{40}$ demonstrates that three predictive cephalometric values in the prediction of Class III malocclusion: the inclination of the condylar axis in relation to the stable basicranial line (Cond Ax-SBL), the inclination of the nasal line to the mandibular line (NL-ML), and the transverse width of the mandibular arch measured at the first deciduous molars. His results suggested accuracy to $95.55 \%{ }^{40}$

The goal of intervention in these cases is to provide a better environment in which the patient can grow. The success of early treatment is variable, but prediction formulas do exist for this process. The goals of these prediction formulas are to accurately differentiate those patients in which early treatment will work, from those who will need future surgery. Many studies have been done on predictive values of Class III growth including the success and methodologies of early treatment ${ }^{40-42}$, the stability of facemask therapy ${ }^{9}$, if surgery is indicated or not ${ }^{43-46}$, and many other aspects of this malocclusion. Ghiz ${ }^{41}$, in his paper suggests that a forward position of the mandible, small ramal lengths, large mandibular length, and obtuse gonial angle are highly associated with unsatisfactory treatment outcomes after pubertal growth. ${ }^{41}$ However the underlying significance made clear in many of the papers is that Class III growth involves many factors and careful consideration of all these is paramount in the treatment of these patients.

Another question that arises relates to whether or not the morphogenetic pattern of the patient once established changes. According to Andrews and his parallel growth theory ${ }^{47}$, all growth remains constant from early childhood to adulthood. Behrents ${ }^{24}$ and Ochoa and Nanda ${ }^{48}$ in their respective research indicate this to be true as they found growth at nasion and A point 
stay relatively constant with age. Also in agreement are Sadowsky ${ }^{49}$ and Proffit ${ }^{25}$ who say that often the morphologic proportions of the face remain constant over the growth of the individual. However, according to others, this may account for most of the patients, but not all. In fact much research exists that indicates that craniofacial growth patterns do change over time. ${ }^{18,27,29}$ These non-normal growers are the main basis for research on the prediction of growth and the use of functional appliances.

There are numerous methods out there for the prediction of growth. Many stem from a few differing opinions to some basic questions. Does one believe in the parallel growth theory? Can you alter growth with the use of functional appliances? Many of these growth predictions involve the success or failure in early treatment, surgery, or orthopedic appliances. In his article, Proffit talks of the envelope of discrepancy in which orthodontics alone, orthodontics and growth, or surgery can be relied upon to correct malocclusions. ${ }^{25}$ In another paper Rudolph states that if serial cephalometric head films can be taken around ages $6,8,10$, and 12, then good growers can be separated from poor growers. ${ }^{50}$ Turchetta $^{51}$ concludes that it still remains difficult to accurately predict the future growth of each individual patient. However, Schulhof ${ }^{52}$ uses computerized cephalometrics to obtain parameter that suggest a patient will grow into a Class III malocclusion. Like Andrews ${ }^{47}$ he says that normal growers have similar changes in nasion growth as mandibular growth. However, in the Class III individual, more mandibular growth was seen. $^{52}$

In predicting Class III growth and response treatment, many parameters have been suggested as helpful. The main predictions of this group indicate whether appliances and orthodontics will suffice to correct the problem, or if surgery will be needed. ANB angle, 
maxillo-mandibular ratio, lower incisor angulation, wits appraisal, anterior cranial base length, lower gonial angle, angulation of the condylar axis, transverse mandibular width, and chin position are all considered in different combinations to predict future mandibular growth, and whether early treatment will prevent future surgery. ${ }^{40-46}$ Other predictors use pretreatment and post-treatment radiographs after completion of facemask therapy to predict the probability of future relapse. Such is the case with Ngan's GTRV (growth treatment response vector) analysis which compares horizontal changes of the maxilla in proportion to the horizontal changes in the mandible. ${ }^{42}$ In Enlow's ${ }^{53}$ book, Essentials of facial growth, he speaks of the brachycephalic individual. Brachycephalic individuals are characterized by rounder and wider cranial cavities. The result of this is a more posterior location of the maxilla and a shorter but wider nasomaxillary complex. These conditions are suggestive of a Class III facial pattern. ${ }^{53}$

Although prediction of growth and being able to rely on this prediction for treatment of growing patients is much sought after, the results from many of these papers indicate its difficulty. Proffit Quotes -While these predictive values may be able to predict $70-80 \%$ of a population - on an individual basis it again may not stack up so well.," ${ }^{25}$ Ochoa in his paper states that while the group statistical means provide a summing up of tendencies, they may not be able to be applied to individuals as variation is too large. ${ }^{48}$ Many other papers agree with this fact as well; it may be dangerous to rely on statistics of means to predict individual growth. In a paper by Williams ${ }^{16}$, no one morphologic trait existed in the prediction of future Class III facial types because of the many different skeletal combinations that exists. However, he does find that many of the same characteristic emerged among the tested group in varying amounts. ${ }^{16}$ Nanda also supports this, concluding growth prediction is very difficult to do well because of the extreme variability among patients. ${ }^{54}$ This is not to say that these predictive values are not 
valuable as they may show trends that the patient is approaching. While these cannot be followed as all or none, they can be taken into consideration. Proffit reminds us that the best results are achieved in good growers while the poorest results are achieved in poor growers. ${ }^{25}$

\section{Timing of treatment of the Class III malocclusion}

Throughout history many different appliances have been used in the correction of the Class III malocclusion. This includes many different kinds of bite positioners to, what is the gold standard of today, the facemask appliance. While these appliances have provided correction to differing degrees, each has both advantages and disadvantages. In the evaluation of the CS 2000 appliance, it is necessary to look at previous success with other appliances and then compare it to the results of this study. Also looked at will be timing of treatment of the Class III individual.

One of the most important factors in the correction of the Class III patient is timing. If incorrect, it can drastically affect the outcome of treatment. In his text, Proffit notes that correction of mandibular prognathism should take place before the age of 7 . Correction of a maxillary deficiency should take place before the age of $10^{11}$. The early parameter seems to be when the patient is able to adequately comply with instructions. In agreement, Baccetti ${ }^{55}$ in his study with the mandibular retractor appliance concluded that the optimum time to correct Class III malocclusions with a functional appliance is in the deciduous dentition ${ }^{55}$. In his study, Fanchi ${ }^{56}$ evaluated the influence of treatment timing influence of Class III post pubertal patients. One group had received treatment in late deciduous to early mixed dentitions, the other in the 
late mixed dentition. In agreement with Proffit and Baccetti, he found that those patients treated in the late deciduous to early mixed dentition benefited more. However, both groups did benefit and this correction came as a result of skeletal changes. ${ }^{56}$

\section{Appliances in the treatment of the Class III malocclusion}

In the treatment of the Class III patient, the goal of these appliances is to correct the Class III jaw pattern at an early age, thus providing a more favorable growth environment for the jaws as the patient grows ${ }^{57}$. However, even when the jaw discrepancy is corrected at an early age, if

the patient continues to grow in a Class III pattern, surgery may still be needed later on. Turpin ${ }^{58}$ addressed this issue of early treatment and found it was advisable in his study. He concluded that a more favorable outcome of early treatment could be accomplished when the patient had a convergent facial type, an anterior-posterior functional shift, symmetrical condylar growth, has remaining growth, a mild skeletal disharmony, provides good cooperation, no familial history of Class III facial type, and good facial esthetics. The absence of one or more of these factors could lead the orthodontist to conclude that early treatment may not be beneficial in preventing surgery of the Class III patient.

The vast variety of appliances used in this correction includes the mandibular retractor, the Frankel III appliance ${ }^{59,60}$, differing bite positioners, and the facemask ${ }^{61-63}$. In a study by Tollaro $^{64}$, he used the mandibular retractor in treatment of the Class III individual. His results indicate that this appliance is able to change the growth rotation of the mandible to compensate for excessive mandibular growth ${ }^{64}$. In a similar study, Baik ${ }^{59}$ looked at the Frankel functional 
regulator III in growing Class III patients ${ }^{59}$. He found that correction came from backward and downward rotation of the mandible and lingual tipping of the lower incisors. Garattini used a Bionator III appliance in his study and concluded the majority of results to be attributed to dentoalveolar changes ${ }^{65}$. Similar results are noted by Kidner, with the use of a Class III Twin Block $^{66}$. However, Proffit ${ }^{11}$ notes that these changes are not skeletal in origin, but mainly dental. These appliances allow the maxillary molars to migrate mesially and hold the lower molars in place. They also procline the upper incisors and retrocline the lower incisors, rotate the occlusal plane and/or the chin posterior, but have no major effect on the skeletal growth of the mandible or maxilla ${ }^{11}$. A removable appliance of note, the modified tandem traction bow, is reported to produce a higher percentage of skeletal changes as presented by Atalay ${ }^{67}$. In this study, he uses maxillary and mandibular splints with attachments for elastics to protract the maxilla. His results suggest a significant forward movement of Apt. (skeletal change) and a small backward rotation of the mandible ${ }^{67}$. However, some of the most significant skeletal treatment effects are produced by the facemask appliance which has benefited Class III patients with both maxillary retrusion and/or mandibular prognathism ${ }^{37,58,68}$.

\section{The use of the facemask in the treatment of Class III malocclusion}

The main appliance in the early correction of Class III patients is the facemask appliance. The facemask is a removable appliance that achieves its desired effect by using the forehead and the chin as anchorage. Elastics are then hooked in a down and forward vector from a maxillary appliance to the bow of the facemask. 12 ounces of force is applied bilaterally and the patient is

asked to wear it for 12-14 hours per day ${ }^{11}$. The main goal of this facemask is to provide skeletal 
correction by limiting growth of the mandible and protraction of the deficient maxillary complex in a down and forward direction. While this is thought to be the main effect, da Silva Filho ${ }^{69}$ also notes that this appliance also rotates the mandible down and back, distalizes mandibular teeth, and mesializes of the maxillary teeth and states that this is how the correction occurs ${ }^{69}$.

Many studies have been done to evaluate the effectiveness of the facemask in the skeletal correction of Class III malocclusions? In his study, Chong ${ }^{70}$ agrees with Da Silva because of downward and backward rotation of the mandible ${ }^{70}$. Nartallo ${ }^{71}$ adds that both skeletal and dental effects are involved in the correction ${ }^{71}$. Even with a dental component, Pangrazio-Kulbersh ${ }^{57}$ established the stability of facemask treatment in comparison to a surgically corrected group ${ }^{57}$. Another paper that studies the effects of facemask treatment is a study done by Ngan et. $\mathrm{al}^{61}$. In this paper, a method of cephalometric evaluation described by Bjork and Pancherz ${ }^{72,73}$ is used to analyze changes brought about by facemask therapy. 30 patients serving as their own control were treated with RPE and facemask for 6 months. His results suggest an average forward movement of A pt., backward rotation of the mandible, proclination of maxillary incisors, and retroclination of the mandibular incisors, which led to a $6.2 \mathrm{~mm}$ overjet correction ${ }^{61}$. Baccetti ${ }^{74}$, in another paper, looked at how age effects treatment outcomes with a bonded RPE and facemask. He found that in the early treatment group (6.8 years \pm 0.6 years) a significant forward movement of A point occurred, while in the late treatment group (10.3 years \pm 1.0 year) no significant A point movement was achieved. Both group showed a restriction in mandibular length, but the result was more noted in the early treatment group ${ }^{74}$. In another of his papers, Baccetti $^{75}$ looked once again at the optimal timing for treatment with a bonded RPE and a facemask. Once again he found that the early treatment group ( 7.0 years \pm 0.6 years $)$ showed a significantly more forward movement of A point than the late treatment group ( 8.7 years \pm 1.0 
years). A restriction of mandibular growth was seen in both groups with a more upward and forward direction of condylar growth. In the late treatment group, a more pronounced down and backward rotation of the mandible was seen with an increase of lower anterior facial height. Post-treatment, Baccetti found that Class III growth patterns returned in the absence of any skeletal retention appliances ${ }^{75}$. Westwood ${ }^{76}$, in her paper also found a return to Class III growth patterns once treatment was complete and recommends an overcorrection during facemask treatment. The results of this present study on the CS2000® appliance will be indirectly compared to the results of these papers. This will then suggest the usefulness of the CS2000® appliance in the correction of Class III facial types as indirectly compared to the facemask. 


\section{CHAPTER III: MATERIALS AND METHODS}

\section{Experimental Design and Methods}

The treatment group consisted of 75 patients who were treated consecutively with the CS2000® appliance at the offices of Dr. Mike Williams in Gulfport, MS. The inclusion criteria were:

1) No previous orthodontic treatment

2) Patients in the early mixed to early permanent dentitions (ages 6 to 15)

3) Patients had a pre-treatment Wits measurement less than $0 \mathrm{~mm}$

4) Patients received comprehensive orthodontic treatment with $\operatorname{CS} 2000 \AA$ appliance

5) Pre-treatment and post-treatment records between 8 months and 2 years

The exclusion criteria included poor quality radiographs and missing radiographs from either time point (pre-treatment or post-treatment). The final sample size consisted of 30 patients (15 males and 15 females). The mean age of the pre-treatment starting sample was $9.6 \pm 2.1$ years (Table 10). The treatment record consisted of lateral cephalometric radiographs taken before treatment began with the CS2000® appliance (pre-treatment, T1) and at completion of treatment with the CS2000® appliance or two years into treatment (post-treatment, T2). The average treatment time was $1.3 \pm 0.3$ years. Note that for a few of the patients included in the study, actual treatment with the CS2000® appliance continued beyond the T2 records. However, to control the variability in the length of treatment time, a maximum of 2 years between pre and post-treatment records was included in the inclusion criteria. Also note, once 
treatment with the CS2000 appliance was complete, patients continued with comprehensive braces to finalize treatment.

\section{Appliance Design}

\section{CS 2000® appliance}

As designed by Dr. Williams, the CS $2000 ®$ appliance has both an upper and lower member. Depending on the patient's needs, the upper and lower appliances have differing components consisting of differing expansion components. The main components of these appliances are the inter-arch closed coil NiTi springs in the same vector as Class III elastics.

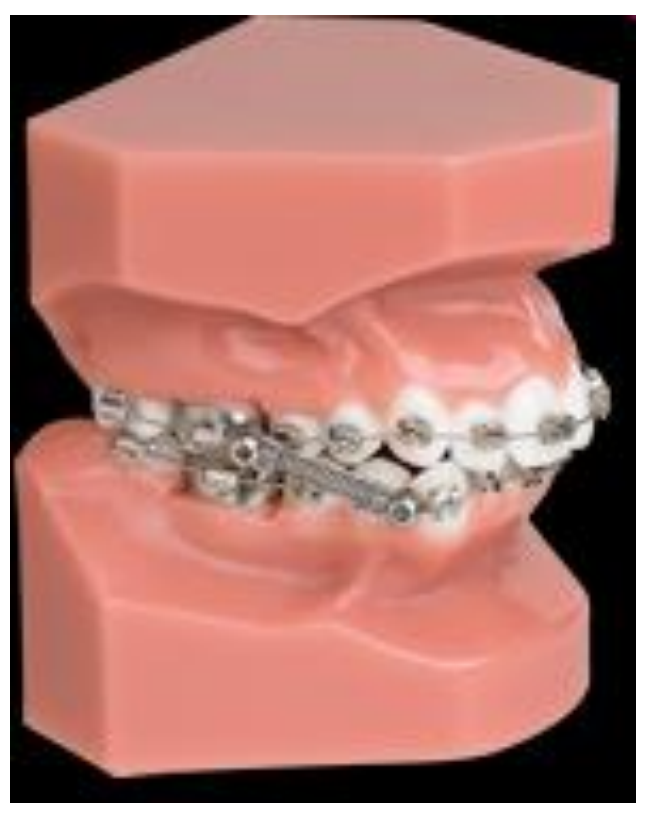

Figure 4. The CS2000® appliance 


\section{IRB Approval}

IRB exemption was obtained from West Virginia University prior to beginning this research study (Appendix A). Approval was also granted from Dr. Michael Williams for the use of his orthodontic records.

\section{Cephalometric Radiographs}

1.) Treatment Group

a. Lateral cephalometric films were collected from pre-treatment records before treatment began

b. Lateral cephalometric films were collected from post-treatment records after CS2000® appliance removal

c. The two radiographs were then compared to allow a final calculation of average total effect seen by the CS2000® appliance in addition to normal growth of each patient during the treatment time prescribed.

\section{Research Design}

1) Films from pre-treatment and post-treatment records were collected and then digitized using Dolphin Imaging (Dolphin Imaging, Chatsworth, CA) software. This allowed for landmark identification and adjusting for magnification.

2) All of the angular measurements were found using Dolphin Imaging (Dolphin Imaging, Chatsworth, CA) and reported to the nearest $0.1^{\circ}$ 
3) Films were printed 1:1 using a Kodak ESP 7250 printer (Kodak, Atlanta, GA), and then traced by one investigator using a \#2 lead pencil on .003 inch matt cephalometric acetate tracing film (3M Unitek, Monrovia, CA)

4) The films were traced using a published cephalometric analysis and landmarks described by Bjork $^{72}$ and Pancherz ${ }^{73}$ (described below). All measurements were done using a digital caliper (accurate to $.01 \mathrm{~mm}$ ) and reported to the nearest $0.1 \mathrm{~mm}$.

5) Data was analyzed statistically using paired t tests to compare the amounts of maxillary and mandibular skeletal and dento-alveolar changes seen in the treatment group from pre-treatment to post-treatment. (T2-T1).

\section{Assessment of Records}

Films were traced by one investigator and compared using the cephalometric analysis as described by Bjork ${ }^{72}$ and Pancherz ${ }^{73}$. Measurements were taken in the sagittal, vertical, and angular relationships as described below. To see identification landmarks and reference lines, see Table 2 and Table 3 located below.

\section{Cephalometric Records}

The cephalometric analysis of changes induced by the CS2000® appliance followed the model described by Bjork ${ }^{72}$ in 1947 and again by Pancherz ${ }^{73}$ in 1982.. This analysis provided a means to compare changes in the sagittal, vertical, and angular dimensions induced by treatment. The results of the study on the CS2000® appliance were then compared indirectly to other appliances attempting to produce the same treatment effects, namely the facemask. The specifics of each measurement are listed in Table 4Table 5Table 6. 


\section{Definition of Reference Lines}

\begin{tabular}{|c|c|c|}
\hline Symbol & Name & Definition \\
\hline $\mathrm{Ii}$ & Incison inferious & $\begin{array}{l}\text { The incisal point of the most prominent } \\
\text { mandibular central incisor }\end{array}$ \\
\hline Is & Incison superious & $\begin{array}{l}\text { The incisal point of the most prominent maxillary } \\
\text { central incisor }\end{array}$ \\
\hline Iia & Mandibular incisor apex & $\begin{array}{l}\text { The root apex of the most prominent mandibular } \\
\text { central incisor }\end{array}$ \\
\hline Isa & Maxillary incisor apex & $\begin{array}{l}\text { The root apex of the most prominent maxillary } \\
\text { central incisor }\end{array}$ \\
\hline $\mathrm{Mi}$ & Molar inferious & $\begin{array}{l}\text { The mesial contact point of the mandibular } \\
\text { permanent first molar }\end{array}$ \\
\hline Mic & $\begin{array}{l}\text { Molar inferious mesial } \\
\text { cusp }\end{array}$ & $\begin{array}{l}\text { The mesio-buccal cusp tip of the mandibular first } \\
\text { molar }\end{array}$ \\
\hline Ms & Molar superious & $\begin{array}{l}\text { The mesial contact point of the maxillary } \\
\text { permanent first molar }\end{array}$ \\
\hline Msc & $\begin{array}{l}\text { Molar superious mesial } \\
\text { cusp }\end{array}$ & $\begin{array}{l}\text { The mesio-buccal cusp tip of the maxillary first } \\
\text { molar }\end{array}$ \\
\hline $\mathrm{Co}$ & Condylion & $\begin{array}{l}\text { The most supero-posterior point on the curvature } \\
\text { of the condylar head }\end{array}$ \\
\hline $\mathrm{Pg}$ & Pogonion & The most prominent point of the chin \\
\hline ANS & Anterior Nasal Spine & The apex of the spina nasalis anterior \\
\hline A pt. & Subspinale & $\begin{array}{l}\text { The deepest point in the concavity of the anterior } \\
\text { maxilla between the ANS and alveolar crest }\end{array}$ \\
\hline PNS & Posterior Nasal Spine & $\begin{array}{l}\text { The most posterior point on the contour of the } \\
\text { palate in the midsagittal plane }\end{array}$ \\
\hline $\mathrm{Me}$ & Menton & The deepest point of the mandibular symphysis \\
\hline Go & Gonion & $\begin{array}{l}\text { The lowest point of the bony contour of the angle } \\
\text { of the mandible }\end{array}$ \\
\hline $\mathrm{S}$ & Sella & The center of Sella turcica \\
\hline $\mathrm{N}$ & Nasion & The most anterior point of the nasofrontal suture \\
\hline B pt. & Supramentale & $\begin{array}{l}\text { The innermost point on the contour of the } \\
\text { mandible between the incisor tooth and the bony }\end{array}$ \\
\hline
\end{tabular}

Table 2. Skeletal and Dental Landmarks 


\begin{tabular}{|l|l|l|}
\hline Symbol & \multicolumn{1}{|c|}{ Name } & \multicolumn{1}{c|}{ Definition } \\
\hline NSL & Sella-Nasion Line & Reference line joining Nasion and Sella \\
\hline OL & Occlusal Line & $\begin{array}{l}\text { Reference line joining the maxillary incisal edge and } \\
\text { the molar superious mesial cusp tip }\end{array}$ \\
\hline OLp & $\begin{array}{l}\text { Occlusal Line } \\
\text { Perpendicular }\end{array}$ & $\begin{array}{l}\text { Reference line produced by dropping a perpendicular } \\
\text { line from sella to the occlusal plane }\end{array}$ \\
\hline Ols & Occlusal Line Sella & $\begin{array}{l}\text { Reference line parallel to OL passing through sella } \\
\text { (perpendicular to OLp passing through sella) }\end{array}$ \\
\hline NL & Maxillary Line & $\begin{array}{l}\text { Reference line joining anterior nasal spine and posterior } \\
\text { nasal spine }\end{array}$ \\
\hline ML & Mandibular Line & Reference line joining menton and gonion \\
\hline
\end{tabular}

\section{Table 3. Definition of Reference Lines}

\section{Sagittal Measurements}

Dental and skeletal changes in the sagittal relationship were assessed using the Occlusal line of T1 (OL) and the Occlusal plane perpendicular of T1 (OLp) described in Table 4. All landmark measurements were referenced from this line. From the T1 film, the OL and OLp were established to set up a reference grid. This reference grid was then used to assess change in the $\mathrm{T} 1$ and T2 films, superimposing over the anterior cranial base. Changes induced by treatment could then be assessed referencing all points to OLp. In addition to these points, a Wits measurement was also used. Table 4 and Figure 5 below describe this process.

\begin{tabular}{|l|l|}
\hline \multicolumn{1}{|c|}{ Variables } & \multicolumn{1}{c|}{ Definition } \\
\hline Skeletal measuring points: & \\
\hline OLp-A pt. & Position of maxillary base \\
\hline OLp-B pt. & Position of mandibular base (symphysis) \\
\hline
\end{tabular}




\begin{tabular}{|l|l|}
\hline OLp-Pg & Position of mandibular base (chin) \\
\hline OLp-Co & Position of Condyle \\
\hline Wits analysis & $\begin{array}{l}\text { Position of the maxillary base relative to the mandibular } \\
\text { base }\end{array}$ \\
\hline Dental measuring points: & \\
\hline Is-OLp & Position of maxillary central incisor \\
\hline Ii-OLp & Position of mandibular incisor \\
\hline Is-OLp minus Ii-OLp & Overjet \\
\hline Ms-OLp & Position of maxillary first permanent molar \\
\hline Mi-OLp & Position of mandibular first molar \\
\hline Ms-OLp minus Mi-OLp & Molar Relationship \\
\hline
\end{tabular}

Table 4. Sagittal Measurements

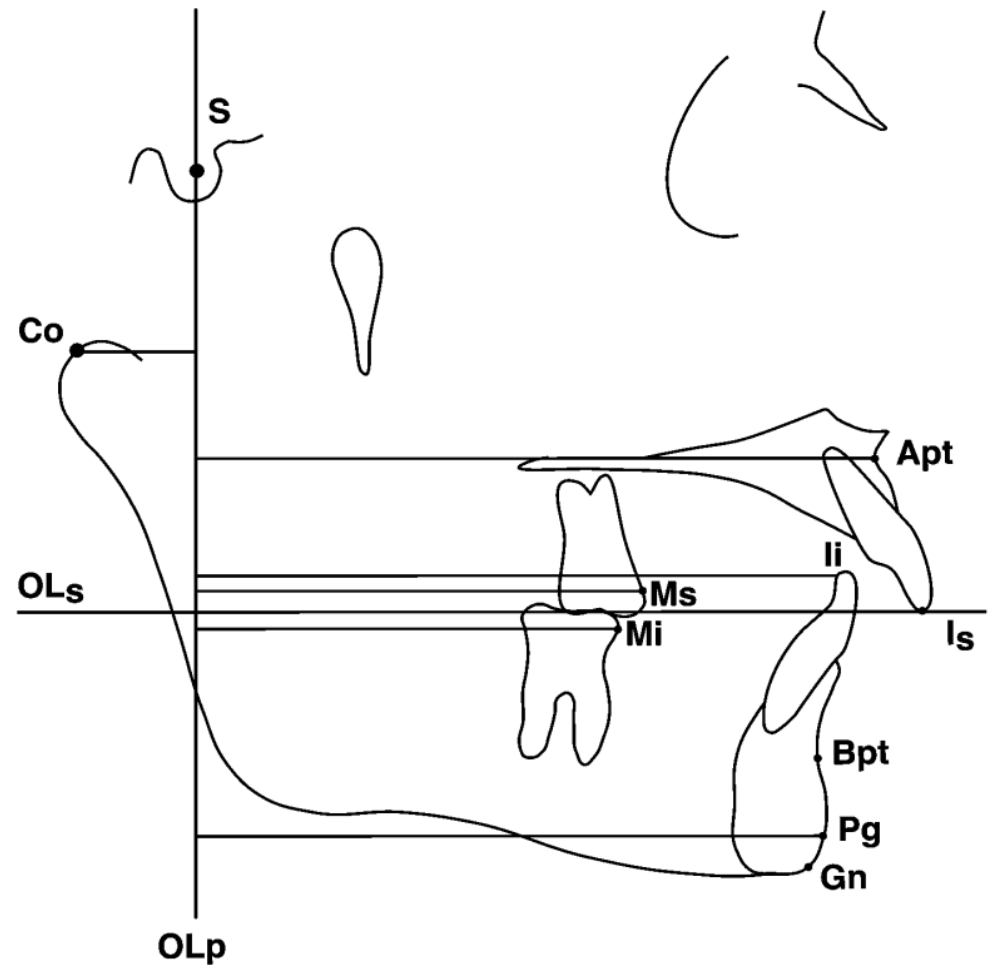

Figure 5. Cephalometric landmarks and lines used for sagittal measurements 


\section{Vertical measurements}

Table 5 and Figure 6 below illustrate measurements in the vertical dimension. The superimposition technique and reference grid based on OL and OLp were used the same as in the assessment of sagittal change. Vertical measurements included OLs, NL, ML, and OL (Figure 6). A measurement of ANS to Me was also included.

\begin{tabular}{|l|l|}
\hline Variables & Definition \\
\hline Skeletal measuring points: & \\
\hline OLs-A pt. & Maxillary vertical position \\
\hline ANS-Me & Lower facial height \\
\hline Dental measuring points: & \\
\hline Is-NL & Position of maxillary central incisor \\
\hline Ii-ML & Position of mandibular central incisor \\
\hline Distance from li perpendicular To OL & Overbite \\
\hline Msc-NL & Position of maxillary permanent first molar \\
\hline Mic-ML & Position of mandibular permanent first molar \\
\hline
\end{tabular}

Table 5. Vertical Measurements 


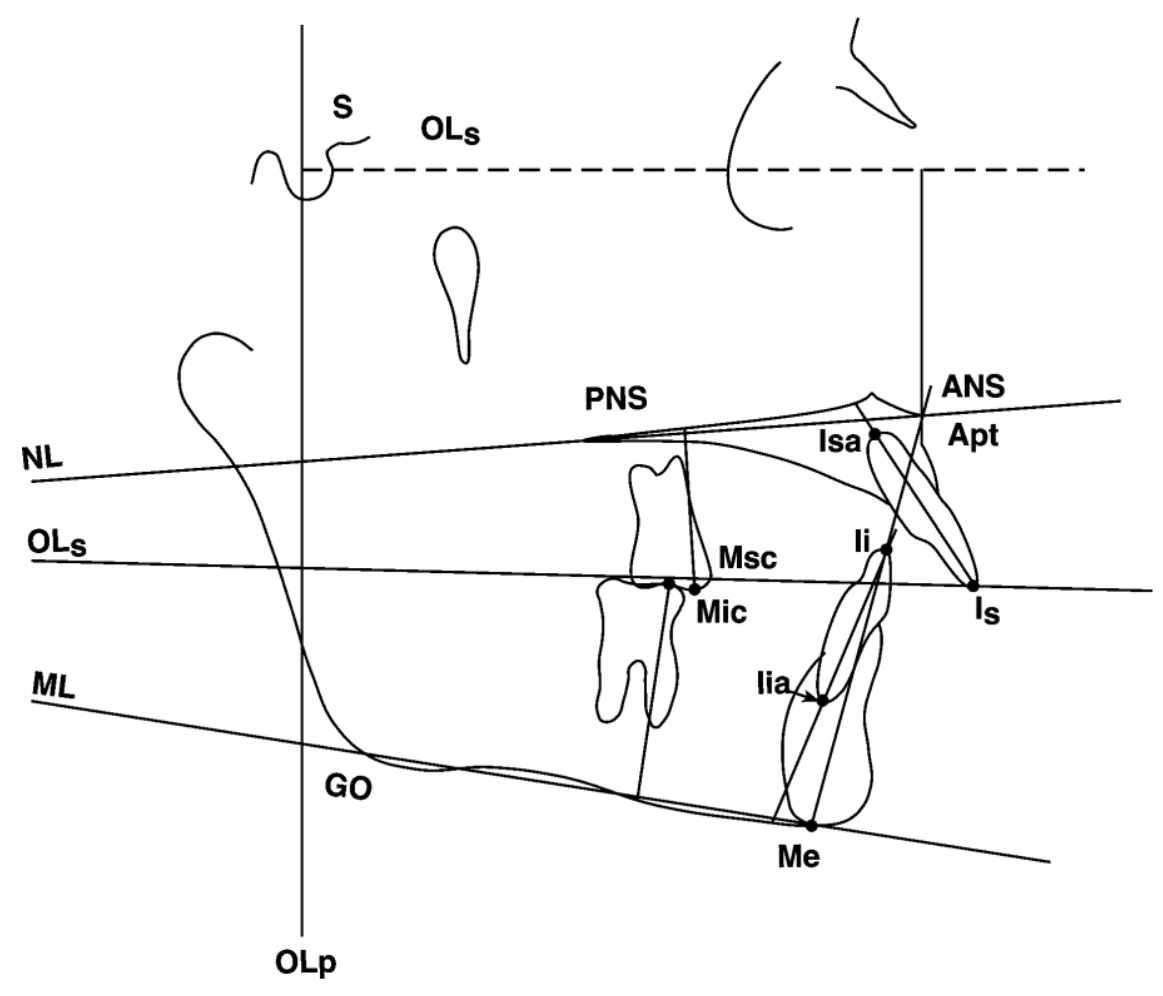

Figure 6. Cephalometric landmarks and lines for vertical measurements

\section{Angular Measurements}

Table 6 and Figure 7 below illustrate measurements in the angular dimension. These measurements were performed to assess changes in the dentofacial complex.

\begin{tabular}{|l|l|}
\hline Variables & $\underline{\text { Definition }}$ \\
\hline Skeletal measuring points: & \\
\hline SNA & Maxillary base relative to SNL \\
\hline SNB & Mandibular base relative to SNL \\
\hline ANB & SNA minus SNB \\
\hline SNL_-NL & Palatal plane angle \\
\hline SNL-ML & Mandibular plane angle \\
\hline
\end{tabular}




\begin{tabular}{|l|l|}
\hline SNL_OL & Occlusal plane angle \\
\hline Dental measuring points: & \\
\hline Is/SNL & Maxillary central incisor angle \\
\hline Ii/ML & Mandibular central incisor angle \\
\hline Isa-Is/lia—-Ii & Interincisal angle \\
\hline
\end{tabular}

\section{Table 6. Angular Measurements}

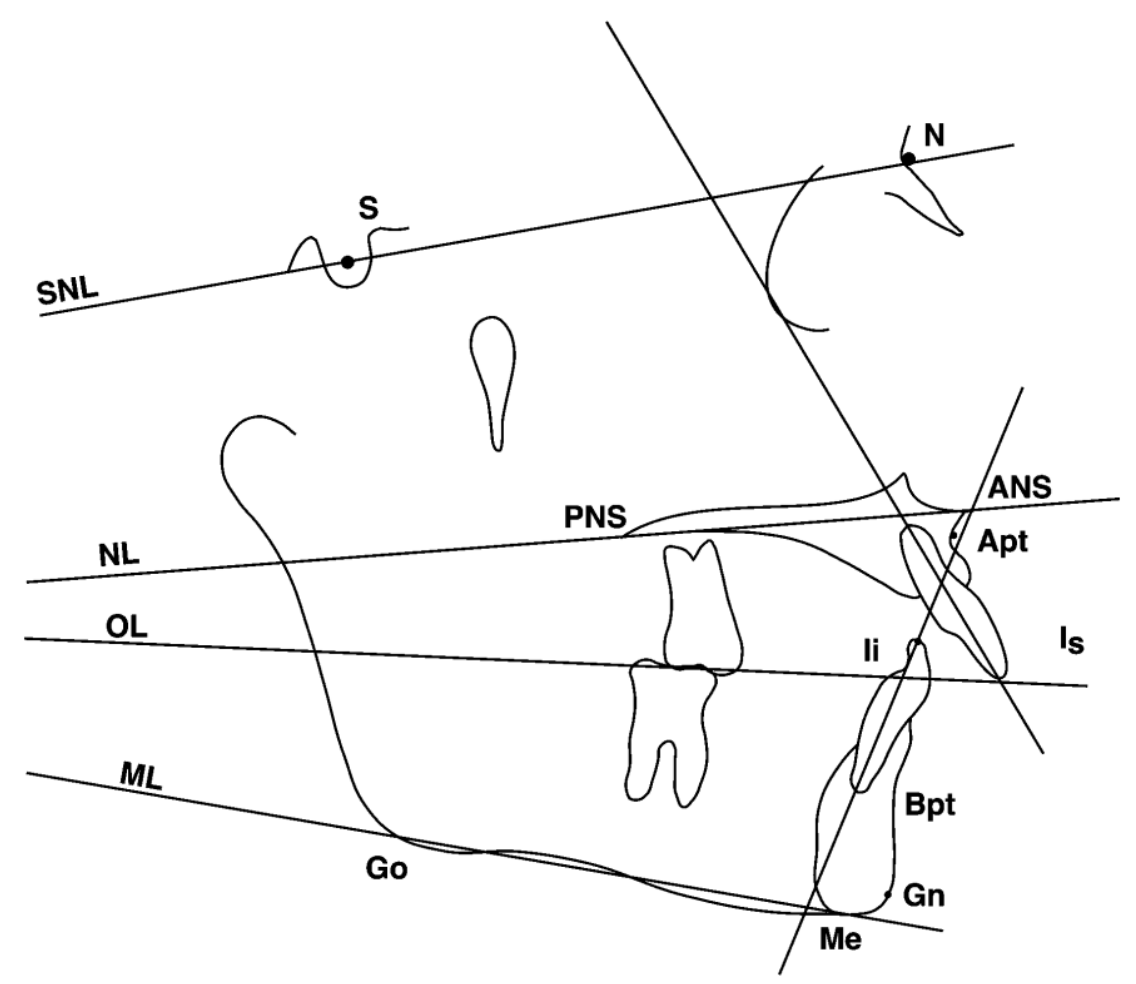

Figure 7. Cephalometric landmarks and lines for angular measurements 


\section{Method Error}

The reliability of the cephalometric measurements were tested by investigating the error in locating, superimposing, and measuring the differences in the landmarks. Pre-treatment and post-treatment radiographs of ten randomly selected patients were retraced two weeks after the initial tracing and analyzed to evaluate error. For all cephalometric variables, differences between the measurements recorded at the first tracing and the second tracing session were compared for each individual at T1 and T2. A correlation coefficient was then calculated for each individual variable at each time point ( $\mathrm{T} 1$ and $\mathrm{T} 2)$. The correlation results presented in Table 7, show how closely each variable from the first tracing session were replicated during the second tracing session. Correlations of the variables from both the pre-treatment and posttreatment records are shown. In Table 8, measurements of the results of post-treatment minus pre-treatment (T2-T1) from the first tracing session were compared to the measurements of the results of post-treatment minus pre-treatment (T2-T1) from the second retracing session. The calculations show, the mean difference, standard deviation, minimum difference, and maximum difference for the two tracing sessions ((T2-T1 from tracing session 2) - (T2-T1 from tracing session 1)).

\begin{tabular}{|l|r|r|r|r|r|r|}
\hline \multirow{2}{*}{ Variables } & \multicolumn{3}{|c|}{ T1 } & \multicolumn{3}{c|}{ T2 } \\
\cline { 2 - 7 } & Mean (1st) & Mean (2nd) & $\begin{array}{l}\text { Reliability } \\
\text { coefficient }\end{array}$ & Mean (1st) & Mean (2nd) & $\begin{array}{l}\text { Reliability } \\
\text { coefficient }\end{array}$ \\
\hline Sagittal: & & & & & & \\
\hline OLp-A pt. & 68.1 & 68.0 & 0.98 & 69.5 & 69.2 & 0.99 \\
\hline OLp-B pt. & 74.5 & 74.3 & 0.99 & 71.7 & 71.6 & 0.99 \\
\hline OLp-Pg & -10.7 & 76.5 & 0.99 & 74.2 & 74.2 & 0.99 \\
\hline OLp-Co & -4.6 & -3.9 & 0.9 & -10.0 & -9.5 & 0.95 \\
\hline Wits & 73.8 & 73.7 & 0.98 & 78.4 & 78.3 & 0.99 \\
\hline Is-OLp & 75.0 & 74.8 & 0.99 & 72.1 & 71.9 & 0.98 \\
\hline li-OLp & & & & & & \\
\hline
\end{tabular}




\begin{tabular}{|l|r|r|r|r|r|r|}
\hline Overjet & -1.2 & -1.1 & 0.98 & 6.3 & 6.4 & 0.99 \\
\hline Ms-OLp & 46.9 & 46.9 & 0.98 & 49.5 & 49.6 & 0.98 \\
\hline Mi-OLp & 49.4 & 49.3 & 0.98 & 46.7 & 46.7 & 0.99 \\
\hline Molar Relationship & -2.5 & -2.4 & 0.98 & 2.8 & 2.9 & 0.99 \\
\hline Vertical: & & & & & & \\
\hline OLs-A pt. & 27.5 & 27.9 & 0.99 & 29.8 & 30.1 & 0.99 \\
\hline ANS-Me & 54.8 & 54.6 & 0.99 & 60.3 & 60.3 & 0.99 \\
\hline Is-NL & 23.0 & 22.8 & 0.99 & 22.9 & 22.9 & 0.96 \\
\hline li-ML & 33.6 & 33.5 & 0.98 & 35.7 & 35.7 & 0.97 \\
\hline Overbite & 2.7 & 2.6 & 0.98 & 0.5 & 0.7 & 0.95 \\
\hline Msc-NL & 18.2 & 18.2 & 0.81 & 20.9 & 20.7 & 0.94 \\
\hline Mic-ML & 24.1 & 23.9 & 0.85 & 23.8 & 23.8 & 0.97 \\
\hline Angular: & & & & & & \\
\hline SNA & 80.7 & 80.4 & 0.99 & 83.7 & 82.9 & 0.97 \\
\hline SNB & 80.6 & 80.4 & 0.99 & 80.3 & 79.8 & 0.97 \\
\hline ANB & 0.1 & 0.0 & 0.96 & 3.4 & 3.1 & 0.92 \\
\hline SNL-NL & 9.9 & 9.7 & 0.87 & 7.2 & 7.7 & 0.97 \\
\hline SNL-ML & 33.0 & 32.7 & 0.99 & 34.8 & 35.1 & 0.98 \\
\hline SNL-OL & 19.7 & 19.6 & 0.99 & 17.1 & 17.2 & 0.99 \\
\hline Is/SNL & 101.4 & 101.9 & 0.98 & 114.5 & 114.1 & 0.98 \\
\hline li/ML & 88.3 & 90.1 & 0.98 & 83.0 & 83.9 & 0.96 \\
\hline Interincisal Angle & 137.3 & 135.5 & 0.99 & 127.8 & 126.9 & 0.98 \\
\hline
\end{tabular}

Table 7. Correlation Coefficients for individual variable at $\mathrm{T} 1$ and $\mathrm{T} 2$ from the first and second tracing sessions

\begin{tabular}{|c|c|c|c|c|}
\hline \multirow[t]{2}{*}{ Variables } & \multicolumn{4}{|c|}{ T2-T1 (Differences of repeated tracings 1 and 2) } \\
\hline & Mean & SD & Max & Min \\
\hline \multicolumn{5}{|l|}{ Sagittal: } \\
\hline OLp-A pt. & -0.2 & 0.3 & 0.3 & -0.7 \\
\hline OLp-B pt. & 0.1 & 0.3 & 0.7 & -0.3 \\
\hline OLp-Pg & 0.2 & 0.5 & 1.0 & -0.4 \\
\hline OLp-Co & 0.3 & 0.8 & 1.6 & 1.2 \\
\hline Wits & -0.8 & 1.2 & 0.9 & -2.9 \\
\hline Is-OLp & 0.0 & 0.5 & 0.4 & -1.2 \\
\hline li-OLp & -0.1 & 0.4 & 0.8 & -0.7 \\
\hline Overjet & 0.0 & 0.5 & 0.8 & -0.9 \\
\hline Ms-OLp & 0.1 & 0.6 & 1.2 & -0.9 \\
\hline Mi-OLp & 0.1 & 0.6 & 0.9 & -0.8 \\
\hline Molar Relationship & 0.1 & 0.5 & 1.0 & -0.8 \\
\hline
\end{tabular}




\begin{tabular}{|c|r|r|r|r|}
\hline Vertical: & & & & \\
\hline OLs-A pt. & 0.0 & 0.5 & 0.6 & -1.1 \\
\hline ANS-Me & 0.2 & 0.3 & 0.6 & -0.4 \\
\hline Is-NL & 0.2 & 0.7 & 1.5 & -0.7 \\
\hline Ii-ML & 0.1 & 0.7 & 1.5 & -0.7 \\
\hline Overbite & 0.2 & 0.4 & 0.9 & -0.5 \\
\hline Msc-NL & -0.1 & 1.5 & 3.2 & -2.3 \\
\hline Mic-ML & 0.2 & 1.3 & 2.6 & -1.1 \\
\hline Angular: & & & & \\
\hline SNA & -0.5 & 1.0 & 0.7 & -2.2 \\
\hline SNB & -0.3 & 1.1 & 1.2 & -2.4 \\
\hline ANB & -0.2 & 0.4 & 0.3 & -0.6 \\
\hline SNL-NL & 0.7 & 2.2 & 3.9 & -3.4 \\
\hline SNL-ML & 0.6 & 0.9 & 2.0 & -1.0 \\
\hline SNL-OL & 0.2 & 0.4 & 0.7 & -0.6 \\
\hline Is/SNL & -0.9 & 1.2 & 0.9 & -3.3 \\
\hline li/ML & -0.9 & 2.0 & 2.2 & -3.2 \\
\hline Interincisal Angle & 0.8 & 2.4 & 4.2 & -2.6 \\
\hline
\end{tabular}

Table 8. Mean, SD, Min, and Max differences for the two tracing sessions ((T2-T1 from tracing session 2) - (T2-T1 from tracing session 1)).

The method of cephalometric analysis used in this study was determined to be reliable and repeatable. The correlations ranged from 0.81 to 0.99 , with the majority being above 0.95 . Also the mean differences of the results found from tracing session two compared to tracing session one were small.

\section{Dental and Skeletal contributions to overjet and molar relationship}

\section{corrections}

In order to calculate the contribution of skeletal and dental components in the correction of overjet and molar relationship the following was used (Table 9). 


\begin{tabular}{|l|l|}
\hline Overjet & Molar relationship \\
\hline Skeletal contribution & Skeletal contribution: \\
\hline 1. OLp - A pt. & 1. OLp - A pt. \\
\hline 2. OLp - Pg & 2. OLp - Pg \\
\hline Dental contribution & Dental contribution \\
\hline 3. OLp - A pt. minus Is/OLp & 3. OLp - A pt. minus Is/OLp \\
\hline 4. OLp - Pg minus Ii/OLp & 4. OLp - Pg minus Ii/OLp \\
\hline Overjet correction & \\
\hline Sum of $1,2,3$, and 4 & Sum of $1,2,3$, and 4 \\
\hline
\end{tabular}

Table 9. Calculation of overjet and molar relationship changes

Using the table above (Table 9) and adding specific variables, the following formula was used to assess overjet correction:

\begin{tabular}{|c|}
\hline Overjet Correction $=$ Maxilla + Mx incisor - Mandible - Md i \\
Maxilla $=$ OLp-A pt. \\
Mx incisor $=$ Is-OLp minus OLp-A pt. \\
Mandible $=$ OLp-Pg \\
Mandibular incisor $=$ Ii-OLp minus OLp-Pg
\end{tabular}

Using the table above (Table 9) and adding specific variables, the following formula was used to assess molar relationship correction:

Molar Relationship Correction $=$ Maxilla + Mx molar - Mandible - Md

Maxilla $=$ OLp-A pt.




Mx molar $=$ Ms-OLp minus OLp-A pt.
Mandible $=$ OLp-Pg
Mandibular incisor $=$ Mi-OLp minus OLp-Pg

\section{Statistics}

1.) Mean, standard deviation, minimum and maximum measurements of each variable were calculated from the pre-treatment (T1) and post-treatment (T2) groups.

2.) Paired t-tests with a significance of $\mathrm{p}<0.05$ ( $95 \%$ confidence interval) was used to compare each variable for (T2-T1). 


\section{CHAPTER IV: RESULTS}

\section{Age and Sex Distribution of Treatment Group}

The final treatment group consisted of 30 patients (15 females and 15 males). The average age at the beginning of treatment (T1) was 9.6 years (10.4 for females and 8.7 for males). The average age at the completion of treatment was 10.9 years ( 11.7 for females and 10.1 for males). The average treatment time was 1.3 years (1.3 years for females and 1.4 years for males) and ranged from 0.8 to 2.0 years. Table 10 shows these results.

\begin{tabular}{|l|r|r|r|r|}
\hline & \multicolumn{1}{|c|}{ MEAN } & \multicolumn{1}{c|}{ S.D. } & \multicolumn{1}{c|}{ MAX } & \multicolumn{1}{c|}{ MIN } \\
\hline POOLED & & & & \\
\hline Pre-Treatment (T1) & 9.6 & 2.1 & 14.6 & 6.5 \\
\hline Post-Treatment (T2) & 10.9 & 2.2 & 15.9 & 7.6 \\
\hline (T2-T1) & 1.3 & 0.3 & 2.0 & 0.8 \\
\hline MALES & & & & \\
\hline Pre-Treatment (T1) & 8.7 & 1.7 & 11.3 & 6.5 \\
\hline Post-Treatment (T2) & 10.1 & 1.8 & 13.0 & 7.6 \\
\hline (T2-T1) & 1.4 & 0.4 & 2.0 & 0.9 \\
\hline FEMALES & & & & \\
\hline Pre-Treatment (T1) & 10.4 & 2.2 & 14.6 & 6.6 \\
\hline Post-Treatment (T2) & 11.7 & 2.3 & 15.9 & 7.7 \\
\hline (T2-T1) & 1.3 & 0.3 & 1.8 & 0.8 \\
\hline
\end{tabular}

Table 10. Ages of patients at Pre-Treatment and Post-Treatment

\section{Pre-Treatment Craniofacial Morphology}

A table examining the pre-treatment craniofacial morphology of the treatment group is shown below. 


\begin{tabular}{|c|c|c|c|c|}
\hline \multicolumn{5}{|c|}{ Pre-Treatment Craniofacial Morphology } \\
\hline Variable & Mean & S.D. & Max & Min \\
\hline \multicolumn{5}{|l|}{ Sagittal: } \\
\hline OLp-A pt. & 68.3 & 2.7 & 74.4 & 63.4 \\
\hline OLp-B pt. & 74.3 & 3.4 & 81.8 & 67.4 \\
\hline OLp-Pg & 76.7 & 4.1 & 85.2 & 69.7 \\
\hline OLp-Co & -10.2 & 3.7 & -5.0 & -19.7 \\
\hline Wits & -4.2 & 2.1 & -0.1 & -8.2 \\
\hline Is-OLp & 74.1 & 3.9 & 83.7 & 68.4 \\
\hline li-OLp & 74.1 & 3.9 & 87.4 & 67.2 \\
\hline Overjet & 0.0 & 2.3 & 4.4 & -3.7 \\
\hline Ms-OLp & 47.1 & 3.4 & 55.1 & 41.0 \\
\hline Mi-OLp & 49.6 & 3.2 & 56.3 & 43.5 \\
\hline Molar Relationship & -2.6 & 1.9 & 0.5 & -7.5 \\
\hline \multicolumn{5}{|l|}{ Vertical: } \\
\hline Ols-Apt & 29.4 & 5.2 & 39.6 & 17.9 \\
\hline ANS-Me & 56.4 & 5.0 & 67.8 & 48.7 \\
\hline Is-NL & 23.4 & 2.2 & 28.1 & 19.9 \\
\hline li-ML & 34.1 & 2.5 & 39.5 & 29.6 \\
\hline Overbite & 2.3 & 1.6 & 5.9 & 0.0 \\
\hline Msc-NL & 18.8 & 2.4 & 23.6 & 14.7 \\
\hline Mic-ML & 24.8 & 2.3 & 29.1 & 20.6 \\
\hline \multicolumn{5}{|l|}{ Angular: } \\
\hline SNA & 80.1 & 3.8 & 87.3 & 73.6 \\
\hline SNB & 80.4 & 3.6 & 89.1 & 73.9 \\
\hline ANB & -0.3 & 1.6 & 3.0 & -3.7 \\
\hline SNL-NL & 9.0 & 3.3 & 10.6 & 2.9 \\
\hline SNL-ML & 32.8 & 5.0 & 45.1 & 23.6 \\
\hline SNL-OIf & 18.3 & 3.8 & 27.6 & 10.2 \\
\hline Is/SNL & 102.2 & 9.0 & 125.3 & 84.9 \\
\hline li/ML & 85.8 & 7.2 & 100.3 & 72.7 \\
\hline Interincisal Angle & 139.1 & 13.3 & 169.8 & 104.9 \\
\hline
\end{tabular}

Table 11. Pre-Treatment craniofacial morphology

\section{Cephalometric Changes}

Changes in cephalometric measurements of individual patients treated with the CS2000® appliance before treatment (T1) and 8 months to 2 years after treatment began (post-treatment, T2) are shown in Table 12, Table 13Table 14. 


\begin{tabular}{|c|c|c|c|c|c|c|c|c|}
\hline \multirow{3}{*}{\begin{tabular}{|l|} 
Patient \\
\end{tabular}} & \multirow[t]{2}{*}{ Overjet } & \multirow{2}{*}{\multicolumn{2}{|c|}{$\begin{array}{l}\text { Maxillary Mandibular } \\
\text { incisor incisor }\end{array}$}} & \multirow{2}{*}{$\begin{array}{c}\text { Molar } \\
\text { relationship }\end{array}$} & \multirow{2}{*}{\multicolumn{4}{|c|}{ 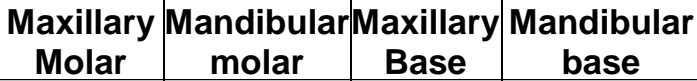 }} \\
\hline & & & & & & & & \\
\hline & \\
\hline 1 & 5.2 & 6.2 & 1.0 & 6.2 & 5.8 & -0.4 & 1.6 & 2.3 \\
\hline 2 & 0.2 & 4.9 & 4.7 & -1.7 & -1.7 & 0.0 & 1.1 & -1.2 \\
\hline 3 & 4.7 & 2.8 & -1.9 & 8.9 & 3.5 & \begin{tabular}{|c|}
-5.4 \\
\end{tabular} & 1.3 & \begin{tabular}{|l|}
-2.3 \\
\end{tabular} \\
\hline 4 & 0.5 & 1.4 & 0.9 & 7.1 & 3.1 & -4.0 & 1.5 & \begin{tabular}{|c|}
-1.8 \\
\end{tabular} \\
\hline 5 & 1.5 & 2.4 & 0.9 & 1.1 & 2.2 & 1.1 & 1.0 & -3.0 \\
\hline 6 & 0.4 & 0.3 & -0.1 & 0.2 & \begin{tabular}{|c|}
-1.6 \\
\end{tabular} & \begin{tabular}{|c|}
-1.8 \\
\end{tabular} & 0.6 & \begin{tabular}{|l|}
-2.6 \\
\end{tabular} \\
\hline 7 & 4.3 & 3.5 & -0.8 & 2.2 & 2.7 & 0.5 & 0.7 & \begin{tabular}{|c|}
-3.6 \\
\end{tabular} \\
\hline 8 & 5.1 & 4.8 & -0.3 & 6.4 & 3.9 & -2.5 & 0.8 & -0.8 \\
\hline 9 & 6.4 & 2.3 & -4.1 & 6.6 & 1.7 & -4.9 & 0.6 & -3.0 \\
\hline 10 & 11.4 & 5.8 & -5.6 & 8.1 & 1.5 & -6.6 & 1.3 & -3.8 \\
\hline 11 & 7.6 & 5.3 & -2.3 & 8.0 & 4.2 & -3.8 & 1.2 & -1.0 \\
\hline 12 & 5.0 & 3.2 & -1.8 & 7.7 & 5.0 & -2.7 & 1.3 & -2.1 \\
\hline 13 & 7.1 & 7.0 & -0.1 & -1.8 & 1.8 & 3.6 & 1.0 & 2.0 \\
\hline 14 & 5.6 & 4.8 & -0.8 & 5.9 & 4.3 & -1.6 & 2.1 & 0.0 \\
\hline 15 & 2.7 & -0.2 & -2.9 & 5.4 & 3.2 & -2.2 & 0.5 & -3.1 \\
\hline Mean & $4.5^{*}$ & $3.6^{*}$ & -0.9 & $4.7^{*}$ & $2.6^{*}$ & $-2.0^{*}$ & $1.1^{*}$ & $-1.6^{*}$ \\
\hline SD & 3.1 & 2.1 & 2.4 & 3.7 & 2.1 & 2.7 & 0.4 & 1.9 \\
\hline Max & 11.4 & 7.0 & 4.7 & 8.9 & 5.8 & 3.6 & 2.1 & 2.3 \\
\hline Min & 0.2 & -0.2 & -5.6 & -1.8 & -1.7 & -6.6 & 0.5 & -3.8 \\
\hline \multicolumn{9}{|l|}{ Males } \\
\hline 1 & 10.2 & 7.6 & -2.6 & 6.2 & 3.9 & -2.3 & 1.9 & -0.3 \\
\hline 2 & 9.2 & 5.2 & -4.0 & 5.8 & -0.7 & -6.5 & 0.7 & -2.9 \\
\hline 3 & 3.6 & 2.3 & -1.3 & 2.3 & 2.1 & -0.2 & 0.8 & -2.2 \\
\hline 4 & 3.9 & 5.9 & 2.0 & 2.5 & 0.2 & -2.3 & 1.5 & -1.2 \\
\hline 5 & 5.0 & 2.6 & -2.4 & 3.5 & 3.0 & -0.5 & 2.4 & -1.6 \\
\hline 6 & 8.9 & 3.8 & -5.1 & 8.4 & 4.0 & -4.4 & 1.8 & $\begin{array}{l}-6.2 \\
\end{array}$ \\
\hline 7 & 0.9 & 3.5 & 2.6 & -3.0 & -0.2 & 2.8 & 1.4 & 1.4 \\
\hline 8 & 1.1 & 1.8 & 0.7 & 8.5 & 4.9 & -3.6 & 1.6 & 0.2 \\
\hline 9 & 0.1 & 3.3 & 3.2 & 4.5 & 4.1 & -0.4 & 3.1 & -1.0 \\
\hline 10 & 7.4 & 6.6 & -0.8 & 10.4 & 8.1 & \begin{tabular}{|c|}
-2.3 \\
\end{tabular} & 2.5 & $\begin{array}{l}-0.7 \\
\end{array}$ \\
\hline 11 & 11.0 & 7.0 & -4.0 & 0.4 & 1.2 & 0.8 & 1.0 & -1.4 \\
\hline 12 & 7.3 & 9.5 & 2.2 & 6.6 & 6.0 & -0.6 & 4.8 & 0.9 \\
\hline 13 & 5.7 & 1.8 & -3.9 & 6.9 & 0.9 & -6.0 & 1.5 & \begin{tabular}{|c|}
-3.9 \\
\end{tabular} \\
\hline 14 & 5.0 & 3.6 & -1.4 & 8.2 & 2.5 & \begin{tabular}{|l|}
-5.7 \\
\end{tabular} & 1.3 & \begin{tabular}{|c|}
-1.9 \\
\end{tabular} \\
\hline 15 & 4.1 & 5.2 & 1.1 & 1.3 & \begin{tabular}{|c|}
-0.1 \\
\end{tabular} & -1.4 & 2.2 & -0.4 \\
\hline Mean & $5.6^{*}$ & $4.6^{*}$ & -0.9 & $4.8^{*}$ & $2.7^{*}$ & $-2.2^{*}$ & $1.9^{*}$ & $-1.4^{*}$ \\
\hline SD & 3.4 & 2.3 & 2.7 & 3.6 & 2.5 & 2.7 & 1.0 & 1.9 \\
\hline Max & 11.0 & 9.5 & 3.2 & 10.4 & 8.1 & 2.8 & 4.8 & 1.4 \\
\hline Min & 0.1 & 1.8 & -5.1 & -3.0 & -0.7 & -6.5 & 0.7 & -6.2 \\
\hline \multicolumn{9}{|l|}{ Pooled } \\
\hline Mean & $5.0^{*}$ & $4.1^{*}$ & -0.9 & $4.8^{*}$ & $2.7^{*}$ & $-2.1^{*}$ & $1.5^{\star}$ & $-1.5^{\star}$ \\
\hline SD & 3.2 & 2.3 & 2.5 & 3.6 & 2.3 & 2.6 & 0.9 & 1.9 \\
\hline Max & 11.4 & 9.5 & 4.7 & 10.4 & 8.1 & 3.6 & 4.8 & 2.3 \\
\hline Min & 0.1 & -0.2 & -5.6 & -3.0 & \begin{tabular}{|l|}
-1.7 \\
\end{tabular} & -6.6 & 0.5 & -6.2 \\
\hline
\end{tabular}

Table 12. Individual comparison of sagittal changes from Pre-Treatment to PostTreatment (T2-T1) for female, male and pooled groups 


\begin{tabular}{|c|c|c|c|c|c|c|c|c|c|c|}
\hline Patient & $\begin{array}{l}\text { Max. } \\
\text { base }\end{array}$ & Overbite & LFH & \begin{tabular}{|c|} 
Max. \\
incisor
\end{tabular} & $\begin{array}{l}\text { Mand. } \\
\text { Incisor }\end{array}$ & $\begin{array}{l}\text { Max. } \\
\text { molar }\end{array}$ & \begin{tabular}{|l|} 
Mand. \\
Molar \\
\end{tabular} & NL/SNL & ML/SNL & OL/SNL \\
\hline \multicolumn{11}{|c|}{\begin{tabular}{|l|l|} 
Female & \\
\end{tabular}} \\
\hline 1 & 3.4 & -1.4 & 1.7 & 4.3 & -2.9 & 5.2 & -2.8 & -1.0 & -1.6 & -1.3 \\
\hline 2 & 4.1 & -3.7 & 5.3 & 1.1 & 2.6 & -0.3 & 2.1 & -0.1 & 2.9 & -2.2 \\
\hline 3 & 2.4 & -1.8 & 6.5 & 2.0 & 1.9 & 2.4 & -1.0 & -1.9 & 2.9 & -1.1 \\
\hline 4 & 3.0 & -2.6 & 5.1 & 0.3 & 2.1 & 1.7 & 0.0 & -2.0 & 1.4 & -0.7 \\
\hline 5 & 1.5 & -1.0 & 4.8 & 1.6 & 1.9 & 1.5 & 0.9 & -4.0 & 1.8 & -2.0 \\
\hline 6 & 1.6 & 1.3 & $\begin{array}{ll}6.7 \\
\end{array}$ & 4.1 & 3.5 & 2.4 & 0.8 & -1.1 & 4.0 & -1.5 \\
\hline 7 & 1.9 & -2.1 & 5.0 & -1.9 & 3.4 & 1.6 & 2.6 & -3.8 & -1.6 & -2.2 \\
\hline 8 & 2.0 & 0.2 & 5.4 & 0.3 & 4.9 & 3.4 & -0.9 & -2.7 & 0.5 & -1.4 \\
\hline 9 & 1.3 & 0.2 & 2.8 & -0.9 & 2.2 & 1.7 & -2.6 & -1.3 & 0.6 & -2.0 \\
\hline 10 & 0.7 & -4.1 & 6.2 & -1.0 & 0.7 & 3.4 & -2.7 & -2.2 & 3.1 & -1.5 \\
\hline 11 & 2.2 & -0.8 & 7.5 & 0.6 & 3.1 & 4.9 & -1.8 & -2.7 & 2.3 & -0.8 \\
\hline 12 & 2.6 & -1.6 & 6.5 & -0.9 & 4.5 & 3.2 & 0.4 & -4.4 & -0.6 & -4.2 \\
\hline 13 & 1.2 & -3.7 & 7.0 & -2.3 & 3.1 & 2.3 & 0.5 & -3.1 & 1.4 & -1.7 \\
\hline 14 & 3.6 & -0.3 & 3.0 & 1.1 & 1.2 & 3.5 & -1.5 & -0.4 & 1.9 & -1.3 \\
\hline 15 & 1.5 & -0.6 & 5.7 & 2.3 & 0.9 & 3.7 & -0.3 & -0.2 & 4.8 & -1.1 \\
\hline Mean & $2.2^{*}$ & $-1.5^{*}$ & $5.3^{*}$ & 0.7 & $2.2^{*}$ & $2.7^{*}$ & -0.4 & $-2.1^{*}$ & $1.6^{*}$ & $-1.7^{*}$ \\
\hline SD & 1.0 & 1.6 & 1.7 & 2.0 & 1.9 & 1.4 & 1.7 & 1.4 & 1.9 & 0.8 \\
\hline Max & 4.1 & 1.3 & 7.5 & 4.3 & 4.9 & 5.2 & 2.6 & -0.1 & 4.8 & -0.7 \\
\hline Min & 0.7 & -4.1 & 1.7 & -2.3 & -2.9 & -0.3 & -2.8 & -4.4 & -1.6 & -4.2 \\
\hline \multicolumn{11}{|l|}{ Males } \\
\hline 1 & 3.0 & -0.9 & 4.2 & 1.6 & 0.6 & 1.7 & -1.0 & \begin{tabular}{|c|}
-3.6 \\
\end{tabular} & 2.7 & -0.5 \\
\hline 2 & 2.8 & -3.1 & 3.6 & -1.7 & 1.5 & 2.6 & -1.6 & -3.2 & 1.1 & -3.8 \\
\hline 3 & 1.6 & -4.9 & 5.5 & \begin{tabular}{|l|}
-1.3 \\
\end{tabular} & 1.5 & 0.2 & 3.7 & \begin{tabular}{|c|}
-1.6 \\
\end{tabular} & 2.7 & -0.5 \\
\hline 4 & 3.5 & -0.1 & 4.5 & -1.1 & 5.3 & 1.3 & 1.3 & -1.5 & \begin{tabular}{l|l}
-0.3 \\
\end{tabular} & -0.5 \\
\hline 5 & 3.4 & -0.4 & 7.1 & 2.8 & 3.4 & 3.3 & 0.5 & \begin{tabular}{|c|}
-4.3 \\
\end{tabular} & 2.5 & -4.4 \\
\hline 6 & 4.6 & -5.1 & 5.1 & -2.9 & 1.3 & 1.4 & 0.6 & -6.9 & -1.5 & -5.6 \\
\hline 7 & 0.6 & -3.7 & 3.9 & 0.5 & 0.2 & 0.0 & 2.4 & \begin{tabular}{|l|}
-3.2 \\
\end{tabular} & -1.5 & -2.0 \\
\hline 8 & 2.8 & 0.5 & 6.3 & 3.9 & 2.6 & 0.4 & -0.9 & -8.0 & -0.8 & -1.8 \\
\hline 9 & 4.9 & -0.9 & 3.3 & 0.9 & 3.0 & 2.4 & 0.6 & 0.2 & 0.1 & $\begin{array}{l}-1.5 \\
\end{array}$ \\
\hline 10 & 3.3 & -0.7 & 6.0 & 2.7 & 2.2 & 4.8 & -0.9 & 0.1 & 4.8 & $\begin{array}{l}-1.7 \\
\end{array}$ \\
\hline 11 & 1.0 & 1.8 & 2.6 & 1.3 & \begin{tabular}{|l|}
1.7 \\
\end{tabular} & 1.6 & -0.8 & -2.1 & 1.2 & -2.1 \\
\hline 12 & 3.2 & 2.0 & 7.8 & -0.7 & 4.2 & 6.2 & -0.8 & 0.9 & 3.6 & -1.2 \\
\hline 13 & 1.2 & -3.1 & 5.7 & 0.0 & 2.2 & 2.8 & -0.1 & 0.2 & 3.2 & $\begin{array}{l}-1.7 \\
\end{array}$ \\
\hline 14 & 0.9 & -4.1 & 3.5 & -1.1 & 0.1 & 2.7 & -1.5 & -1.5 & 0.5 & -1.5 \\
\hline 15 & 4.3 & -1.7 & 4.6 & 0.7 & 2.8 & 2.5 & 2.5 & -1.0 & -2.1 & -2.4 \\
\hline Mean & $2.7^{*}$ & $-1.6 *$ & $4.9^{*}$ & 0.4 & $2.2^{*}$ & $2.3^{*}$ & 0.3 & $-2.4^{*}$ & 1.1 & $-2.1^{*}$ \\
\hline SD & 1.4 & 2.3 & 1.5 & 1.9 & 1.4 & 1.7 & 1.6 & 2.6 & 2.1 & 1.5 \\
\hline Max & 4.9 & 2.0 & 7.8 & 3.9 & 5.3 & 6.2 & 3.7 & 0.9 & 4.8 & -0.5 \\
\hline Min & 0.6 & -5.1 & 2.6 & -2.9 & 0.1 & 0.0 & -1.6 & -8.0 & -2.1 & -5.6 \\
\hline \multicolumn{11}{|l|}{ Pooled } \\
\hline Mean & $2.5^{\star}$ & $-1.5^{\star}$ & $5.1^{*}$ & 0.5 & $2.2^{*}$ & $2.5^{\star}$ & -0.1 & $-2.2^{*}$ & $1.3^{*}$ & $-1.9^{*}$ \\
\hline SD & 1.2 & 1.9 & 1.6 & 1.9 & 1.6 & 1.5 & 1.7 & 2.0 & 2.0 & 1.2 \\
\hline Max & 4.9 & 2.0 & 7.8 & 4.3 & 5.3 & 6.2 & 3.7 & 0.9 & 4.8 & -0.5 \\
\hline Min & 0.6 & -5.1 & 1.7 & -2.9 & -2.9 & -0.3 & -2.8 & -8.0 & -2.1 & -5.6 \\
\hline
\end{tabular}

Table 13. Individual comparison of vertical changes from Pre-Treatment to PostTreatment (T2-T1) for female, male and pooled groups 


\begin{tabular}{|c|c|c|c|c|c|c|c|c|}
\hline & SNA & SNB & ANB & $\begin{array}{c}\text { Max. } \\
\text { Incisor }\end{array}$ & $\begin{array}{l}\text { Mand. } \\
\text { Incisor }\end{array}$ & $\begin{array}{c}\text { Interincisal } \\
\text { angle }\end{array}$ & OLp-Co & Wits \\
\hline \multicolumn{9}{|l|}{ Female } \\
\hline 1 & 0.5 & 0.1 & 0.4 & 8.9 & 7.5 & -14.7 & -0.1 & 1.6 \\
\hline 2 & 0.0 & -0.8 & 0.7 & 10.6 & 12.0 & -25.6 & 2.0 & -1.5 \\
\hline 3 & 1.9 & -1.3 & 3.2 & 1.3 & -6.2 & 2.0 & 0.6 & 3.8 \\
\hline 4 & 0.6 & -0.7 & 1.3 & 3.5 & 6.7 & -11.6 & 0.4 & 2.7 \\
\hline 5 & 2.8 & 0.7 & 2.1 & -1.3 & 2.9 & -3.4 & 1.3 & 2.3 \\
\hline 6 & 0.7 & -0.3 & 1.0 & -4.1 & -1.5 & 1.7 & 2.5 & 0.7 \\
\hline 7 & 2.8 & 0.9 & 1.8 & 12.3 & \begin{tabular}{|l|}
1.3 \\
\end{tabular} & -12.0 & \begin{tabular}{|c|}
-1.3 \\
\end{tabular} & 5.8 \\
\hline 8 & 1.2 & 0.3 & 1.0 & 15.2 & -3.6 & -12.1 & -1.5 & 6.5 \\
\hline 9 & 1.9 & -0.4 & 2.3 & 15.2 & -3.2 & -12.7 & 1.5 & 8.2 \\
\hline 10 & 3.1 & -1.4 & 4.5 & 18.4 & -7.7 & $\mid-13.7$ & -0.4 & 8.4 \\
\hline 11 & 1.8 & -0.9 & 2.8 & 14.5 & -4.3 & -12.4 & 0.0 & 8.3 \\
\hline 12 & 5.5 & 2.6 & 2.9 & 16.4 & 4.7 & -20.6 & -0.6 & 7.7 \\
\hline 13 & 3.1 & 1.5 & 1.6 & 28.4 & -5.4 & -24.4 & 1.4 & 7.0 \\
\hline 14 & -1.2 & -1.3 & 0.1 & 13.0 & -5.6 & -9.2 & -4.0 & 4.4 \\
\hline 15 & -1.6 & -3.0 & 1.3 & -0.5 & -3.4 & -0.9 & 2.2 & 3.2 \\
\hline Mean & $1.5^{\star}$ & -0.3 & $1.8^{*}$ & $10.1^{*}$ & -0.4 & $-11.3^{*}$ & 0.3 & $4.6^{*}$ \\
\hline SD & 1.8 & 1.4 & 1.2 & 8.8 & 5.9 & 8.5 & 1.7 & 3.1 \\
\hline Max & 5.5 & 2.6 & 4.5 & 28.4 & 12.0 & 2.0 & 2.5 & 8.4 \\
\hline Min & -1.6 & -3.0 & 0.1 & -4.1 & -7.7 & -25.6 & -4.0 & -1.5 \\
\hline \multicolumn{9}{|l|}{ Males } \\
\hline 1 & 3.0 & -0.8 & 3.5 & 13.9 & -3.4 & -13.2 & 0.4 & 4.9 \\
\hline 2 & 5.7 & 1.5 & 4.3 & 21.5 & -5.2 & -17.5 & 0.6 & 8.4 \\
\hline 3 & 1.6 & -0.7 & 2.3 & 8.6 & -4.5 & -6.8 & 1.8 & 1.2 \\
\hline 4 & 2.0 & -0.5 & 2.4 & 20.3 & 4.9 & $\mid-24.9$ & \begin{tabular}{|c|}
-1.3 \\
\end{tabular} & 7.1 \\
\hline 5 & 6.1 & 1.8 & 4.4 & -4.8 & -8.7 & 11.2 & 0.7 & 5.7 \\
\hline 6 & 4.9 & -0.5 & 5.4 & 10.6 & -6.1 & -2.9 & -1.8 & 10.8 \\
\hline 7 & 2.2 & 2.1 & 0.1 & 11.4 & 8.6 & -18.6 & 0.8 & \begin{tabular}{|l|}
-1.3 \\
\end{tabular} \\
\hline 8 & 2.9 & 1.1 & 1.8 & -4.3 & -0.9 & 6.0 & 0.3 & 2.8 \\
\hline 9 & 1.9 & -0.4 & 2.2 & 0.7 & 8.8 & -9.7 & -2.7 & 3.8 \\
\hline 10 & -0.6 & -2.8 & 2.2 & 13.4 & -6.4 & -11.8 & 2.0 & 5.5 \\
\hline 11 & 0.7 & -0.6 & 1.2 & 22.4 & -5.4 & \begin{tabular}{|c|}
-18.3 \\
\end{tabular} & 2.1 & 4.2 \\
\hline 12 & 2.3 & -1.3 & 3.6 & 8.5 & -1.4 & -10.7 & -0.6 & 9.2 \\
\hline 13 & 2.4 & -1.6 & 4.0 & 7.5 & -2.8 & \begin{tabular}{|c|}
-7.3 \\
\end{tabular} & -0.2 & 5.6 \\
\hline 14 & 2.3 & -0.5 & 2.6 & 12.0 & -1.2 & -11.3 & 0.1 & 5.1 \\
\hline 15 & 2.7 & 1.9 & 0.8 & 10.1 & -1.7 & -6.4 & 0.3 & 1.4 \\
\hline Mean & $2.7^{*}$ & -0.1 & $2.7^{*}$ & $10.1^{*}$ & -1.7 & $-9.5^{*}$ & 0.2 & $5.0^{*}$ \\
\hline SD & 1.8 & 1.4 & 1.5 & 8.2 & 5.3 & 9.3 & 1.4 & 3.2 \\
\hline Max & 6.1 & 2.1 & 5.4 & 22.4 & 8.8 & 11.2 & 2.1 & 10.8 \\
\hline Min & -0.6 & -2.8 & 0.1 & -4.8 & -8.7 & -24.9 & -2.7 & -1.3 \\
\hline \multicolumn{9}{|l|}{ Pooled } \\
\hline Mean & $2.1^{*}$ & -0.2 & $2.3^{*}$ & $10.1^{*}$ & -1.0 & $-10.4^{*}$ & 0.2 & $4.8^{*}$ \\
\hline SD & 1.9 & 1.4 & 1.4 & 8.4 & 5.5 & 8.8 & 1.5 & 3.1 \\
\hline Max & 6.1 & 2.6 & 5.4 & 28.4 & 12.0 & 11.2 & 2.5 & 10.8 \\
\hline Min & -1.6 & -3.0 & 0.1 & -4.8 & -8.7 & -25.6 & -4.0 & -1.5 \\
\hline
\end{tabular}

Table 14. Individual comparison of angular changes, OLp-Co, and Wits from PreTreatment to Post-Treatment (T2-T1) for female, male and pooled groups 


\section{Comparison of the Treatment Group}

Post-treatment effects of the CS2000 ${ }^{\circledR}$ appliance are compared to pre-treatment records. The differences between these groups were then analyzed. The statistical significance as well as the quantification of these results is presented in Table 15Table 16, and Table 17. 27 variables in the sagittal, vertical, and angular directions are presented as well as calculations of overjet and molar relationship correction during treatment. Results shown are from effects of the CS2000® appliance in combination with normal growth during the treatment time.

\section{Sagittal Differences}

For the pooled patient group, significant differences were found between all sagittal measurements except OLp-Co $(\mathrm{p}=.4402)$ and Ii-OLp (.0638). For OLp-A pt., OLp-B pt., OLpPg, Is-OLp, Overjet, Ms-OLp, Mi-OLp, Molar Relationship, and Wits, there was high significance $(\mathrm{p}<.05)$. For the female patient group, significant differences were found between all sagittal measurements except Ii-Olp $(p=.1839)$ and OLp-Co $(p=.5554)$. For OLp-A pt., OLpB pt., OLp-Pg, Is-OLp, Overjet, Ms-OLp, Mi-OLp, Molar Relationship, and Wits, there was high significance $(\mathrm{p} \leq .005)$. For the male patient group, significant differences were found between all sagittal measurements except Ii-Olp $(p=.2175)$ and OLp-Co $(p=.6411)$. For OLp-A pt., OLp-B pt., OLp-Pg, Is-OLp, Overjet, Ms-OLp, Mi-OLp, Molar Relationship, and Wits, there was high significance $(\mathrm{p}<.05)$. These results indicate no significant differences between genders.

When using a significance of $\mathrm{p}<.05$, the following sagittal variables were found to be significant between post and pre-treatment in the pooled group: OLp-A pt., OLp-B pt., OLp-Pg, 
Is-OLp, Ii-OLp, Overjet, Ms-OLp, Mi-OLp, Molar Relationship, and Wits. The position of the maxillary base (OLp-A pt.) moved forward on average $1.5 \mathrm{~mm}$. The position of the mandibular base OLp-Pg moved posterior $1.5 \mathrm{~mm}$ on average. These together equal a $3.0 \mathrm{~mm}$ skeletal correction in overjet and molar relationship correction. OLp-B pt. was also measured and compared and found similar results to OLp-Pg (-1.6mm movement). In an attempt to monitor the condylar head position during treatment and as a check on the assumption that all records were taken in centric relation, OLp-Co was measured. The average change in OLp-Co was found to be $0.2 \mathrm{~mm}$ forward and was found to be non-significant. The relationship of the maxillary base to the mandibular base relative to the functional occlusal plane (Wits) for the pre-treatment group was found to be $-4.2 \mathrm{~mm}$ and post-treatment was $0.6 \mathrm{~mm}$, for an average significant change of $4.8 \mathrm{~mm}$. The maxillary incisor (Is-OLp) was found to move forward $4.1 \mathrm{~mm}$, while the mandibular incisor was found to move posterior $-0.9 \mathrm{~mm}$, but was not significant. This equates into a $5.0 \mathrm{~mm}$ overjet correction. The maxillary molar (Ms-OLp) was found to move forward 2.7 $\mathrm{mm}$, while the mandibular first molar was found to move posterior $2.1 \mathrm{~mm}$, for a molar relationship correction of $4.8 \mathrm{~mm}$. These values were all found to be significant.

\section{Vertical Differences}

For the pooled patient group, significant differences were found between all vertical measurements except, Is-NL ( $\mathrm{p}=.1283$ ) and Mic-ML ( $\mathrm{p}=.8012)$. For OLs-Apt, ANS-Me, Ii-ML, Overbite, and Msc-NL, a very high significance was found $(\mathrm{p}=.0001)$. For the female patient group, significant differences were found between all vertical measurements except Is-NL $(\mathrm{p}=.1813)$ and Mic-ML ( $\mathrm{p}=.3502)$. For OLs-Apt, ANS-Me, Ii-ML, Overbite, and Msc-NL, a high significance was found $(\mathrm{p}<.05)$. For the male patient group, significant differences were 
found between all vertical measurements except Is-NL $(\mathrm{p}=.4567)$ and Mic-ML $(\mathrm{p}=.3502)$. For OLs-Apt, ANS-Me, Ii-ML, Overbite, and Msc-NL, a high significance was found $(\mathrm{p}<.05)$. ). These results indicate no significant differences between genders.

When using a significance of $\mathrm{p}<.05$, the following vertical variables were found to be significant between post and pre-treatment in the pooled group: OLs-Apt, ANS-Me, Ii-ML, Overbite, and Msc-NL. The maxillary base (OLs-A pt.) was found to move inferiorly $2.5 \mathrm{~mm}$. The lower facial height ANS-Me in increased from $56.4 \mathrm{~mm}$ to $61.5 \mathrm{~mm}$ for a change in lower facial height of $5.1 \mathrm{~mm}$. The maxillary incisor (Is-NL) extruded $0.5 \mathrm{~mm}$ as compared to a reference line from ANS-PNS $0.5 \mathrm{~mm}$, but was not significant. The mandibular incisor (Ii-ML) also extruded $2.2 \mathrm{~mm}$ from the mandibular plane (Go-Me) and was significant. During treatment overbite decreased $1.5 \mathrm{~mm}$. The maxillary molar (Msc-NL) erupted $2.5 \mathrm{~mm}$, while the mandibular molar (Mic-ML) remained relatively unchanged, intruding $0.1 \mathrm{~mm}$ which was found to be non-significant.

\section{Angular Differences}

For the pooled patient group, significant differences were found between all angular measurements except, SNB $(\mathrm{p}=.4887)$ and, Ii/ML $\mathrm{p}=(.3126)$. For SNA, ANB, SNL-NL, SNLML, SNL-OLf, Is/SNL, and interincisal angle, a very high significance was found $(\mathrm{p}=.0001)$, $((p=.0009)$ for SNL-ML). For the female patient group, significant differences were found between all angular measurements except, $\mathrm{SNB}(\mathrm{p}=.4600)$ and, Ii/ML $\mathrm{p}=(.8036)$. For SNA, ANB, SNL-NL, SNL-ML, SNL-OLf, Is/SNL, and interincisal angle, a high significance was found $(\mathrm{p}<.05)$. For the male patient group, significant differences were found between all angular measurements except, SNB ( $\mathrm{p}=.8193)$, SNL-ML $(\mathrm{p}=.0670)$ and, Ii/ML $\mathrm{p}=(.2340)$. For 
SNA, ANB, SNL-NL, SNL-OLf, Is/SNL, and interincisal angle, a high significance was found $(\mathrm{p}<.05)$. The results indicate no significant differences between genders except to the SNL-ML angle.

When using a significance of $\mathrm{p}<.05$, the following angular variables were found to be significant between post and pre-treatment in the pooled group: SNA, ANB, SNL-NL, SNLML, SNL-OLf, Is/SNL, and interincisal angle. SNA increased $2.1^{\circ}$ during treatment and was significant, while SNB remained relatively unchanged, decreasing $0.2^{\circ}$, and was found nonsignificant. ANB thus increased $2.3^{\circ}$ during treatment and found significant. The maxillary plane angle (NL-SNL) decreased $2.2^{\circ}$, while the mandibular plane angle (ML-SNL) increased by $1.3^{\circ}$. The functional occlusal plane during treatment was found to decrease $1.9^{\circ}$ and was significant. The maxillary incisor (Is-NL) was found to procline $10.1^{\circ}$ during treatment in relation to the SNL. The mandibular incisor retroclined $1.0^{\circ}$ during treatment in relation to the mandibular plane (Go-Me), but was not significant. The interincisal angle pre-treatment was measured at $139.1^{\circ}$ and decreased $10.4^{\circ}$ during treatment to $128.7^{\circ}$ post-treatment and was significant. A diagram summarizing the vertical and angular changes is shown in Figure 8. 


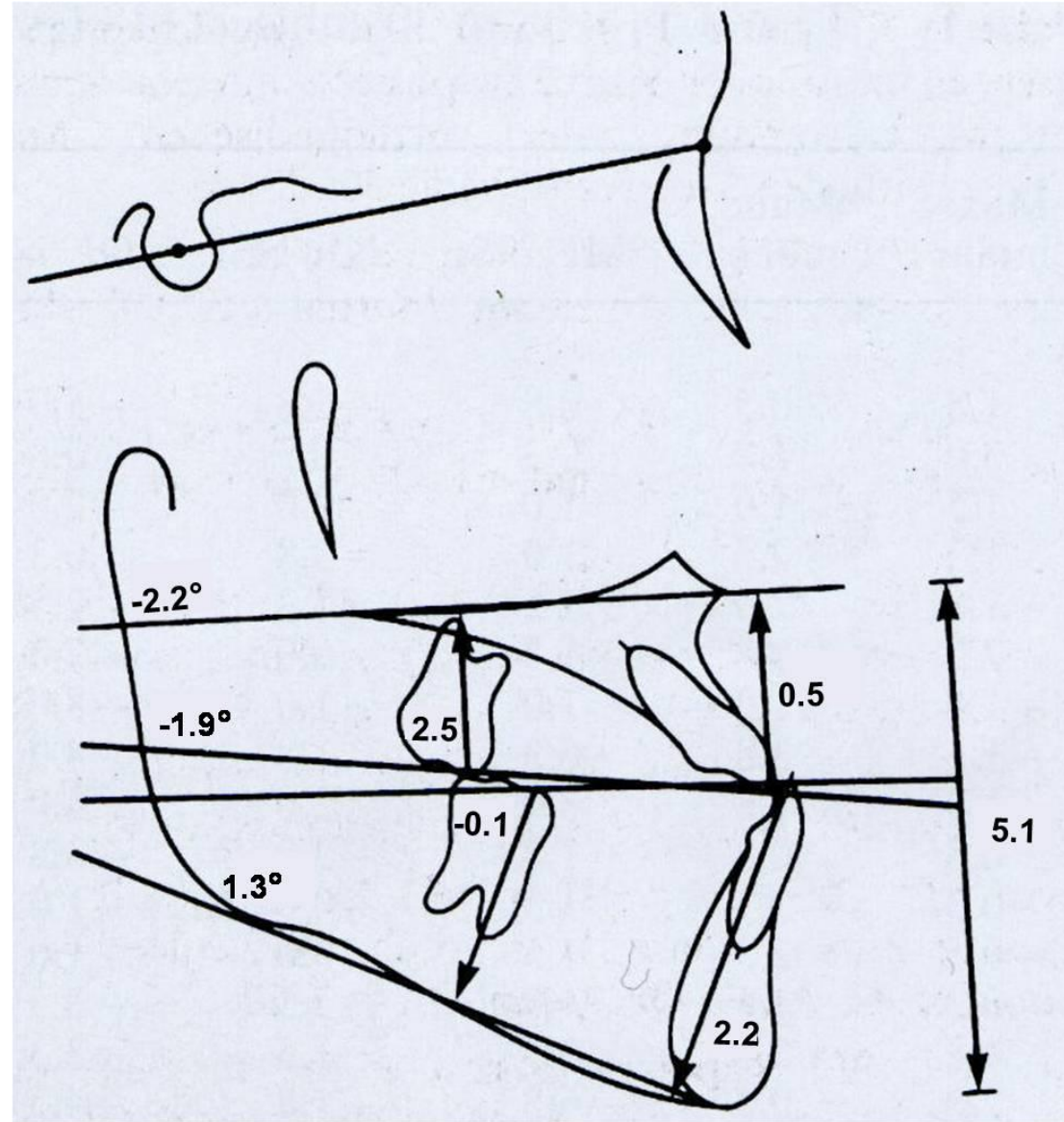

Figure 8. Diagram of vertical and angular changes (T2-T1) 


\begin{tabular}{|c|c|c|c|c|c|c|c|}
\hline \multirow{3}{*}{ Variable } & \multicolumn{7}{|c|}{ POOLED (MALES AND FEMALES) } \\
\hline & \multicolumn{2}{|c|}{ Pre-Treatment (T1) } & \multicolumn{2}{|c|}{ Post-Treatment (T2) } & \multirow[t]{2}{*}{ Sig } & \multirow[b]{2}{*}{ T2-T1 } & \multirow[t]{2}{*}{ P value } \\
\hline & Mean & S.D. & Mean & S.D. & & & \\
\hline \multicolumn{8}{|l|}{ Sagittal: } \\
\hline OLp-A pt. & 68.3 & 2.7 & 69.8 & 2.9 & $*$ & 1.5 & .0001 \\
\hline OLp-B pt. & 74.3 & 3.4 & 72.7 & 4.0 & $*$ & -1.6 & .0001 \\
\hline OLp-Pg & 76.7 & 4.1 & 75.2 & 4.7 & * & -1.5 & .0001 \\
\hline OLp-Co & -10.2 & 3.7 & -10.9 & 3.8 & NS & 0.2 & .4402 \\
\hline Wits & -4.2 & 2.1 & 0.6 & 3.3 & $*$ & 4.8 & .0001 \\
\hline Is-OLp & 74.1 & 3.9 & 78.3 & 4.2 & $*$ & 4.1 & .0001 \\
\hline li-OLp & 74.1 & 3.9 & 73.2 & 4.1 & NS & -0.9 & .0638 \\
\hline Overjet & 0.0 & 2.3 & 5.0 & 2.7 & $*$ & 5.0 & .0001 \\
\hline Ms-OLp & 47.1 & 3.4 & 49.7 & 3.3 & $*$ & 2.7 & .0001 \\
\hline Mi-OLp & 49.6 & 3.2 & 47.5 & 4.7 & $*$ & -2.1 & .0001 \\
\hline Molar Relationship & -2.6 & 1.9 & 2.2 & 3.1 & $*$ & 4.8 & .0001 \\
\hline \multicolumn{8}{|l|}{ Vertical: } \\
\hline Ols-Apt & 29.4 & 5.2 & 31.9 & 5.3 & $*$ & 2.5 & .0001 \\
\hline ANS-Me & 56.4 & 5.0 & 61.5 & 5.2 & $*$ & 5.1 & .0001 \\
\hline Is-NL & 23.4 & 2.2 & 24.0 & 2.7 & NS & 0.5 & .1283 \\
\hline Ii-ML & 34.1 & 2.5 & 36.2 & 3.1 & $*$ & 2.2 & .0001 \\
\hline Overbite & 2.3 & 1.6 & 0.8 & 1.4 & $*$ & -1.5 & .0001 \\
\hline Msc-NL & 18.8 & 2.4 & 21.3 & 2.4 & $*$ & 2.5 & .0001 \\
\hline Mic-ML & 24.8 & 2.3 & 24.7 & 2.6 & NS & -0.1 & .8012 \\
\hline \multicolumn{8}{|l|}{ Angular: } \\
\hline SNA & 80.1 & 3.8 & 82.2 & 3.8 & $*$ & 2.1 & .0001 \\
\hline SNB & 80.4 & 3.6 & 80.2 & 3.5 & NS & -0.2 & .4887 \\
\hline ANB & -0.3 & 1.6 & 2.0 & 1.9 & $*$ & 2.3 & .0001 \\
\hline SNL-NL & 9.0 & 3.3 & 6.8 & 2.8 & $*$ & -2.2 & .0001 \\
\hline SNL-ML & 32.8 & 5.0 & 34.2 & 4.9 & $*$ & 1.3 & .0009 \\
\hline SNL-Olf & 18.3 & 3.8 & 16.4 & 3.7 & $*$ & -1.9 & .0001 \\
\hline Is/SNL & 102.2 & 9.0 & 112.4 & 8.9 & $*$ & 10.1 & .0001 \\
\hline $\mathrm{li} / \mathrm{ML}$ & 85.8 & 7.2 & 84.8 & 7.4 & NS & -1.0 & .3126 \\
\hline Interincisal Angle & 139.1 & 13.3 & 128.7 & 13.1 & $*$ & -10.4 & .0001 \\
\hline
\end{tabular}

Table 15. Quantification of Pre and Post-Treatment measurements in pooled group (T2T1) 


\begin{tabular}{|c|c|c|c|c|c|c|c|}
\hline \multirow{3}{*}{ Variable } & \multicolumn{7}{|c|}{ FEMALES } \\
\hline & \multicolumn{2}{|c|}{ Pre-Treatment (T1) } & \multicolumn{2}{|c|}{ Post-Treatment (T2) } & \multirow{2}{*}{ Sig } & \multirow[b]{2}{*}{$\mathrm{T} 2-\mathrm{T} 1$} & \multirow{2}{*}{$P$ value } \\
\hline & Mean & S.D. & Mean & S.D. & & & \\
\hline \multicolumn{8}{|l|}{ Sagittal: } \\
\hline OLp-A pt. & 67.9 & 2.6 & 69.0 & 2.6 & $*$ & 1.1 & .0001 \\
\hline OLp-B pt. & 73.4 & 3.1 & 71.8 & 4.2 & $*$ & -1.5 & .0038 \\
\hline OLp-Pg & 76.2 & 4.1 & 74.6 & 5.2 & $*$ & -1.6 & .0050 \\
\hline OLp-Co & -10.2 & 3.7 & -9.9 & 3.2 & NS & 0.3 & .5554 \\
\hline Wits & -3.5 & 1.7 & 1.1 & 3.0 & $*$ & 4.6 & .0001 \\
\hline Is-OLp & 73.3 & 2.7 & 76.9 & 2.9 & $*$ & 3.6 & .0001 \\
\hline li-OLp & 72.6 & 2.5 & 71.7 & 3.3 & NS & -0.9 & .1839 \\
\hline Overjet & 0.7 & 2.2 & 5.2 & 2.9 & $*$ & 4.5 & .0001 \\
\hline Ms-OLp & 46.9 & 3.2 & 49.6 & 3.3 & $*$ & 2.6 & .0003 \\
\hline Mi-OLp & 49.5 & 3.2 & 47.4 & 4.6 & $*$ & -2.0 & .0112 \\
\hline Molar Relationship & -2.5 & 2.0 & 2.2 & 3.1 & $*$ & 4.7 & .0002 \\
\hline \multicolumn{8}{|l|}{ Vertical: } \\
\hline Ols-Apt & 29.3 & 4.9 & 31.5 & 4.6 & $*$ & 2.2 & .0001 \\
\hline ANS-Me & 57.3 & 5.8 & 62.5 & 5.7 & $*$ & 5.3 & .0001 \\
\hline Is-NL & 23.9 & 2.4 & 24.6 & 2.7 & NS & 0.7 & .1813 \\
\hline li-ML & 34.0 & 2.8 & 36.2 & 3.6 & $*$ & 2.2 & .0004 \\
\hline Overbite & 2.4 & 1.8 & 0.9 & 1.3 & $*$ & -1.5 & .0029 \\
\hline Msc-NL & 19.1 & 2.7 & 21.8 & 2.7 & $*$ & 2.7 & .0001 \\
\hline Mic-ML & 24.5 & 2.5 & 24.1 & 3.0 & NS & -0.4 & .3502 \\
\hline \multicolumn{8}{|l|}{ Angular: } \\
\hline SNA & 78.5 & 3.2 & 80.0 & 2.5 & $*$ & 1.5 & .0056 \\
\hline SNB & 78.7 & 2.6 & 78.4 & 2.2 & NS & -0.3 & .4600 \\
\hline ANB & -0.2 & 1.6 & 1.6 & 1.8 & $*$ & 1.8 & .0001 \\
\hline SNL-NL & 9.6 & 3.6 & 7.5 & 3.2 & $*$ & -2.1 & .0001 \\
\hline SNL-ML & 35.0 & 4.6 & 36.6 & 3.9 & $*$ & 1.6 & .0057 \\
\hline SNL-Olf & 19.4 & 2.9 & 17.7 & 2.7 & $*$ & -1.7 & .0001 \\
\hline Is/SNL & 98.8 & 5.8 & 108.9 & 7.7 & $*$ & 10.1 & .0006 \\
\hline $\mathrm{li} / \mathrm{ML}$ & 82.4 & 6.8 & 82.0 & 6.7 & NS & -0.4 & .8036 \\
\hline Interincisal Angle & 143.8 & 11.9 & 132.5 & 11.6 & $*$ & -11.3 & .0001 \\
\hline
\end{tabular}

Table 16. Quantification of Pre and Post-Treatment measurements in female group (T2T1) 


\begin{tabular}{|c|c|c|c|c|c|c|c|}
\hline \multirow{3}{*}{ Variable } & \multicolumn{7}{|c|}{ MALES } \\
\hline & \multicolumn{2}{|c|}{ Pre-Treatment (T1) } & \multicolumn{2}{|c|}{ Post-Treatment (T2) } & \multirow[t]{2}{*}{ Sig } & \multirow[b]{2}{*}{ T2-T1 } & \multirow[t]{2}{*}{$P$ value } \\
\hline & Mean & S.D. & Mean & S.D. & & & \\
\hline \multicolumn{8}{|l|}{ Sagittal: } \\
\hline OLp-A pt. & 68.8 & 2.8 & 70.6 & 2.9 & $*$ & 1.9 & .0001 \\
\hline OLp-B pt. & 75.2 & 3.5 & 73.5 & 3.8 & $*$ & -1.7 & .0039 \\
\hline OLp-Pg & 77.2 & 4.3 & 75.8 & 4.2 & $*$ & -1.4 & .0124 \\
\hline OLp-Co & -11.9 & 3.6 & -11.8 & 4.3 & NS & 0.2 & .6411 \\
\hline Wits & -4.9 & 2.4 & 0.1 & 3.5 & $*$ & 5.0 & .0001 \\
\hline Is-OLp & 75.0 & 4.8 & 79.6 & 5.0 & $*$ & 4.6 & .0001 \\
\hline li-OLp & 75.6 & 4.4 & 74.7 & 4.4 & NS & -0.9 & .2175 \\
\hline Overjet & -0.7 & 2.3 & 4.9 & 2.6 & $*$ & 5.6 & .0001 \\
\hline Ms-OLp & 47.2 & 3.7 & 49.8 & 3.4 & $*$ & 2.7 & .0012 \\
\hline Mi-OLp & 49.8 & 3.3 & 47.6 & 5.1 & $*$ & -2.2 & .0070 \\
\hline Molar Relationship & -2.6 & 1.9 & 2.2 & 3.2 & $*$ & 4.8 & .0002 \\
\hline \multicolumn{8}{|l|}{ Vertical: } \\
\hline Ols-Apt & 29.5 & 5.7 & 32.2 & 6.1 & $*$ & 2.7 & .0001 \\
\hline ANS-Me & 55.6 & 3.9 & 60.5 & 4.5 & $*$ & 4.9 & .0001 \\
\hline Is-NL & 22.9 & 2.1 & 23.3 & 2.7 & NS & 0.4 & .4567 \\
\hline li-ML & 34.1 & 2.2 & 36.2 & 2.8 & $*$ & 2.2 & .0001 \\
\hline Overbite & 2.2 & 1.3 & 0.6 & 1.4 & $*$ & -1.6 & .0152 \\
\hline Msc-NL & 18.5 & 2.2 & 20.7 & 2.1 & $*$ & 2.3 & .0001 \\
\hline Mic-ML & 25.0 & 2.0 & 25.3 & 2.0 & NS & 0.3 & .3502 \\
\hline \multicolumn{8}{|l|}{ Angular: } \\
\hline SNA & 81.7 & 3.8 & 84.3 & 3.7 & $*$ & 2.7 & .0001 \\
\hline SNB & 82.1 & 3.7 & 82.0 & 3.6 & NS & -0.1 & .8193 \\
\hline ANB & -0.4 & 1.6 & 2.3 & 2.1 & $*$ & 2.7 & .0001 \\
\hline SNL-NL & 8.5 & 3.0 & 6.1 & 2.3 & $*$ & -2.4 & .0031 \\
\hline SNL-ML & 30.7 & 4.6 & 31.7 & 4.8 & NS & 1.1 & .0670 \\
\hline SNL-Olf & 17.2 & 4.2 & 15.1 & 4.1 & $*$ & -2.1 & .0001 \\
\hline Is/SNL & 105.7 & 10.5 & 115.8 & 8.9 & $*$ & 10.1 & .0003 \\
\hline li/ML & 89.2 & 6.0 & 87.5 & 7.2 & NS & -1.7 & .2340 \\
\hline Interincisal Angle & 134.4 & 13.3 & 124.9 & 13.9 & $*$ & -9.5 & .0015 \\
\hline
\end{tabular}

Table 17. Quantification of Pre and Post-Treatment measurements in female group (T2T1) 


\section{Overjet and Molar Relationship Correction (T2-T1)}

The amount of dental and skeletal contributions to overjet and molar relationship correction from the pre-treatment group to the post-treatment group was calculated using the formulas described previously in Table 9 and shown below in Figure 9Figure 10. The amount of overjet correction seen from pre-treatment to post-treatment was $5.0 \mathrm{~mm}(3 \mathrm{~mm}$ of this correction was attributed skeletal changes and $2 \mathrm{~mm}$ to dental changes). The $3 \mathrm{~mm}$ of skeletal change was brought about by the maxilla moving forward $1.5 \mathrm{~mm}$ and the mandible moving posterior $1.5 \mathrm{~mm}$. The $2 \mathrm{~mm}$ of dental changes were seen by the maxillary incisor protracting 2.6 $\mathrm{mm}$ and the mandibular incisor also protracting $0.6 \mathrm{~mm}$. Molar relationship correction was attributed to $3 \mathrm{~mm}$ of skeletal correction and $1.8 \mathrm{~mm}$ of dental correction. Of the $3 \mathrm{~mm}$ skeletal change, $1.5 \mathrm{~mm}$ of this came from the maxilla moving forward and $1.5 \mathrm{~mm}$ from the mandible moving posterior. The $1.8 \mathrm{~mm}$ of dental correction is the result of the maxillary molar protracting $1.2 \mathrm{~mm}$ and the mandibular molar moving posterior $0.6 \mathrm{~mm}$. In Figure 9Figure 10 , the calculations are shown, including diagrams that show the anterior and posterior movements of the maxilla, mandible, maxillary incisors and molars, and mandibular incisors and molars. A pitchfork analysis is also shown in Figure 11 to display the contributions of skeletal and dental changes in the final correction of overjet and molar relationship. Attention should be given to the fact that these results are a combination of treatment effects seen using the CS2000® appliance in combination with the normal growth of each patient during the treatment time prescribed. 
Overjet Correction (5.0)= Maxilla (1.5 mm) + Mx incisor (2.6) - Mandible (-1.5) - Md incisor (0.6)

$$
\text { Maxilla }=\text { OLp-A pt. (1.5) }
$$

Mx incisor $=$ Is-OLp (4.1) $\operatorname{minus~OLp-A~pt.~(1.5)~}=2.6$

Mandible $=$ OLp-Pg $(-1.5)$

Mandibular incisor $=\mathrm{Ii}-\mathrm{OLp}(-0.9)$ minus OLp-Pg (-1.5)

Overjet Correction

of $\quad 5.0 \mathrm{~mm}$

Skeletal contribution

$=\quad 3.0 \mathrm{~mm}$

Dental contribution

$=\quad 2.0 \mathrm{~mm}$

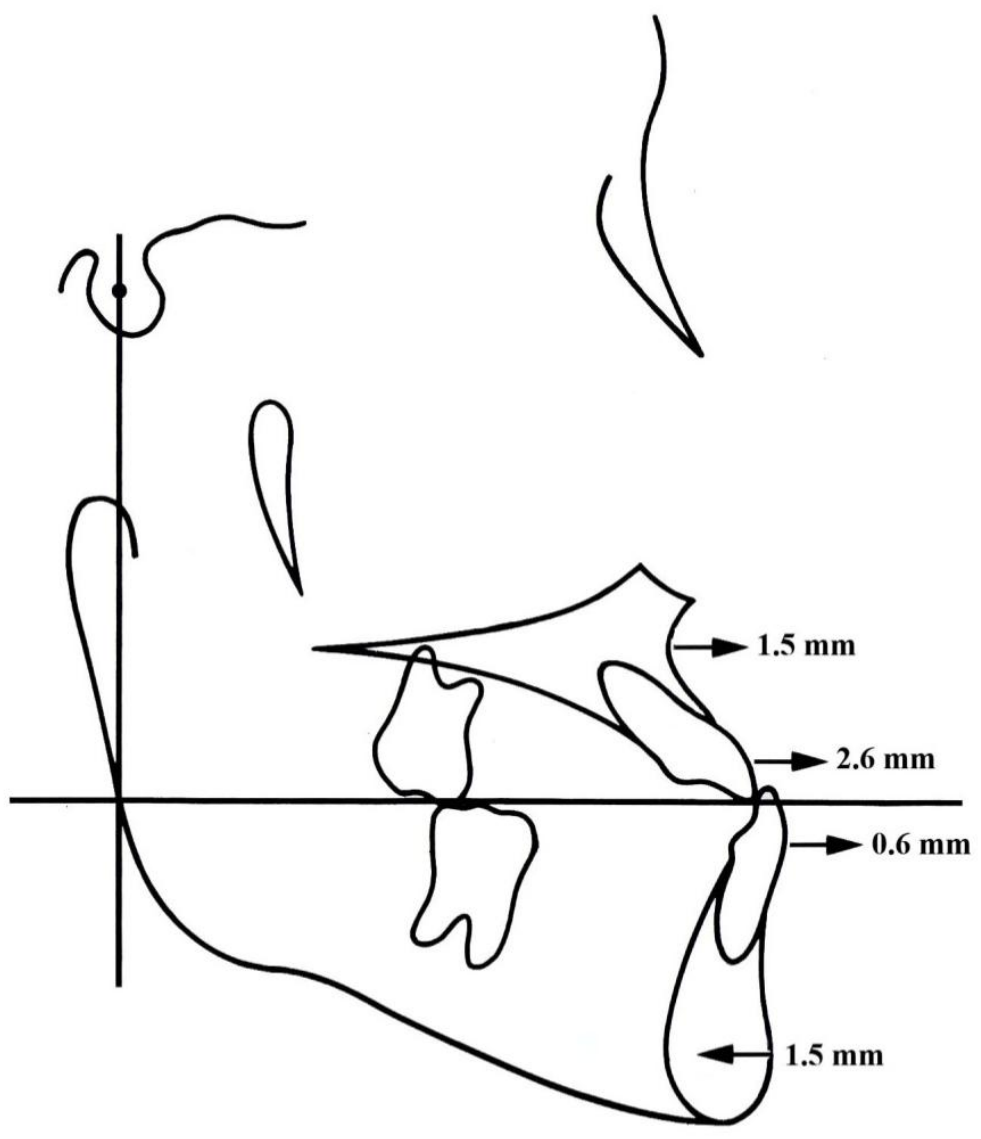

Figure 9. Skeletal and Dental Contributions to Overjet Correction (T2-T1) 
Molar Relationship Correction = Maxilla (1.5) + Mx molar (1.2) - Mandible (-1.5) - Md molar (-0.6)

$$
\text { Maxilla }=\text { OLp-A pt. (1.5) }
$$

Mx molar $=$ Ms-OLp (2.7) minus OLp-A pt. (1.5)

$$
\text { Mandible }=\text { OLp-Pg (-1.5) }
$$

Mandibular incisor $=$ Mi-OLp (-2.1) minus OLp-Pg (-1.5)
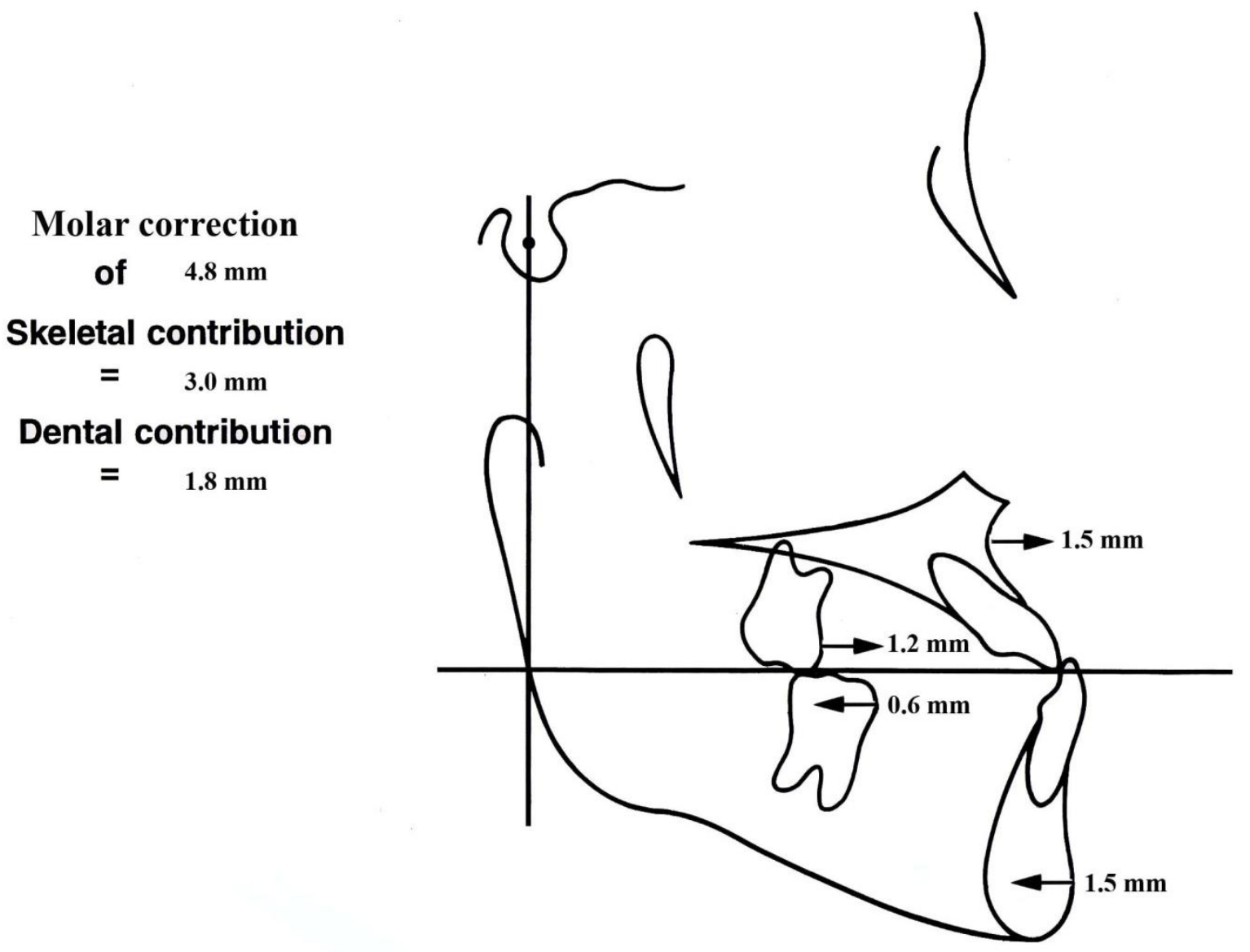

Figure 10. Skeletal and Dental Contributions to Molar relationship Correction (T2-T1) 


\begin{tabular}{|cccc|}
\hline Overjet Correction: & & Molar Relationship Correction: & \\
Skeletal Contribution: & & Skeletal Contribution: & 1.5 \\
1.) Maxilla & 1.5 & 1.) Maxilla & 1.5 \\
2.) Mandible & 1.5 & 2.) Mandible & \\
Dental Contribution: & & Dental Contribution: & 1.2 \\
3.) Mx incisor & 2.6 & 3.) Mx molar & 0.6 \\
4.) Md incisor & -0.6 & 4.) Md molar &
\end{tabular}
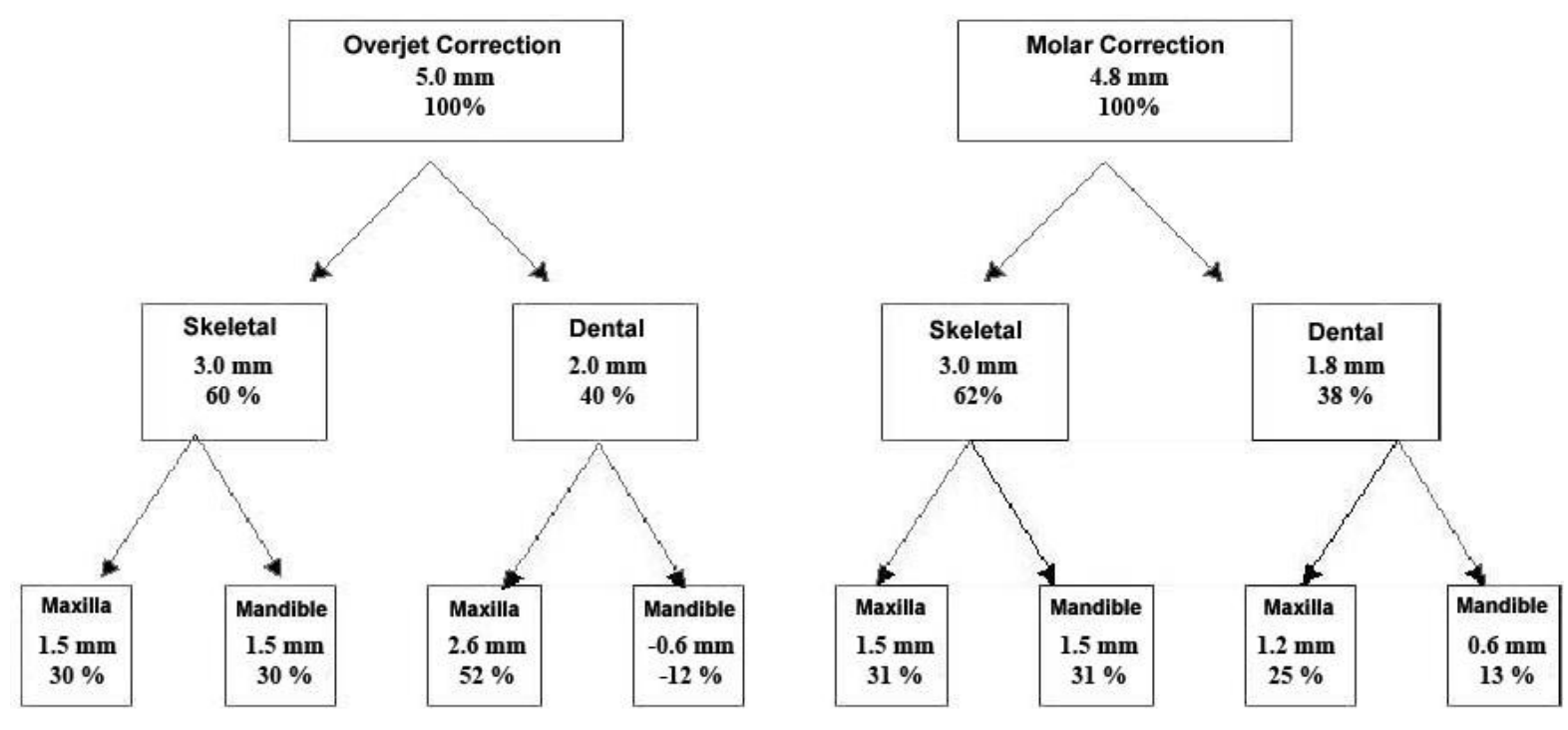

Figure 11. Pitchfork Analysis of Overjet and Molar Relationship Correction 


\section{CHAPTER V: DISCUSSION}

\section{Gender Analysis}

When comparing the significance of each variable in the sagittal, vertical, and angular dimensions, no difference was found between genders except for ML-SNL, which was found non-significant in males, but significant in both the pooled and female groups. Due to the similarities amongst the groups (pooled, male, and female), the following is a discussion regarding the pooled group only.

\section{Pre-Treatment Craniofacial Morphology}

The average pre-treatment ANB angles were $-0.3(-0.2$ in females and -0.4 in males), and the Wits appraisal was $-4.2 \mathrm{~mm}$ for the pooled group ( -3.5 for females and -4.9 for males). This shows the inconsistency of ANB and Wits measurements in describing Class III malocclusions, as was also shown by Del Santo ${ }^{77}$, Hurmerinta ${ }^{78}$, and Rushton ${ }^{79}$. The appliance in this study was designed to treat patients with a Class III malocclusion who desired a nonsurgical treatment plan. However, it is not the aim of this study, to determine which patients should receive treatment with the CS2000® appliance, only to determine how the appliance works. If one subscribes to the ANB angle presented in our pre-treatment group, patients with only a mild Class III skeletal relationship are studied, most of the malocclusion coming from a dental means. However, this provides no deterioration of the results shown, as patients were also studied from the pretreatment group that had far more severe ANB angles indicating a Class III skeletal problem (Appendix B). Also noted in the pre-treatment group was an average overjet of $0.0 \mathrm{~mm}$ and in most cases an anterior crossbite (Appendix B). 


\section{Comparison of the Pre-Treatment and Post-Treatment groups (T2-T1)}

In the literature, no other articles were found that describe treatment effects of the CS2000® appliance as it is relatively new. However, the differing modalities of treating Class III malocclusions non-surgically are vast and diverse, from facemask treatment with and without expansion $^{61-63,67,71}$, to removable appliances such as the Frankel III $^{59,60}$, Bionator III $^{65}$, modified tandem traction bow ${ }^{67}$, and Class III Twin Block ${ }^{66}$, to interarch protraction springs as described by Liou $^{80}$. With the recent increase in popularity of Miniscrews and Miniplates ${ }^{81,82}$, even more possibilities are available.

The present study consisted of 30 patients meeting the inclusion and exclusions criteria presented earlier. The CS2000® appliance in these patients was in place from 8 months to 2 years. In a few of these patients treatment with the appliance carried on longer than the posttreatment record. However, to better control the variability of treatment length, a two year maximum was used.

\section{Sagittal Differences}

Of the 11 sagittal variables noted, nine of them were found to be significant compared from pre-treatment (T1) to post-treatment (T2). One of the more significant results in this study, as well as other Class III protraction studies, is the forward movement of the maxillary base (A pt.). In the present study, A pt., as well as all other sagittal variables, was referenced to OLp in a method described by Bjork ${ }^{72}$ and Pancherz ${ }^{73}$. The findings of this study indicate that A pt. moved forward $1.5 \mathrm{~mm}$, with a range of 0.5 to $4.8 \mathrm{~mm}$ over a period of 8 months to 2 years. In a 
study by $\mathrm{Ngan}^{61}$, that looked at effects of maxillary expansion and protraction of 30 subjects over 6 months treated with maxillary expansion and protraction facemask, A pt. was found to move forward an average of $1.8 \mathrm{~mm}$ with a range from- $1.5 \mathrm{~mm}$ to $5.8 \mathrm{~mm}$. However, this measurement factors out growth which the present study does not. Baccetti, in his papers found a $2.3 \mathrm{~mm}$ and $3.1 \mathrm{~mm}$ forward movement of A point in the early treatment groups ${ }^{74,75}$. In review of the literature, other forward movements of A pt. have been reported anywhere from $1.5 \mathrm{~mm}$ by Williams in $1997^{83}$ to $3.4 \mathrm{~mm}$ by Nartallo-Turley ${ }^{71}$. In a more recent paper by Loiu, using a maxillary expansion and constriction protocol, achieved $5.8 \mathrm{~mm}$ average forward movement of A pt. in 3 months time ${ }^{84}$. While the correction of the CS2000® appliance is slightly less as compared to facemask therapy, it remains a fixed appliance and factors out compliance issues. When comparing the CS2000® appliance to removable appliances such as the tandem traction bow appliance ${ }^{67}$ and FR $\mathrm{III}^{59}$, similar results are seen. Atalay found an increase of $1.8 \mathrm{~mm}$ of CoA pt. in his early treatment group using his tandem traction bow appliance ${ }^{67}$. In a study by Baik, et. al. ${ }^{59}$ A point was found to move forward $1.3 \mathrm{~mm}$ in the treatment group over 1.3 years of treatment. However, when compared to the control group, the A pt. change was found to be nonsignificant.

The mandibular base was found to move posterior $1.5 \mathrm{~mm}$ and was partially due to a down and backward rotation of the mandible as evidenced by a $5.1 \mathrm{~mm}$ changes in lower facial height (ANS-Me) and an increase in the mandibular plane angle of $1.3^{\circ}$. Backward and downward rotation of the mandible during treatment is supported by other studies as well. ${ }^{61,71,85}$ Baccetti noted this rotation of the mandible in the late treatment groups of both his papers ${ }^{74,75}$. In his early treatment group, he found a $2.5 \mathrm{~mm}$ restriction in mandibular protrusion ${ }^{75}$. In the study described earlier by Ngan, $2.5 \mathrm{~mm}$ posterior movement of the mandibular base was seen, 
as was a $2.9 \mathrm{~mm}$ increase in lower facial height ${ }^{61}$. The FR III appliance also showed a net backward movement of the mandibular base $(-0.8 \mathrm{~mm})$ and also showed a redirection of the mandible in a down and backward rotation ${ }^{59,60}$ as did the tandem traction bow used by Atalay ${ }^{67}$. The Bionator III showed $3.1 \mathrm{~mm}$ increase in lower facial height and also showed an increase in mandibular plane angle, indicating a down and backward rotation of the mandible as well. ${ }^{65}$

In this study, OLp-Co was measured to evaluate changes in conylion position throughout treatment, but mainly as an evaluation of records being taken in CR. Had a pre-treatment or posttreatment record been taken with a significant shift, the measurement of OLp-Co would change drastically. This was not seen in the measurements (Table 17), thus it can be assumed that all records were taken with the patient in a clinically acceptable CR position and results presented in the study are not simply from a $\mathrm{CR} / \mathrm{CO}$ shift.

Wits measurements for the treatment group were carried out to assess the relative change in position of the maxillary base as referenced to the mandibular base, referenced to the OLf. Wits measurements were found to improve $4.8 \mathrm{~mm}$ from a pre-treatment average of $-4.2 \mathrm{~mm}$. This result is similar to the facemask study done by $\mathrm{Ngan}^{61}$, but significantly more than the $2.1 \mathrm{~mm}$ Wits change seen by the FR III over two to three years of treatment time ${ }^{60}$, and a $2.7 \mathrm{~mm}$ improvement seen with the Bionator III appliance used by Garattini over 2 years ${ }^{65}$. This change can be partially attributed to a change in the occlusal plane rotation, as its inclination decreased during treatment $\left(-1.9^{\circ}\right)$ as referenced from SNL. The palatal plane also rotated in a counterclockwise direction as its angle decrease $2.2 \mathrm{~mm}$ throughout treatment as well. Similar results of the occlusal and palatal planes rotating counter clockwise with treatment are seen in facemask studies by $\operatorname{Ngan}^{62}$ and Nartallo-Turley ${ }^{71}$. Also noting a counterclockwise rotation of the maxilla and clockwise rotation of the mandible was Liou ${ }^{80}$. In this study he uses a maxillary 
expansion and constriction protocol, and then bends an inter-arch spring that attaches to the upper and lower first molars ${ }^{80}$. He notes a $5.8 \mathrm{~mm}$ forward movement of A pt., but attributes $2 \mathrm{~mm}$ of this to the expansion procedure.

Overjet correction of the treatment group was found to be $5.0 \mathrm{~mm}$. This resulted from a $3.0 \mathrm{~mm}$ skeletal change $(60 \%), 1.5 \mathrm{~mm}$ forward movement of A pt. and a 1.5 posterior movement of the mandibular base (OLp-Pg). The other $40 \%$ of the total overjet correction was attributed to a $2.6 \mathrm{~mm}$ forward movement of the maxillary incisor and a $0.6 \mathrm{~mm}$ posterior movement (non-significant) of the mandibular incisor. In all of the other studies the maxillary incisor moved forward. In the facemask studies $1.7 \mathrm{~mm}^{61} 1.2 \mathrm{~mm}^{63}$, and $1.7 \mathrm{~mm}^{71}$. With the FR III appliance a $1.3 \mathrm{~mm}$ forward movement of the maxillary incisor was seen after factoring out growth $^{59}$. The lower incisors in most of the other studies moved posterior, $1 \mathrm{~mm}$ in a facemask paper by $\operatorname{Arman}^{63}$ when referencing from the NB line. The removable FR III showed a $3.6 \mathrm{~mm}$ posterior movement of the mandibular incisor when compared a control group. ${ }^{59}$ These results were in contrast to the present study and the study done by Nartallo-Turley ${ }^{71}$ which found a 0.7 $\mathrm{mm}$ forward movement of the lower incisor. When comparing overjet corrections, $\mathrm{Ngan}^{61}$ with expansion and facemask therapy found and average overjet correction of $6.2 \mathrm{~mm}$ which resulted from about $70 \%$ skeletal effects. In other papers using protraction facemask, overjet correction was listed at $6.11 \mathrm{~mm}$ over one year of treatment ${ }^{63}$, and $5.2 \mathrm{~mm}$ in a paper by Nartallo-Turley ${ }^{71}$. In a paper by Westwood and McNamara, $4.8 \mathrm{~mm}$ of overjet correction was seen ${ }^{76}$. With removable appliances such as the FR III, a $4.4 \mathrm{~mm}$ overjet correction over 2.5 years was seen by Levin $^{60}$ and a overjet correction of $4.1 \mathrm{~mm}$ was seen by Baik ${ }^{59}$ over 1.3 years of treatment. The overjet correction seen by the CS2000® appliance was more than that seen in the FR III appliance group but a bit smaller than the correction shown by facemask treatment. 
The average molar relationship correction provided by the CS2000® appliance was 4.8 $\mathrm{mm}$. This was similar to facemask studies carried out by Ngan where a $4.5 \mathrm{~mm}$ molar relationship correction was seen ${ }^{61,62}$. In his study however, $4.3 \mathrm{~mm}(96 \%)$ of this correction was attributed to skeletal contribution ${ }^{61}$. In our study only $62 \%(3.0 \mathrm{~mm})$ of the correction was attributed to skeletal means. Westwood and McNamara found a $3.8 \mathrm{~mm}$ improvement in molar relationship $^{76}$. With the removable FR III a $3.3 \mathrm{~mm}$ correction of molar relationship was seen ${ }^{60}$.

With $62 \%$ skeletal correction of molar relationship, the other $38 \%$ was due to dental movement of the upper and lower first molars. In the present study, the maxillary molar protracted $1.2 \mathrm{~mm}$, while the mandibular molar retracted $0.6 \mathrm{~mm}$, for a $1.8 \mathrm{~mm}$ dental change. The movement of the maxillary molar are similar to those seen by $\mathrm{Ngan}^{61}$. He found the upper molar to move forward $1.6 \mathrm{~mm}$, but in contrast to the present study found the lower molar to also move forward $1.4 \mathrm{~mm}$. In the FR III study the mandibular molar remained relatively unchanged, while the maxillary molar protracted $1.9 \mathrm{~mm}^{59}$. The present study shows a greater change in molar relationship correction than both the facemask studies and those on the FR III. However, when compared to the facemask, the CS2000® appliance has more dental effects when looking at molar relationship correction.

\section{Vertical Differences}

Of the 7 vertical variables studies, 5 were found to be significant. Both the vertical movement of the upper incisor $(0.5 \mathrm{~mm})$, referenced to $\mathrm{NL}$, and the vertical movement of the lower molar $(-0.1 \mathrm{~mm})$, referenced to ML, were found non-significant factors associated with the

vertical changes. This contrasted to the facemask study done by $\operatorname{Ngan}^{61}$ where he found a 1.4 $\mathrm{mm}$ extrusion of the lower first molar and a $0.4 \mathrm{~mm}$ intrusion of the upper incisor. In the FR III 
study, when factoring out the control group, the maxillary incisor remained relatively unchanged, extruding $0.1 \mathrm{~mm}$, while the mandibular molar intruded $0.9 \mathrm{~mm}^{59}$.

The lower incisor extruded $2.2 \mathrm{~mm}$, which was found significant. This result differed from the facemask results, where only a 0.3 and $0.6 \mathrm{~mm}$ extrusion was found of the lower incisor $^{61,62}$. The greater change in extrusion of the lower incisor using the CS2000® appliance presumably results from the action of the closed coil spring that is attached in the mandibular anterior area bilaterally (Figure 4). In the FR III, when compared to the control group, the mandibular incisor intruded $0.5 \mathrm{~mm}^{59}$.

In the treatment group, overbite decreased $1.5 \mathrm{~mm}$ from pre-treatment to post-treatment. This result is similar to that noted by Ngan, where he found a bite opening of $2.6 \mathrm{~mm}$ in his facemask study ${ }^{61}$. These results are similar to other facemask studies by $\operatorname{Arman}^{68}$ and $\operatorname{Ngan}^{62,63}$, but contrast the results seen in the FR III studies, where overbite deepened $1.3 \mathrm{~mm}$ in the study by Baik $^{59}$, and also in the FR III study by Levin ${ }^{60}(1.6 \mathrm{~mm})$.

In the facemask study done by $\mathrm{Ngan}^{61}$, a $0.9 \mathrm{~mm}$ extrusion of the maxillary molar was seen. The FR III appliance produced $0.3 \mathrm{~mm}$ extrusion of the maxillary first molar ${ }^{59}$. In the CS2000® study, the maxillary molar perhaps made the most significant change of the vertical variables, extruding $2.5 \mathrm{~mm}$. This change presumably, like the lower incisor extrusion, results from the location of the attachment of the closed coil springs to be on the maxillary first molars bilaterally.

The vertical position of the maxillary body moved downward $2.5 \mathrm{~mm}$. This result is significantly greater than results presented in the facemask study by $\mathrm{Ngan}^{61}$ where only a 0.4 mm vertical change was observed. Baccetti found almost no change in vertical intermaxillary relationships in his early group, while in the late treatment groups, he found a backward rotation 
of the mandible, decreasing ML-NL $2^{\circ 75}$. In the FR III study by Baik, a $1.4 \mathrm{~mm}$ inferior movement of A pt. was seen in the treatment group ${ }^{59}$.

When observing the changes seen in the vertical dimension many interesting points can be made. The maxillary incisor moved inferiorly only $0.5 \mathrm{~mm}$ in comparison to the $2.5 \mathrm{~mm}$ inferior movement of the maxillary base. When compared with the maxillary molar extrusion an intrusion of $2.0 \mathrm{~mm}$ was seen with the maxillary incisors. The NL in reference to SN decreases on average $2.2^{\circ}$. This resulted counterclockwise rotation of the maxillary base, which is common with Class III correction modalities. The maxillary first molar extruded $2.5 \mathrm{~mm}$ which was relatively equal to the inferior movement of A point but significantly more than the inferior movement of the maxillary incisor. This extrusion, without any compensation seen from the lower posterior dentition (intrusion) or significant vertical growth of the mandible, could have played a major role in the mandibular body's back and downward rotation, and the increase seen in lower facial height, discussed earlier. In conjunction with the lower incisor and maxillary molar extrusion and the maxillary incisor remaining relatively in the same location, the occlusal plane as a unit decreased in angulation in reference to SNL. This result then attributes, in part, to the improvements seen in Wits measurements.

\section{Angular Differences}

Of the 9 angular variables presented, only two were found to be non-significant, the angle of the lower incisor to the mandibular plane and SNB. The lower incisor angulation to ML was found to decrease $1^{\circ}$. Arman, in a paper looking at the facemask appliance found a $4.1 \mathrm{~mm}$

retroclination of the lower incisors ${ }^{63}$. Ngan found a $4.0 \mathrm{~mm}$ retroclination of the lower incisors in his facemask study. ${ }^{62}$ With the Class III Twin Block appliance, a $4.4 \mathrm{~mm}$ retroclination was 
found $^{66}$. The FR III study by Baik ${ }^{59}$ found lower incisor retroclination of $3.4 \mathrm{~mm}$ while Levin ${ }^{60}$ found a $-1.4^{\circ}$ change. All these results significantly contrast the non-significant lower incisor angulation change seen with the CS2000® appliance.

The SNB angle change noted for the CS2000® appliance was $-0.2^{\circ}$. This was nonsignificant and showed that the primary contributor to the change in ANB angle was SNA. SNA in the present study was shown to increase in $2.1^{\circ}$ for an average ANB improvement of $2.3^{\circ}$. Facemask papers by $\operatorname{Ngan}^{61}, \operatorname{Arman}^{63}$, and Nartallo-Turley ${ }^{71}$ indicated respective changes in ANB of $3.0^{\circ}, 2.6^{\circ}$, and $3.7^{\circ}$ respectively. However, more of the changes in these papers can be attributed to SNB angle changes. In these three papers, SNB changes were found to contribute $1.5^{\circ}$ by $\mathrm{Ngan}^{61}, 0.7^{\circ}$ by $\operatorname{Arman}^{63}$, and $1.3^{\circ}$ by Nartallo-Turley ${ }^{71}$. In a paper by Westwood and McNamara $^{76}$, ANB improved $3.4^{\circ}$ with $1.8^{\circ}$ of this correction being attribute to SNB. In a FR III studies by Levin ${ }^{60}$ and Baik ${ }^{59}$, a $2.1^{\circ}$ and $1.9^{\circ}$ improvement in ANB angles was found. The results of ANB in these studies come from $0.8^{\circ}$ changes in SNB angles and $1.3^{\circ}$ and $1.1^{\circ}$ degree changes in SNA angles, respectively. When using a Class III Twin Block appliance an average ANB improvement of $1.43^{\circ}$ was seen with a significant contribution of this coming from SNB $1.39^{\circ 66}$. The tandem traction bow appliance also showed a significant part of the ANB correction $\left(1.7^{\circ}\right)$ coming from SNB $\left(1.1^{\circ}\right)^{63}$. These results significantly contrast the CS $2000 ®$ appliance where SNB had almost no change. The Bionator III appliance used by Garattini showed similar results to the FR III studies with a $2.5^{\circ}$ improvement in ANB $\left(0.7^{\circ} \text { improvement of SNB }\right)^{65}$.

The maxillary incisor angulation was found to increase $10.1^{\circ}$ in the treatment group. Along with the change in lower incisor inclination, this resulted in an interincisal angle decrease of $10.4^{\circ}$. Both these results were found to be highly significant. In Ngan's papers on the facemask appliance he notes a $3.4^{\circ}$ increase in maxillary incisor inclination in one paper ${ }^{61}$ and a 
$3.7^{\circ}$ increase in another ${ }^{62}$. Arman showed a $2.1^{\circ}$ net increase in his facemask paper ${ }^{63}$. In the FR III a $3.7^{\circ}$ increase was seen by Levin ${ }^{60}$, while Baik found a $4.7^{\circ}$ increase in maxillary incisor angulation $^{59}$. Results from the Class III Twin Block study shows $5.7^{\circ}$ changes $^{66}$. These results are far less than the $10.1^{\circ}$ changes seen with the CS2000 ${ }^{\circledR}$ appliance. The probable factor being that the $\mathrm{CS} 2000{ }^{\circledR}$ appliance is fixed, while the other appliances including the facemask are removable in nature.

\section{Overall Correction produced by the CS2000 appliance}

In a final calculation of treatment effects of the CS2000® appliance, it was found that total overjet correction was $5.0 \mathrm{~mm}$ and total molar relationship correction was $4.8 \mathrm{~mm}$. For both overjet and molar relationship correction, around $60 \%$ (60\% and $62 \%$ respectively) were seen from skeletal changes in A pt., which protracted forward $1.5 \mathrm{~mm}$ and moved downward $2.5 \mathrm{~mm}$. This $2.5 \mathrm{~mm}$ skeletal change of A pt. was seen in conjunction with only a $0.5 \mathrm{~mm}$ downward movement of the maxillary central incisor as measured from NL. When comparing the dental changes seen with the incisors and molars it was found the occlusal plane rotated counterclockwise. This type of rotation is seen with the palatal plane angulation as well. These changes are common in other appliances used in Class III correction as well ${ }^{61,71,85}$. With the force application (i.e. the attachment of the closed coil springs) of the CS2000® appliance being located at the maxillary first molars and in the anterior area of the mandibular arch (canine to first bicuspid area), it seems reasonable that a extrusion of the mandibular incisors $(2.2 \mathrm{~mm})$ and the maxillary molars $(2.5 \mathrm{~mm})$ was found. As noted before, when discussing trends in the vertical differences, with a significant extrusion of the maxillary molars, in the absence of a mandibular compensation, molar intrusion or vertical growth of the rami, a downward and 
backward rotation of the mandible is seen. This may account partially for the skeletal correction of the mandible $(1.5 \mathrm{~mm})$ and in part to the $60 \%$ skeletal contributions to overjet and molar relationship correction. With roughly $60 \%$ of overjet correction and molar relationship correction being skeletal, the other $40 \%$ is attributed to dental means. This correction can be attributed to smaller changes seen by the mandibular teeth, with the majority of dental correction being attributed to protraction of the maxillary incisors and first molars. The $60 \%$ skeletal changes seen with the CS2000® appliance is slightly less than that seen in the facemask study by $\operatorname{Ngan}^{61}$ ( $70 \%$ of overjet change and $96 \%$ of molar relationship change), but slightly more than the skeletal percentage of changes seen with other removable appliances such as the FR III ${ }^{59}$. 


\section{CHAPTER VI: SUMMARY AND CONCLUSIONS}

\section{Summary}

The purpose of the present study was to determine the skeletal and dental changes seen in a group of patient who had undergone treatment with an inter-arch spring loaded module, the CS2000® appliance. The results of this study would then be indirectly compared to results research done on various other Class III correction appliances, namely the facemask.

The treatment group consisted of 30 patients treated in the private practice office of Dr. Michael Williams in Gulfport, MS, (15 males, 15 females) with an average pre-treatment age of 9.6 and post-treatment age of 10.9. The average treatment time for the pooled group studied was 1.3 years. Radiographs from pre-treatment and post-treatment records were collected and digitized using Dolphin Imaging (Dolphin Imaging, Chatsworth, CA) software and printed out 1:1, which allowed for landmark identification and adjusting for magnification. A custom cephalometric analysis was performed as described by Bjork $^{72}$ and Pancherz ${ }^{73}$ which used a reference grid set up by the pre-treatment radiograph to evaluate changes post-treatment. Paired t-tests were used to determine if any significant difference existed between the mean measurements of the pre and post-treatment radiographs. The hypothesis tested was that The CS $2000 ®$ provides no significant sagittal, vertical, or angular changes between T1 (pre-treatment) and T2 (post-treatment) as measured by lateral cephalometric radiographs. 


\section{Conclusion}

The hypothesis was rejected due to the findings of the following statistically significant variables observed:

1.) Significant sagittal, vertical, and angular changes were seen between the pre-treatment and post-treatment. The maxillary base was found to move $1.5 \mathrm{~mm}$ forward, while the mandibular base moved $1.5 \mathrm{~mm}$ posterior. ANB and Wits measurements improved a significant level throughout treatment as well. The maxillary incisor moved forward 2.6 $\mathrm{mm}$ while the mandibular incisor only move $0.6 \mathrm{~mm}$ forward. The maxillary molar moved $1.2 \mathrm{~mm}$ forward while the mandibular molar moved $0.6 \mathrm{~mm}$ posterior. These sagittal, vertical, and angular changes contributed to the overjet and molar relationship correction.

2.) The average overjet correction found a skeletal contribution of $60 \%$ and a $40 \%$ dental contribution. The molar relationship correction found a $62 \%$ skeletal influence a $38 \%$ dental contribution.

\section{Other Conclusions}

The CS 2000 appliance produces its correction by:

1.) Protraction of the maxillary base

2.) Proclination of the maxillary incisors

3.) Extrusion of the maxillary molars and mandibular incisors which rotates the occlusal plane in a counterclockwise direction

4.) Retraction of the mandibular base (partially coming from a downward an back rotation)

5.) Mesialization of the maxillary molars

6.) Distalization of the mandibular molars. 


\section{CHAPTER VII: RECCOMENDATIONS FOR FUTURE}

\section{RESEARCH}

\section{Recommendations}

1.) Compare the results of the present study to a control group of matched age and gender. This would factor out the growth contributing to the overall changes and allow more accurate comparisons with other studies done on Class III correction appliances.

2.) Follow-up with the patients studied for 1 year, 3 years, and 5 years post-treatment. This would allow for evaluation of the stability of the CS2000® appliance.

3.) Repeat the study in adult patients to see if there are any significant skeletal effects. This would evaluate if the CS2000® appliance could be used in patients who don't want to have surgical correction.

4.) Repeat the study collecting records from a different orthodontist using the CS $2000 \AA$ appliance. This would allow a comparison between practitioners and evaluate the reproducibility of the treatment effects seen by the CS2000® appliance.

5.) 3D cone beam study of the CS $2000 \circledR$ appliance to better study its' effects in all three planes of space. 


\section{APPENDIX A: IRB APPROVAL}

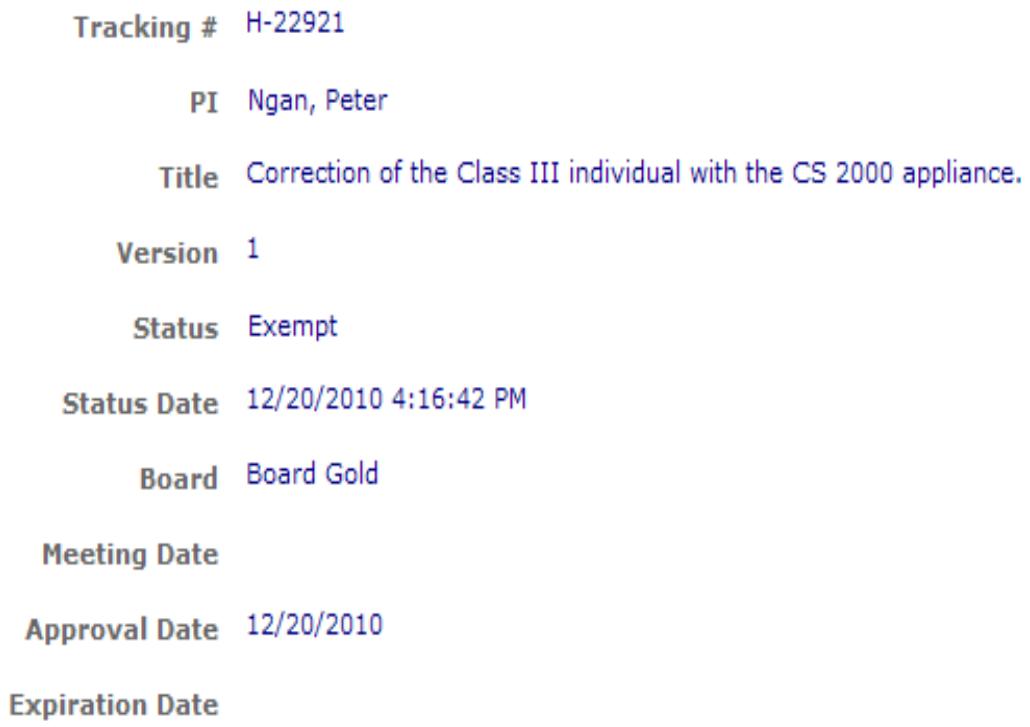




\section{APPENDIX B: PRE AND POST-TREATMENT VARIABLE MEASUREMENTS FOR EACH INDIVIDUAL PATIENT}




\begin{tabular}{|c|c|c|c|c|c|c|}
\hline Patient & $\begin{array}{c}\text { OLp-A } \\
\text { pt. }\end{array}$ & $\begin{array}{c}\text { OLp-B } \\
\text { pt. }\end{array}$ & OLp-Pg & Is-OLp & li-OLp & Overjet \\
\hline \multicolumn{7}{|l|}{ FEMALE } \\
\hline 1 & 66.9 & 72.1 & 73.5 & 70.9 & 72.9 & -2.0 \\
\hline 2 & 67.2 & 74.3 & 77.1 & 74.5 & 71.6 & 2.9 \\
\hline 3 & 67.5 & 72.7 & 73.6 & 71.5 & 73.6 & -2.1 \\
\hline 4 & 67.7 & 73.1 & 79.4 & 72.2 & 69.3 & 2.9 \\
\hline 5 & 68.3 & 74.8 & 78.9 & 74.6 & 72.5 & 2.1 \\
\hline 6 & 70.0 & 70.4 & 72.3 & 75.2 & 73.1 & 2.1 \\
\hline 7 & 63.9 & 67.4 & 69.7 & 70.6 & 70.0 & 0.6 \\
\hline 8 & 69.9 & 75.5 & 79.5 & 77.9 & 76.0 & 1.9 \\
\hline 9 & 66.7 & 72.3 & 73.6 & 74.1 & 72.9 & 1.2 \\
\hline 10 & 63.4 & 70.2 & 71.6 & 69.9 & 72.1 & -2.2 \\
\hline 11 & 64.6 & 70.3 & 73.3 & 68.7 & 67.2 & 1.5 \\
\hline 12 & 69.1 & 78.2 & 81.7 & 73.7 & 75.8 & -2.1 \\
\hline 13 & 72.9 & 77.1 & 83.4 & 76.0 & 71.6 & 4.4 \\
\hline 14 & 68.6 & 78.0 & 79.9 & 72.9 & 74.6 & -1.7 \\
\hline 15 & 71.4 & 74.2 & 75.5 & 76.8 & 75.8 & 1.0 \\
\hline Mean & 67.9 & 73.4 & 76.2 & 73.3 & 72.6 & 0.7 \\
\hline SD & 2.6 & 3.1 & 4.1 & 2.7 & 2.5 & 2.2 \\
\hline Max & 72.9 & 78.2 & 83.4 & 77.9 & 76.0 & 4.4 \\
\hline Min & 63.4 & 67.4 & 69.7 & 68.7 & 67.2 & -2.2 \\
\hline \multicolumn{7}{|l|}{ MALE } \\
\hline 1 & 69.0 & 72.8 & 73.4 & 72.7 & 74.7 & -2.0 \\
\hline 2 & 68.8 & 77.5 & 80.7 & 75.5 & 76.6 & -1.1 \\
\hline 3 & 71.0 & 79.0 & 83.0 & 77.6 & 80.2 & -2.6 \\
\hline 4 & 67.6 & 68.4 & 69.7 & 73.1 & $\mid 71.6$ & 1.5 \\
\hline 5 & 66.2 & 76.6 & 77.7 & 74.1 & 75.6 & -1.5 \\
\hline 6 & 71.8 & 80.9 & 83.4 & 83.7 & 87.4 & -3.7 \\
\hline 7 & 74.4 & 81.8 & 85.2 & 83.2 & 78.9 & 4.3 \\
\hline 8 & 64.4 & 72.4 & 72.9 & 72.2 & 71.4 & 0.8 \\
\hline 9 & 71.7 & 75.0 & 77.5 & 80.2 & 77.3 & 2.9 \\
\hline 10 & 67.3 & 73.6 & 75.0 & 69.0 & 72.1 & -3.1 \\
\hline 11 & 71.1 & 75.5 & 76.3 & 73.9 & 75.3 & -1.4 \\
\hline 12 & 68.7 & 74.4 & 75.4 & 78.0 & 77.1 & 0.9 \\
\hline 13 & 67.6 & 73.8 & 75.4 & 73.7 & 75.3 & -1.6 \\
\hline 14 & 64.9 & 72.3 & 74.8 & 69.1 & 71.1 & -2.0 \\
\hline 15 & 66.8 & 73.9 & 77.6 & 68.4 & 70.0 & -1.6 \\
\hline Mean & 68.8 & 75.2 & 77.2 & 75.0 & 75.6 & -0.7 \\
\hline SD & 2.8 & 3.5 & 4.3 & 4.8 & 4.4 & 2.3 \\
\hline Max & 74.4 & 81.8 & 85.2 & 83.7 & $\begin{array}{l}87.4 \\
\end{array}$ & 4.3 \\
\hline Min & 64.4 & 68.4 & 69.7 & 68.4 & 70.0 & -3.7 \\
\hline \multicolumn{7}{|l|}{ POOLED } \\
\hline Mean & 68.3 & 74.3 & 76.7 & 74.1 & 74.1 & 0.0 \\
\hline SD & 2.7 & 3.4 & 4.1 & 3.9 & 3.9 & 2.3 \\
\hline Max & 74.4 & 81.8 & 85.2 & 83.7 & 87.4 & 4.4 \\
\hline Min & 63.4 & 67.4 & 69.7 & 68.4 & 67.2 & -3.7 \\
\hline
\end{tabular}

Table 18. Sagittal Pre-Treatment 


\begin{tabular}{|c|c|c|c|c|c|}
\hline Patient & Ms-OLp & Mi-OLp & $\begin{array}{c}\text { Ms-OLp } \\
\text { minus Mi-OLp }\end{array}$ & Olp-Co & $\begin{array}{c}\text { Wits } \\
\text { analysis }\end{array}$ \\
\hline \multicolumn{6}{|l|}{ FEMALE } \\
\hline 1 & 46.0 & 50.0 & -4.0 & $\begin{array}{l}-7.3 \\
\end{array}$ & -3.2 \\
\hline 2 & 49.3 & 51.1 & -1.8 & -10.5 & -4.2 \\
\hline 3 & 44.2 & 50.2 & -6.0 & -6.5 & -2.4 \\
\hline 4 & 47.5 & 51.4 & -3.9 & \begin{tabular}{|c|}
-19.7 \\
\end{tabular} & -2.0 \\
\hline 5 & 45.8 & 47.2 & -1.4 & -10.6 & -5.2 \\
\hline 6 & 50.0 & 51.3 & -1.3 & \begin{tabular}{l|l|}
-16.1 \\
\end{tabular} & -0.1 \\
\hline 7 & 43.1 & 44.2 & -1.1 & -9.1 & -3.3 \\
\hline 8 & 51.7 & 51.2 & 0.5 & -8.8 & -3.9 \\
\hline 9 & 44.4 & 49.3 & -4.9 & -11.3 & -4.7 \\
\hline 10 & 44.0 & 45.4 & \begin{tabular}{|c|}
-1.4 \\
\end{tabular} & -9.4 & -3.8 \\
\hline 11 & 42.0 & 43.7 & -1.7 & -11.5 & -5.0 \\
\hline 12 & 49.0 & 55.2 & -6.2 & -7.1 & -6.3 \\
\hline 13 & 52.6 & 53.2 & -0.6 & \begin{tabular}{|c|}
-8.9 \\
\end{tabular} & -1.1 \\
\hline 14 & 46.7 & 49.4 & -2.7 & -5.0 & -5.5 \\
\hline 15 & 47.8 & 49.3 & -1.5 & -11.2 & -2.3 \\
\hline Mean & 46.9 & 49.5 & -2.5 & -10.2 & -3.5 \\
\hline SD & 3.2 & 3.2 & 2.0 & 3.7 & 1.7 \\
\hline Max & 52.6 & 55.2 & 0.5 & -5.0 & -0.1 \\
\hline Min & 42.0 & 43.7 & -6.2 & -19.7 & -6.3 \\
\hline \multicolumn{6}{|l|}{ MALE } \\
\hline 1 & 47.4 & 48.2 & -0.8 & -18.4 & -2.2 \\
\hline 2 & 51.1 & 52.1 & -1.0 & -9.9 & -7.4 \\
\hline 3 & 48.5 & 52.5 & -4.0 & -7.1 & -6.1 \\
\hline 4 & 48.1 & 49.5 & -1.4 & -11.2 & -0.7 \\
\hline 5 & 50.8 & 54.5 & $\begin{array}{l}-3.7 \\
\end{array}$ & $\begin{array}{l}-6.7 \\
\end{array}$ & -8.0 \\
\hline 6 & 47.7 & 50.1 & -2.4 & -15.5 & -8.0 \\
\hline 7 & 55.1 & 56.3 & -1.2 & -11.0 & -4.3 \\
\hline 8 & 41.0 & 48.5 & -7.5 & -14.8 & -8.2 \\
\hline 9 & 49.6 & 52.3 & -2.7 & -15.1 & -1.6 \\
\hline 10 & 43.9 & 49.5 & -5.6 & -11.1 & -4.6 \\
\hline 11 & 45.5 & 46.1 & -0.6 & -13.1 & -3.6 \\
\hline 12 & 45.8 & 47.6 & -1.8 & -8.5 & -5.4 \\
\hline 13 & 46.0 & 48.4 & -2.4 & -13.9 & -4.0 \\
\hline 14 & 41.5 & 43.5 & -2.0 & -15.4 & -5.6 \\
\hline 15 & 45.6 & 47.7 & -2.1 & -7.3 & -3.9 \\
\hline Mean & 47.2 & 49.8 & -2.6 & -11.9 & -4.9 \\
\hline SD & 3.7 & 3.3 & 1.9 & 3.6 & 2.4 \\
\hline Max & 55.1 & 56.3 & -0.6 & $\begin{array}{l}-6.7 \\
\end{array}$ & -0.7 \\
\hline Min & 41.0 & 43.5 & -7.5 & -18.4 & -8.2 \\
\hline \multicolumn{6}{|l|}{ POOLED } \\
\hline Mean & 47.1 & 49.6 & -2.6 & -11.1 & -4.2 \\
\hline SD & 3.4 & 3.2 & 1.9 & 3.7 & 2.1 \\
\hline Max & 55.1 & 56.3 & 0.5 & -5.0 & -0.1 \\
\hline Min & 41.0 & 43.5 & -7.5 & -19.7 & -8.2 \\
\hline
\end{tabular}

Table 19. Sagittal Pre-Treatment 


\begin{tabular}{|c|c|c|c|c|c|c|}
\hline Patient & $\begin{array}{l}\text { OLp-A } \\
\text { pt. }\end{array}$ & $\begin{array}{c}\text { OLp-B } \\
\text { pt. }\end{array}$ & OLp-Pg & Is-OLp & li-OLp & Overjet \\
\hline \multicolumn{7}{|l|}{ FEMALE } \\
\hline 1 & 68.5 & 73.8 & 75.8 & 77.1 & 73.9 & 3.2 \\
\hline 2 & 68.3 & 73.8 & 75.9 & 79.4 & 76.3 & 3.1 \\
\hline 3 & 68.8 & 70.2 & 71.3 & 74.3 & 71.7 & 2.6 \\
\hline 4 & 69.2 & 72.2 & 77.6 & 73.6 & 70.2 & 3.4 \\
\hline 5 & 69.3 & 73.1 & 75.9 & 77.0 & 73.4 & 3.6 \\
\hline 6 & 70.6 & 68.7 & 69.7 & 75.5 & 73 & 2.5 \\
\hline 7 & 64.6 & 64.2 & 66.1 & 74.1 & 69.2 & 4.9 \\
\hline 8 & 70.7 & 75.2 & 78.7 & 82.7 & 75.7 & 7.0 \\
\hline 9 & 67.3 & 69.1 & 70.6 & 76.4 & 68.8 & 7.6 \\
\hline 10 & 64.7 & 65.9 & 67.8 & 75.7 & 66.5 & 9.2 \\
\hline 11 & 65.8 & 68.0 & 72.3 & 74.0 & 64.9 & 9.1 \\
\hline 12 & 70.4 & 75.4 & 79.6 & 76.9 & 74.0 & 2.9 \\
\hline 13 & 73.9 & 78.0 & 85.4 & 83.0 & 71.5 & 11.5 \\
\hline 14 & 70.7 & 78.5 & 79.9 & 77.7 & 73.8 & 3.9 \\
\hline 15 & 71.9 & 71.5 & 72.4 & 76.6 & 72.9 & 3.7 \\
\hline Mean & 69.0 & 71.8 & 74.6 & 76.9 & 71.7 & 5.2 \\
\hline SD & 2.6 & 4.2 & 5.2 & 2.9 & 3.3 & 2.9 \\
\hline Max & 73.9 & 78.5 & 85.4 & 83.0 & 76.3 & 11.5 \\
\hline Min & 64.6 & 64.2 & 66.1 & 73.6 & 64.9 & 2.5 \\
\hline \multicolumn{7}{|l|}{ MALE } \\
\hline 1 & 70.9 & 72 & 73.1 & 80.3 & 72.1 & 8.2 \\
\hline 2 & 69.5 & 74 & 77.8 & 80.7 & 72.6 & 8.1 \\
\hline 3 & 71.8 & 77.4 & 80.8 & 79.9 & 78.9 & 1.0 \\
\hline 4 & 69.1 & 66.8 & 68.5 & 79 & 73.6 & 5.4 \\
\hline 5 & 68.6 & 74.4 & 76.1 & 76.7 & 73.2 & 3.5 \\
\hline 6 & 73.6 & 75.0 & 77.2 & 87.5 & 82.3 & 5.2 \\
\hline 7 & 75.8 & 83.3 & 86.6 & 86.7 & 81.5 & 5.2 \\
\hline 8 & 66.0 & 71.5 & 73.1 & 74.0 & 72.1 & 1.9 \\
\hline 9 & 74.8 & 74.4 & 76.5 & 83.5 & 80.5 & 3.0 \\
\hline 10 & 69.8 & 72.4 & 74.3 & 75.6 & 71.3 & 4.3 \\
\hline 11 & 72.1 & 73.7 & 74.9 & 80.9 & 71.3 & 9.6 \\
\hline 12 & 73.5 & 75.2 & 76.3 & 87.5 & 79.3 & 8.2 \\
\hline 13 & 69.1 & 69.2 & 71.5 & 75.5 & 71.4 & 4.1 \\
\hline 14 & 66.2 & 69.8 & 72.9 & 72.7 & 69.7 & 3.0 \\
\hline 15 & 68.9 & 73.3 & 77.2 & 73.6 & 71.1 & 2.5 \\
\hline Mean & 70.6 & 73.5 & 75.8 & 79.6 & 74.7 & 4.9 \\
\hline SD & 2.9 & 3.8 & 4.2 & 5.0 & 4.4 & 2.6 \\
\hline Max & 75.8 & 83.3 & 86.6 & 87.5 & 82.3 & 9.6 \\
\hline Min & 66.0 & 66.8 & 68.5 & 72.7 & 69.7 & 1.0 \\
\hline \multicolumn{7}{|l|}{ POOLED } \\
\hline Mean & 69.8 & 72.7 & 75.2 & 78.3 & 73.2 & 5.0 \\
\hline SD & 2.85 & 4.02 & 4.69 & 4.23 & 4.09 & 2.71 \\
\hline Max & 75.8 & 83.3 & 86.6 & 87.5 & 82.3 & 11.5 \\
\hline Min & 64.6 & 64.2 & 66.1 & 72.7 & 64.9 & 1.0 \\
\hline
\end{tabular}

Table 20. Sagittal Post-Treatment 


\begin{tabular}{|c|c|c|c|c|c|}
\hline Patient & Ms-OLp & Mi-OLp & $\begin{array}{c}\text { Ms-OLp } \\
\text { minus Mi-OLp }\end{array}$ & Olp-Co & $\begin{array}{c}\text { Wits } \\
\text { analysis }\end{array}$ \\
\hline \multicolumn{6}{|l|}{ FEMALE } \\
\hline 1 & 51.8 & 49.6 & 2.2 & \begin{tabular}{|c|}
-7.4 \\
\end{tabular} & -1.6 \\
\hline 2 & 47.6 & 51.1 & -3.5 & -8.5 & -5.7 \\
\hline 3 & 47.7 & 44.8 & 2.9 & -5.9 & 1.4 \\
\hline 4 & 50.6 & 47.4 & 3.2 & $\begin{array}{l}-19.3 \\
\end{array}$ & 0.7 \\
\hline 5 & 48.0 & 48.3 & -0.3 & $\begin{array}{l}-9.3 \\
\end{array}$ & -2.9 \\
\hline 6 & 48.4 & 49.5 & -1.1 & $\mid-13.6$ & 0.6 \\
\hline 7 & 45.8 & 44.7 & 1.1 & -10.4 & 2.5 \\
\hline 8 & 55.6 & 48.7 & 6.9 & -10.3 & 2.6 \\
\hline 9 & 46.1 & 44.4 & 1.7 & $\begin{array}{l}-9.8 \\
\end{array}$ & 3.5 \\
\hline 10 & 45.5 & 38.8 & 6.7 & -9.8 & 4.6 \\
\hline 11 & 46.2 & 39.9 & 6.3 & -11.5 & 3.3 \\
\hline 12 & 54.0 & 52.5 & 1.5 & -7.7 & 1.4 \\
\hline 13 & 54.4 & 56.8 & -2.4 & -7.5 & 5.9 \\
\hline 14 & 51.0 & 47.8 & 3.2 & -9.0 & -1.1 \\
\hline 15 & 51.0 & 47.1 & 3.9 & -9.0 & 0.9 \\
\hline Mean & 49.6 & 47.4 & 2.2 & -9.9 & 1.1 \\
\hline SD & 3.3 & 4.6 & 3.1 & 3.2 & 3.0 \\
\hline Max & 55.6 & 56.8 & 6.9 & -5.9 & 5.9 \\
\hline Min & 45.5 & 38.8 & -3.5 & -19.3 & -5.7 \\
\hline \multicolumn{6}{|l|}{ MALE } \\
\hline 1 & 51.3 & 45.9 & 5.4 & -18.0 & 2.7 \\
\hline 2 & 50.4 & 45.6 & 4.8 & -9.3 & 1.0 \\
\hline 3 & 50.6 & 52.3 & -1.7 & -5.3 & -4.9 \\
\hline 4 & 48.3 & 47.2 & 1.1 & -12.5 & 6.4 \\
\hline 5 & 53.8 & 54.0 & -0.2 & -6.0 & -2.3 \\
\hline 6 & 51.7 & 45.7 & 6.0 & $\begin{array}{l}-17.3 \\
\end{array}$ & 2.8 \\
\hline 7 & 54.9 & 59.1 & -4.2 & -10.2 & -5.6 \\
\hline 8 & 45.9 & 44.9 & 1.0 & -14.5 & -5.4 \\
\hline 9 & 53.7 & 51.9 & 1.8 & -17.8 & 2.2 \\
\hline 10 & 52.0 & 47.2 & 4.8 & $\begin{array}{l}-9.1 \\
\end{array}$ & 0.9 \\
\hline 11 & 46.7 & 46.9 & -0.2 & -11.0 & 0.6 \\
\hline 12 & 51.8 & 47.0 & 4.8 & -9.1 & 3.8 \\
\hline 13 & 46.9 & 42.4 & 4.5 & -14.1 & 1.6 \\
\hline 14 & 44.0 & 37.8 & 6.2 & -15.3 & -0.5 \\
\hline 15 & 45.5 & 46.3 & -0.8 & -7.0 & -2.5 \\
\hline Mean & 49.8 & 47.6 & 2.2 & -11.8 & 0.1 \\
\hline SD & 3.4 & 5.1 & 3.2 & 4.3 & 3.5 \\
\hline Max & 54.9 & 59.1 & 6.2 & -5.3 & 6.4 \\
\hline Min & 44.0 & 37.8 & -4.2 & -18.0 & -5.6 \\
\hline \multicolumn{6}{|l|}{ POOLED } \\
\hline Mean & 49.7 & 47.5 & 2.2 & -10.9 & 0.6 \\
\hline SD & 3.30 & 4.74 & 3.12 & 3.81 & 3.27 \\
\hline Max & 55.6 & 59.1 & 6.9 & -5.3 & 6.4 \\
\hline Min & 44.0 & 37.8 & -4.2 & -19.3 & -5.7 \\
\hline
\end{tabular}

Table 21. Sagittal Post-Treatment 


\begin{tabular}{|c|c|c|c|c|c|c|c|}
\hline Patient & $\begin{array}{c}\text { OLs-A } \\
\text { pt. }\end{array}$ & ANS-Me & Is-NL & li-ML & li -- OL & Msc-NL & Mic-ML \\
\hline \multicolumn{8}{|l|}{ FEMALE } \\
\hline 1 & 23.6 & 57.7 & 22.3 & 35.7 & 2.3 & 16.4 & 25.5 \\
\hline 2 & 25.3 & 55.2 & 23.4 & 33.5 & 4.0 & 18.3 & 23.3 \\
\hline 3 & 24.0 & 57.3 & 21.9 & 35.6 & 2.6 & 16.4 & 24.9 \\
\hline 4 & 36.1 & 59.1 & 26.0 & 33.3 & 3.4 & 22.3 & 24.4 \\
\hline 5 & 28.8 & 50.1 & 21.3 & 29.6 & 2.3 & 14.7 & 20.6 \\
\hline 6 & 39.6 & 64.4 & 25.5 & 37.2 & 0.0 & 22.8 & 29.1 \\
\hline 7 & 33.2 & 59.7 & 24.4 & 34.9 & 0.3 & 20.6 & 24.0 \\
\hline 8 & 28.4 & 56.8 & 24.7 & 34.5 & 2.7 & 20.0 & 25.7 \\
\hline 9 & 35.1 & 66.8 & 27.9 & 37.3 & 0.3 & 23.2 & 27.1 \\
\hline 10 & 28.1 & 48.9 & 21.5 & 32.4 & 4.5 & 18.0 & 21.9 \\
\hline 11 & 28.5 & 50.4 & 19.9 & 29.6 & 0.8 & 16.9 & 22.6 \\
\hline 12 & 30.8 & 67.8 & 28.1 & 39.5 & 2.8 & 22.4 & 28.8 \\
\hline 13 & 26.2 & 51.1 & 23.4 & 31.0 & 5.9 & 17.5 & 22.3 \\
\hline 14 & 23.1 & 55.3 & 24.9 & 32.7 & 3.9 & 17.5 & 22 \\
\hline 15 & 29.2 & 58.2 & 23.4 & 33.7 & 0.2 & 19.1 & 25.3 \\
\hline Mean & 29.3 & 57.3 & 23.9 & 34.0 & 2.4 & 19.1 & 24.5 \\
\hline SD & 4.9 & 5.8 & 2.4 & 2.8 & 1.8 & 2.7 & 2.5 \\
\hline Max & 39.6 & 67.8 & 28.1 & 39.5 & 5.9 & 23.2 & 29.1 \\
\hline Min & 23.1 & 48.9 & 19.9 & 29.6 & 0.0 & 14.7 & 20.6 \\
\hline \multicolumn{8}{|l|}{ MALE } \\
\hline 1 & 23.0 & 56.0 & 22.7 & 35.2 & 2.0 & 17.6 & 28.0 \\
\hline 2 & 17.9 & 58.3 & 27.0 & 32.5 & 2.6 & 18.1 & 26.1 \\
\hline 3 & 32.3 & 48.7 & 21.0 & 31.9 & 4.2 & 17.7 & 22.1 \\
\hline 4 & 31.5 & 59.4 & 24.1 & 34.8 & 0.6 & 19.4 & 23.8 \\
\hline 5 & 23.8 & 53.6 & 22.9 & 33.2 & 3.1 & 17.5 & 25.7 \\
\hline 6 & 38.3 & 58.0 & 22.9 & 38.8 & 2.7 & 22.8 & 23.7 \\
\hline 7 & 29.0 & 58.1 & 26.5 & 35.1 & 4.2 & 19.0 & 26.8 \\
\hline 8 & 37.8 & 62.3 & 23.1 & 37.3 & 0.0 & 23.6 & 29.1 \\
\hline 9 & 37.3 & 54.5 & 21.4 & 34.9 & 2.7 & 18.3 & 24.9 \\
\hline 10 & 26.0 & 57.7 & 24.3 & 33.6 & 1.9 & 19.1 & 24.7 \\
\hline 11 & 29.8 & 53.1 & 20.6 & 32.3 & 0.8 & 16.1 & 23.4 \\
\hline 12 & 29.7 & 59.6 & 24.5 & 36.1 & 0.2 & 15.9 & 26.9 \\
\hline 13 & 27.9 & 50.1 & 20.9 & 31.2 & 2.6 & 16.3 & 24.1 \\
\hline 14 & 31.8 & 51.1 & 21.1 & 32.5 & 3.4 & 18.1 & 23.3 \\
\hline 15 & 26.1 & 52.9 & 20.7 & 31.7 & 2.3 & 17.7 & 23.0 \\
\hline Mean & 29.5 & 55.6 & 22.9 & 34.1 & 2.2 & 18.5 & 25.0 \\
\hline SD & 5.7 & 3.9 & 2.1 & 2.2 & 1.3 & 2.2 & 2.0 \\
\hline Max & 38.3 & 62.3 & 27.0 & 38.8 & 4.2 & 23.6 & 29.1 \\
\hline Min & 17.9 & 48.7 & 20.6 & 31.2 & 0.0 & 15.9 & 22.1 \\
\hline \multicolumn{8}{|l|}{ POOLED } \\
\hline Mean & 29.4 & 56.4 & 23.4 & 34.1 & 2.3 & 18.8 & 24.8 \\
\hline SD & 5.22 & 4.97 & 2.23 & 2.48 & 1.55 & 2.42 & 2.25 \\
\hline Max & 39.6 & 67.8 & 28.1 & 39.5 & 5.9 & 23.6 & 29.1 \\
\hline Min & 17.9 & 48.7 & 19.9 & 29.6 & 0.0 & 14.7 & 20.6 \\
\hline
\end{tabular}

Table 22. Vertical Pre-Treatment 


\begin{tabular}{|c|c|c|c|c|c|c|c|}
\hline Patient & \begin{tabular}{|c|} 
OLs-A \\
pt.
\end{tabular} & ANS-Me & Is-NL & li-ML & li -- OL & Msc-NL & Mic-ML \\
\hline \multicolumn{8}{|l|}{ FEMALE } \\
\hline 1 & 27.0 & 59.4 & 26.6 & 32.8 & 0.9 & 21.6 & 22.7 \\
\hline 2 & 29.4 & \begin{tabular}{|c|}
60.5 \\
\end{tabular} & 24.5 & 36.1 & 0.3 & 18.0 & 25.4 \\
\hline 3 & 26.4 & 63.8 & 23.9 & 37.5 & 0.8 & 18.8 & 23.9 \\
\hline 4 & 39.1 & 64.2 & 26.3 & 35.4 & 0.8 & 24.0 & 24.4 \\
\hline 5 & 30.3 & 54.9 & 22.9 & 31.5 & 1.3 & 16.2 & 21.5 \\
\hline 6 & 41.2 & 71.1 & 29.6 & 40.7 & 1.3 & 25.2 & 29.9 \\
\hline 7 & 35.1 & 64.7 & 22.5 & 38.3 & \begin{tabular}{|c|}
-1.8 \\
\end{tabular} & 22.2 & 26.6 \\
\hline 8 & 30.4 & 62.2 & 25.0 & 39.4 & 2.9 & 23.4 & 24.8 \\
\hline 9 & 36.4 & 69.6 & 27.0 & 39.5 & 0.5 & 24.9 & 24.5 \\
\hline 10 & 28.8 & 55.1 & 20.5 & 33.1 & 0.4 & 21.4 & 19.2 \\
\hline 11 & 30.7 & 57.9 & 20.5 & 32.7 & 0.0 & 21.8 & 20.8 \\
\hline 12 & 33.4 & 74.3 & 27.2 & 44.0 & 1.2 & 25.6 & 29.2 \\
\hline 13 & 27.4 & 58.1 & 21.1 & 34.1 & 2.2 & 19.8 & 22.8 \\
\hline 14 & 26.7 & 58.3 & 26 & 33.9 & 3.6 & 21.0 & 20.5 \\
\hline 15 & 30.7 & 63.9 & 25.7 & 34.6 & -0.4 & 22.8 & 25.0 \\
\hline Mean & 31.5 & 62.5 & 24.6 & 36.2 & 0.9 & 21.8 & 24.1 \\
\hline SD & 4.6 & 5.7 & 2.7 & 3.6 & 1.3 & 2.7 & 3.0 \\
\hline Max & 41.2 & 74.3 & 29.6 & 44.0 & 3.6 & 25.6 & 29.9 \\
\hline Min & 26.4 & 54.9 & 20.5 & 31.5 & -1.8 & 16.2 & 19.2 \\
\hline \multicolumn{8}{|l|}{ MALE } \\
\hline 1 & 26.0 & 60.2 & 24.3 & 35.8 & 1.1 & 19.3 & 27.0 \\
\hline 2 & 20.7 & 61.9 & 25.3 & 34.0 & -0.5 & 20.7 & 24.5 \\
\hline 3 & 33.9 & 54.2 & 19.7 & 33.4 & -0.7 & 17.9 & 25.8 \\
\hline 4 & 35.0 & 63.9 & 23.0 & 40.1 & 0.5 & 20.7 & 25.1 \\
\hline 5 & 27.2 & 60.7 & 25.7 & 36.6 & 2.7 & 20.8 & 26.2 \\
\hline 6 & 42.9 & 63.1 & 20.0 & 40.1 & $\begin{array}{l}-2.4 \\
\end{array}$ & 24.2 & 24.3 \\
\hline 7 & 29.6 & 62.0 & 27.0 & 35.3 & 0.5 & 19.0 & 29.2 \\
\hline 8 & 40.6 & 68.6 & 27.0 & 39.9 & 0.5 & 24.0 & 28.2 \\
\hline 9 & 42.2 & 57.8 & 22.3 & 37.9 & 1.8 & 20.7 & 25.5 \\
\hline 10 & 29.3 & 63.7 & 27.0 & 35.8 & 1.2 & 23.9 & 23.8 \\
\hline 11 & 30.8 & 55.7 & 21.9 & 34.0 & 2.6 & 17.7 & 22.6 \\
\hline 12 & 32.9 & 67.4 & 23.8 & 40.3 & 2.2 & 22.1 & 26.1 \\
\hline 13 & 29.1 & 55.8 & 20.9 & 33.4 & -0.5 & 19.1 & 24.0 \\
\hline 14 & 32.7 & 54.6 & 20.0 & 32.6 & -0.7 & 20.8 & 21.8 \\
\hline 15 & 30.4 & 57.5 & 21.4 & 34.5 & 0.6 & 20.2 & 25.5 \\
\hline Mean & 32.2 & 60.5 & 23.3 & 36.2 & 0.6 & 20.7 & 25.3 \\
\hline SD & 6.1 & 4.5 & 2.7 & 2.8 & 1.4 & 2.1 & 2.0 \\
\hline Max & 42.9 & 68.6 & 27.0 & 40.3 & 2.7 & 24.2 & 29.2 \\
\hline Min & 20.7 & 54.2 & 19.7 & 32.6 & -2.4 & 17.7 & 21.8 \\
\hline \multicolumn{8}{|l|}{ POOLED } \\
\hline Mean & 31.9 & 61.5 & 24.0 & 36.2 & 0.8 & 21.3 & 24.7 \\
\hline SD & 5.3 & 5.2 & 2.7 & 3.1 & 1.4 & 2.4 & 2.6 \\
\hline Max & 42.9 & 74.3 & 29.6 & 44.0 & 3.6 & 25.6 & 29.9 \\
\hline Min & 20.7 & 54.2 & 19.7 & 31.5 & \begin{tabular}{|c|}
-2.4 \\
\end{tabular} & 16.2 & 19.2 \\
\hline
\end{tabular}

Table 23. Vertical Post-Treatment 


\begin{tabular}{|c|c|c|c|c|c|c|c|c|c|}
\hline Patient & SNA & SNB & ANB & SNL-NL & SNL-ML & SNL_Ols & Is/SNL & $\mathrm{li} / \mathrm{ML}$ & Isa-Is/lia-li \\
\hline \multicolumn{10}{|l|}{ FEMALE } \\
\hline 1 & 80.0 & 79.2 & 0.8 & 6.1 & 36.4 & 18.4 & 96.3 & 82.1 & 145.2 \\
\hline 2 & 78.9 & 79.2 & -0.3 & 10.2 & 38.7 & 21.6 & 101.4 & 75.0 & 144.9 \\
\hline 3 & 80.6 & 79.9 & 0.7 & 5.7 & 35.5 & 18.1 & 96.7 & 83.8 & 144.1 \\
\hline 4 & 73.6 & 77.3 & \begin{tabular}{|c|}
-3.7 \\
\end{tabular} & 7.0 & 30.1 & 15.8 & 95.4 & 77.3 & 157.2 \\
\hline 5 & 79.0 & 80.3 & \begin{tabular}{|c|}
-1.3 \\
\end{tabular} & 8.0 & 33.2 & 18.6 & 107.2 & 79.0 & 140.6 \\
\hline 6 & 79.6 & 79.2 & 0.4 & 6.2 & 30.5 & 11.7 & 104.3 & 91.3 & 133.9 \\
\hline 7 & 75.3 & 73.9 & 1.5 & 16.6 & 45.1 & 21.6 & 101.8 & 83.9 & 129.2 \\
\hline 8 & 76.3 & 76.9 & -0.6 & 12.5 & 33.6 & 21.1 & 100.6 & 90.6 & 135.2 \\
\hline 9 & 77.2 & 77.3 & -0.1 & 10.0 & 41.9 & 20.2 & 103.1 & 81.5 & 133.6 \\
\hline 10 & 79.2 & 79.9 & -0.7 & 12.8 & 31.7 & 19.8 & 104.3 & 97.3 & 126.7 \\
\hline 11 & 77.8 & 78.9 & -1.1 & 13.0 & 32.4 & 19.2 & 100.8 & 79.2 & 147.5 \\
\hline 12 & 74.4 & 77.1 & -2.7 & 10.3 & 39.7 & 21.3 & 91.1 & 76.2 & 153.1 \\
\hline 13 & 77.2 & 76.3 & 0.9 & 11.7 & 32.5 & 24.6 & 84.9 & 72.7 & 169.8 \\
\hline 14 & 86.2 & 85.6 & 0.6 & 2.9 & 29.1 & 18.7 & 93.7 & 78.9 & 158.2 \\
\hline 15 & 82.2 & 79.3 & 3.0 & 10.6 & 34.2 & 19.8 & 100.2 & 87.5 & 138.1 \\
\hline Mean & 78.5 & 78.7 & -0.2 & 9.6 & 35.0 & 19.4 & 98.8 & 82.4 & 143.8 \\
\hline SD & 3.2 & 2.6 & 1.6 & 3.6 & 4.6 & 2.9 & 5.8 & 6.8 & 11.9 \\
\hline Max & 86.2 & 85.6 & 3.0 & 16.6 & 45.1 & 24.6 & 107.2 & 97.3 & 169.8 \\
\hline Min & 73.6 & 73.9 & -3.7 & 2.9 & 29.1 & 11.7 & 84.9 & 72.7 & 126.7 \\
\hline \multicolumn{10}{|l|}{ MALE } \\
\hline 1 & 81.0 & 79.9 & 1.4 & 6.9 & 26.9 & 16.9 & 97.8 & 94.2 & 141.1 \\
\hline 2 & 75.1 & \begin{tabular}{|l|}
75.9 \\
\end{tabular} & -0.8 & 7.7 & 34.6 & 27.6 & 92.2 & 87.5 & 145.7 \\
\hline 3 & 83.2 & 86.4 & -3.2 & 8.4 & 23.6 & 13.7 & 110.7 & 93.9 & 131.8 \\
\hline 4 & 75.5 & 75.2 & 0.3 & 7.0 & 41.8 & 16.9 & 102.3 & 85.9 & 130.0 \\
\hline 5 & 79.9 & 81.1 & -1.3 & 10.7 & 34.0 & 22.5 & 107.9 & 86.1 & 131.9 \\
\hline 6 & 87.3 & 89.1 & -1.8 & 11.9 & 29.4 & 12.4 & 125.3 & 100.3 & 104.9 \\
\hline 7 & 80.0 & 80.3 & -0.3 & 6.1 & 29.6 & 20.1 & 104.4 & 83.8 & 142.2 \\
\hline 8 & 82.9 & 84.5 & -1.6 & 14.8 & 34.2 & 13.9 & 115.3 & 80.2 & 130.3 \\
\hline 9 & 86.3 & 85.8 & 0.6 & 4.5 & 25.7 & 10.2 & 119.1 & 92.3 & 123.0 \\
\hline 10 & 84.6 & 83.1 & 1.5 & 7.7 & 32.5 & 18.8 & 91.2 & 84.9 & 151.4 \\
\hline 11 & 85.9 & 84.5 & 1.4 & 6.2 & 29.2 & 14.7 & 98.5 & 88.0 & 144.4 \\
\hline 12 & 84.1 & \begin{tabular}{|l|}
82.3 \\
\end{tabular} & 1.8 & 4.2 & 33.3 & 18.4 & 115.3 & 91.0 & 120.4 \\
\hline 13 & 81.8 & 81.9 & -0.1 & 8.3 & 25.9 & 16.7 & 111.4 & 98.2 & 124.5 \\
\hline 14 & 76.5 & 79.7 & \begin{tabular}{l|}
-3.2 \\
\end{tabular} & 12.9 & 28.8 & 18.2 & 102.0 & 91.3 & 137.9 \\
\hline 15 & 80.7 & 81.7 & -1.0 & 9.5 & 30.4 & 16.6 & 92.1 & 80.6 & 156.9 \\
\hline Mean & 81.7 & 82.1 & -0.4 & 8.5 & 30.7 & 17.2 & 105.7 & 89.2 & 134.4 \\
\hline SD & 3.8 & \begin{tabular}{|l|} 
\\
\end{tabular} & 1.6 & 3.0 & 4.6 & 4.2 & 10.5 & 6.0 & 13.3 \\
\hline Max & 87.3 & 89.1 & 1.8 & 14.8 & 41.8 & 27.6 & 125.3 & 100.3 & 156.9 \\
\hline Min & 75.1 & \begin{tabular}{|l|}
75.2 \\
\end{tabular} & -3.2 & 4.2 & 23.6 & 10.2 & 91.2 & 80.2 & 104.9 \\
\hline \multicolumn{10}{|l|}{ POOLED } \\
\hline Mean & 80.1 & \begin{tabular}{|l|}
80.4 \\
\end{tabular} & \begin{tabular}{|c|}
-0.3 \\
\end{tabular} & 9.0 & 32.8 & 18.3 & 102.2 & 85.8 & 139.1 \\
\hline SD & 3.8 & 3.6 & 1.6 & 3.3 & 5.0 & 3.8 & 9.0 & 7.2 & 13.3 \\
\hline Max & 87.3 & 89.1 & 3.0 & 16.6 & 45.1 & 27.6 & 125.3 & 100.3 & 169.8 \\
\hline Min & 73.6 & 73.9 & -3.7 & 2.9 & 23.6 & 10.2 & 84.9 & 72.7 & 104.9 \\
\hline
\end{tabular}

Table 24. Angular Pre-Treatment 


\begin{tabular}{|c|c|c|c|c|c|c|c|c|c|}
\hline Patient & SNA & SNB & ANB & SNL-NL & SNL-ML & SNL-Ols & Is/SNL & Ii/ML & Isa-Is/lia-li \\
\hline \multicolumn{10}{|l|}{ FEMALE } \\
\hline 1 & 80.5 & 79.3 & 1.2 & 5.1 & 34.8 & 17.1 & 105.2 & 89.6 & 130.5 \\
\hline 2 & 78.9 & 78.4 & 0.4 & 10.1 & 41.6 & 19.4 & 112.0 & 87.0 & 119.3 \\
\hline 3 & 82.5 & 78.6 & 3.9 & 3.8 & 38.4 & 17.0 & 98.0 & 77.6 & 146.1 \\
\hline 4 & 74.2 & 76.6 & -2.4 & 5.0 & 31.5 & 15.1 & 98.9 & 84.0 & 145.6 \\
\hline 5 & 81.8 & 81.0 & 0.8 & 4.0 & 35.0 & 16.6 & 105.9 & 81.9 & 137.2 \\
\hline 6 & 80.3 & 78.9 & 1.4 & 5.1 & 34.5 & 10.2 & 100.2 & 89.8 & 135.6 \\
\hline 7 & 78.1 & \begin{tabular}{|l|}
74.8 \\
\end{tabular} & 3.3 & 12.8 & 43.5 & 19.4 & 114.1 & 85.2 & 117.2 \\
\hline 8 & 77.5 & 77.2 & 0.4 & 9.8 & 34.1 & 19.7 & 115.8 & 87.0 & 123.1 \\
\hline 9 & 79.1 & 76.9 & 2.2 & 8.7 & 42.5 & 18.2 & 118.3 & 78.3 & 120.9 \\
\hline 10 & 82.3 & 78.5 & 3.8 & 10.6 & 34.8 & 18.3 & 122.7 & 89.6 & 113.0 \\
\hline 11 & 79.6 & 78.0 & 1.7 & 10.3 & 34.7 & 18.4 & 115.3 & 74.9 & 135.1 \\
\hline 12 & 79.9 & 79.7 & 0.2 & 5.9 & 39.1 & 17.1 & 107.5 & 80.9 & 132.5 \\
\hline 13 & 80.3 & 77.8 & 2.5 & 8.6 & 33.9 & 22.9 & 113.3 & 67.3 & 145.4 \\
\hline 14 & 85.0 & 84.3 & 0.7 & 2.5 & 31.0 & 17.4 & 106.7 & 73.3 & 149.0 \\
\hline 15 & 80.6 & 76.3 & 4.3 & 10.4 & 39.0 & 18.7 & 99.7 & 84.1 & 137.2 \\
\hline Mean & 80.0 & 78.4 & 1.6 & 7.5 & 36.6 & 17.7 & 108.9 & 82.0 & 132.5 \\
\hline SD & 2.5 & \begin{tabular}{|l|}
2.2 \\
\end{tabular} & 1.8 & 3.2 & 3.9 & 2.7 & 7.7 & 6.7 & 11.6 \\
\hline Max & 85.0 & 84.3 & 4.3 & 12.8 & 43.5 & 22.9 & 122.7 & 89.8 & 149.0 \\
\hline Min & 74.2 & 74.8 & -2.4 & 2.5 & 31.0 & 10.2 & 98.0 & 67.3 & 113.0 \\
\hline \multicolumn{10}{|l|}{ MALE } \\
\hline 1 & 84.0 & 79.1 & 4.9 & 3.3 & 29.6 & 16.4 & 111.7 & 90.8 & 127.9 \\
\hline 2 & 80.8 & 77.4 & 3.5 & 4.5 & 35.7 & 23.8 & 113.7 & 82.3 & 128.2 \\
\hline 3 & 84.8 & 85.7 & -0.9 & 6.8 & 26.3 & 13.2 & 119.3 & 89.4 & 125.0 \\
\hline 4 & 77.5 & 74.7 & 2.7 & 5.5 & 41.5 & 16.4 & 122.6 & 90.8 & 105.1 \\
\hline 5 & 86.0 & 82.9 & 3.1 & 6.4 & 36.5 & 18.1 & 103.1 & 77.4 & 143.1 \\
\hline 6 & 92.2 & 88.6 & 3.6 & 5.0 & 27.9 & 6.8 & 135.9 & 94.2 & 102.0 \\
\hline 7 & 82.2 & 82.4 & -0.2 & 2.9 & 28.1 & 18.1 & 115.8 & 92.4 & 123.6 \\
\hline 8 & 85.8 & 85.6 & 0.2 & 6.8 & 33.4 & 12.1 & 111.0 & 79.3 & 136.3 \\
\hline 9 & 88.2 & 85.4 & 2.8 & 4.7 & 25.8 & 8.7 & 119.8 & 101.1 & 113.3 \\
\hline 10 & 84.0 & 80.3 & 3.7 & 7.8 & 37.3 & 17.1 & 104.6 & 78.5 & 139.6 \\
\hline 11 & 86.6 & 83.9 & 2.6 & 4.1 & 30.4 & 12.6 & 120.9 & 82.6 & 126.1 \\
\hline 12 & 86.4 & 81.0 & 5.4 & 5.1 & 36.9 & 17.2 & 123.8 & 89.6 & 109.7 \\
\hline 13 & 84.2 & 80.3 & 3.9 & 8.5 & 29.1 & 15.0 & 118.9 & 95.4 & 117.2 \\
\hline 14 & 78.8 & 79.2 & -0.6 & 11.4 & 29.3 & 16.7 & 114.0 & 90.1 & 126.6 \\
\hline 15 & 83.4 & 83.6 & -0.2 & 8.5 & 28.3 & 14.2 & 102.2 & 78.9 & 150.5 \\
\hline Mean & 84.3 & 82.0 & 2.3 & 6.1 & 31.7 & 15.1 & 115.8 & 87.5 & 124.9 \\
\hline SD & 3.7 & 3.6 & 2.1 & 2.3 & 4.8 & 4.1 & 8.9 & 7.2 & 13.9 \\
\hline Max & 92.2 & 88.6 & 5.4 & 11.4 & 41.5 & 23.8 & 135.9 & 101.1 & 150.5 \\
\hline Min & 77.5 & 74.7 & -0.9 & 2.9 & 25.8 & 6.8 & 102.2 & 77.4 & 102.0 \\
\hline \multicolumn{10}{|l|}{ POOLED } \\
\hline Mean & 82.2 & 80.2 & 2.0 & 6.8 & 34.2 & 16.4 & 112.4 & \begin{tabular}{|l|} 
\\
\end{tabular} & 128.7 \\
\hline SD & 3.8 & 3.5 & 1.9 & 2.8 & 4.9 & 3.7 & 8.9 & 7.4 & 13.1 \\
\hline Max & 92.2 & 88.6 & 5.4 & 12.8 & 43.5 & 23.8 & 135.9 & 101.1 & 150.5 \\
\hline Min & 74.2 & 74.7 & -2.4 & 2.5 & 25.8 & 6.8 & 98.0 & 67.3 & 102.0 \\
\hline
\end{tabular}

Table 25. Angular Post-Treatment 


\section{Reference List}

(1) Riolo M, Avery J. Essentials for Orthodontic Practice. Ann Arbor, Michigan: EFOP P; 1993.

(2) Horowitz HS. A study of occlusal relations in 10 to 12 year old Caucasian and Negro children-summary report. Int Dent J 1970 December;20(4):593-605.

(3) Garner LD, Butt MH. Malocclusion in black Americans and Nyeri Kenyans. An epidemiologic study. Angle Orthod 1985 April;55(2):139-46.

(4) Lew KK, Foong WC, Loh E. Malocclusion prevalence in an ethnic Chinese population. Aust Dent J 1993 December;38(6):442-9.

(5) Silva RG, Kang DS. Prevalence of malocclusion among Latino adolescents. Am J Orthod Dentofacial Orthop 2001 March;119(3):313-5.

(6) Bui C, King T, Proffit W, Frazier-Bowers S. Phenotypic characterization of Class III patients. Angle Orthod 2006 July;76(4):564-9.

(7) Wilmot JJ, Barber HD, Chou DG, Vig KW. Associations between severity of dentofacial deformity and motivation for orthodontic-orthognathic surgery treatment. Angle Orthod 1993;63(4):283-8.

(8) Tortop T, Keykubat A, Yuksel S. Facemask therapy with and without expansion. Am J Orthod Dentofacial Orthop 2007 October;132(4):467-74.

(9) Ngan P, Yiu C. Evaluation of treatment and posttreatment changes of protraction facemask treatment using the PAR index. Am J Orthod Dentofacial Orthop 2000 October;118(4):414-20.

(10) Dynaflex. Images of CS 2000 appliance, TB SAG, and MSX 2000 appliances. 2007. Ref Type: Catalog

(11) Proffit W, Fields HW, Jr. Contemporary Orthodontics. 3rd ed. St. Louis, Missouri: Mosby; 2000.

(12) Angle E H. Treatment of malocclusion of the teeth and fractures of the maxillae, Angle's system. 6th ed. Philadelphia: SS White Dental Mfg Co.; 1900.

(13) Sanborn RT. Differences Between the Facial Skeletal Patterns of Class III Malocclusion and Normal Occlusion. Angle Orthod 1955;25:208-22.

(14) Mitani H, Sato K, Sugawara J. Growth of mandibular prognathism after pubertal growth peak. Am J Orthod Dentofacial Orthop 1993 October;104(4):330-6.

(15) Jacobson A, Evans WG, Preston CB, Sadowsky PL. Mandibular prognathism. Am J Orthod 1974 August;66(2):140-71. 
(16) Williams S, Andersen CE. The morphology of the potential Class III skeletal pattern in the growing child. Am J Orthod 1986 April;89(4):302-11.

(17) Battagel JM. The aetiological factors in Class III malocclusion. Eur J Orthod 1993 October;15(5):347-70.

(18) Reyes BC, Baccetti T, McNamara JA, Jr. An estimate of craniofacial growth in Class III malocclusion. Angle Orthod 2006 July;76(4):577-84.

(19) Sato S. Case report: developmental characterization of skeletal Class III malocclusion. Angle Orthod 1994;64(2):105-11.

(20) Chen F, Terada K, Yang L, Saito I. Dental arch widths and mandibular-maxillary base widths in Class III malocclusions from ages 10 to 14. Am J Orthod Dentofacial Orthop 2008 January;133(1):65-9.

(21) Franchi L, Baccetti T. Transverse maxillary deficiency in Class II and Class III malocclusions: a cephalometric and morphometric study on postero-anterior films. Orthod Craniofac Res 2005 February;8(1):21-8.

(22) Chen F, Terada K, Wu L, Saito I. Dental arch widths and mandibular-maxillary base width in Class III malocclusions with low, average and high MP-SN angles. Angle Orthod 2007 January;77(1):3641.

(23) Uysal T, Usumez S, Memili B, Sari Z. Dental and alveolar arch widths in normal occlusion and Class III malocclusion. Angle Orthod 2005 September;75(5):809-13.

(24) Behrents RG. Growth of the aging craniofacial skeleton: Monograph 17, Craniofacial growth series. Ann Arbor: Center for Human Growth and Development; 1985.

(25) Proffit W, Ackermann JL. A systemic approach to orthodontic diagnosis and treatment planning. Current orthodontic concepts and techniques. 3rd ed. St. Louis: CW Mosby; 1985. p. 1-98.

(26) Bjork A, Skieller V. Normal and abnormal growth of the mandible. A synthesis of longitudinal cephalometric implant studies over a period of 25 years. Eur J Orthod 1983;5:1-46.

(27) Miyajima K, McNamara JA, Jr., Sana M, Murata S. An estimation of craniofacial growth in the untreated Class III female with anterior crossbite. Am J Orthod Dentofacial Orthop 1997 October;112(4):425-34.

(28) Ellis E, III, McNamara JA, Jr. Components of adult Class III malocclusion. J Oral Maxillofac Surg 1984 May;42(5):295-305.

(29) Baccetti T, Reyes BC, McNamara JA, Jr. Craniofacial changes in Class III malocclusion as related to skeletal and dental maturation. Am J Orthod Dentofacial Orthop 2007 August;132(2):171.

(30) Litton SF, Ackermann LV, Isaacson RJ, Shapiro BL. A genetic study of Class 3 malocclusion. Am J Orthod 1970 December;58(6):565-77. 
(31) McGuigan DG. The Hapsburgs. London: WH Allen; 1966.

(32) Rakosi T, Schilli W. Class III anomalies: a coordinated approach to skeletal, dental, and soft tissue problems. J Oral Surg 1981 November;39(11):860-70.

(33) Chang HP, Tseng YC, Chang HF. Treatment of mandibular prognathism. J Formos Med Assoc 2006 October;105(10):781-90.

(34) Vadiakas G, Viazis AD. Anterior crossbite correction in the early deciduous dentition. Am J Orthod Dentofacial Orthop 1992 August;102(2):160-2.

(35) Croll TP, Riesenberger RE. Anterior crossbite correction in the primary dentition using fixed inclined planes. I. Technique and examples. Quintessence Int 1987 December;18(12):847-53.

(36) Ngan P, Hu AM, Fields HW, Jr. Treatment of Class III problems begins with differential diagnosis of anterior crossbites. Pediatr Dent 1997 September;19(6):386-95.

(37) Turley PK. Orthopedic correction of Class III malocclusion with palatal expansion and custom protraction headgear. J Clin Orthod 1988 May;22(5):314-25.

(38) Rabie AB, Gu Y. Diagnostic criteria for pseudo-Class III malocclusion. Am J Orthod Dentofacial Orthop 2000 January;117(1):1-9.

(39) Le GM, Philip C, Bandon D. [The functional mandibular prognathism]. Arch Pediatr 2009 January;16(1):77-83.

(40) Franchi L, Baccetti T, Tollaro I. Predictive variables for the outcome of early functional treatment of Class III malocclusion. Am J Orthod Dentofacial Orthop 1997 July;112(1):80-6.

(41) Ghiz MA, Ngan P, Gunel E. Cephalometric variables to predict future success of early orthopedic Class III treatment. Am J Orthod Dentofacial Orthop 2005 March;127(3):301-6.

(42) Ngan P. Early treatment of Class III malocclusion: is it worth the burden? Am J Orthod Dentofacial Orthop 2006 April;129(4 Suppl):S82-S85.

(43) Kerr WJ, Miller S, Dawber JE. Class III malocclusion: surgery or orthodontics? Br J Orthod 1992 February;19(1):21-4.

(44) Pancherz H. Dentofacial orthopedics or orthognathic surgery: is it a matter of age? Am J Orthod Dentofacial Orthop 2000 May;117(5):571-4.

(45) Snow MD, Turvey TA, Walker D, Proffit WR. Surgical mandibular advancement in adolescents: postsurgical growth related to stability. Int J Adult Orthodon Orthognath Surg 1991;6(3):143-51.

(46) Stellzig-Eisenhauer A, Lux CJ, Schuster G. Treatment decision in adult patients with Class III malocclusion: orthodontic therapy or orthognathic surgery? Am J Orthod Dentofacial Orthop 2002 July;122(1):27-37. 
(47) Andrews L. Straight Wire: The Concept and Appliance. San Diego, CA: L.A. Wells Co.; 1989.

(48) Ochoa BK, Nanda RS. Comparison of maxillary and mandibular growth. Am J Orthod Dentofacial Orthop 2004 February;125(2):148-59.

(49) Sadowsky PL. Craniofacial growth and the timing of treatment. Am J Orthod Dentofacial Orthop 1998 January;113(1):19-23.

(50) Rudolph DJ, White SE, Sinclair PM. Multivariate prediction of skeletal Class II growth. Am J Orthod Dentofacial Orthop 1998 September;114(3):283-91.

(51) Turchetta BJ, Fishman LS, Subtelny JD. Facial growth prediction: a comparison of methodologies. Am J Orthod Dentofacial Orthop 2007 October;132(4):439-49.

(52) Schulhof RJ, Nakamura S, Williamson WV. Prediction of abnormal growth in class III malocclusions. Am J Orthod 1977 April;71(4):421-30.

(53) Enlow DH, Hans MG. Essentials of Facial Growth. Saunders; 1996.

(54) Nanda RS, Ghosh J. Longitudinal growth changes in the sagittal relationship of maxilla and mandible. Am J Orthod Dentofacial Orthop 1995 January;107(1):79-90.

(55) Baccetti T, Tollaro I. A retrospective comparison of functional appliance treatment of Class III malocclusions in the deciduous and mixed dentitions. Eur J Orthod 1998 June;20(3):309-17.

(56) Franchi L, Baccetti T, McNamara JA. Postpubertal assessment of treatment timing for maxillary expansion and protraction therapy followed by fixed appliances. Am J Orthod Dentofacial Orthop 2004 November;126(5):555-68.

(57) Pangrazio-Kulbersh V, Berger JL, Janisse FN, Bayirli B. Long-term stability of Class III treatment: rapid palatal expansion and protraction facemask vs LeFort I maxillary advancement osteotomy. Am J Orthod Dentofacial Orthop 2007 January;131(1):7-19.

(58) Turpin. FIND SOURCE AND EDIT. Am J Orthod Dentofacial Orthop 2009.

(59) Baik HS, Jee SH, Lee KJ, Oh TK. Treatment effects of Frankel functional regulator III in children with class III malocclusions. Am J Orthod Dentofacial Orthop 2004 March;125(3):294-301.

(60) Levin AS, McNamara JA, Jr., Franchi L, Baccetti T, Frankel C. Short-term and long-term treatment outcomes with the FR-3 appliance of Frankel. Am J Orthod Dentofacial Orthop 2008 October;134(4):513-24.

(61) Ngan P, Hagg U, Yiu C, Merwin D, Wei SH. Treatment response to maxillary expansion and protraction. Eur J Orthod 1996 April;18(2):151-68.

(62) Ngan P. Cephalometric and Occlusal Changes in Class III Patients after Maxillary Expansion and Protraction. Eur J Orthod 1998;20. 
(63) Arman A, Toygar TU, Abuhijleh E. Profile changes associated with different orthopedic treatment approaches in Class III malocclusions. Angle Orthod 2004 December;74(6):733-40.

(64) Tollaro I, Baccetti T, Franchi L. Mandibular skeletal changes induced by early functional treatment of Class III malocclusion: a superimposition study. Am J Orthod Dentofacial Orthop 1995 November;108(5):525-32.

(65) Garattini G, Levrini L, Crozzoli P, Levrini A. Skeletal and dental modifications produced by the Bionator III appliance. Am J Orthod Dentofacial Orthop 1998 July;114(1):40-4.

(66) Kidner G, DiBiase A, DiBiase D. Class III Twin Blocks: a case series. J Orthod 2003 September;30(3):197-201.

(67) Atalay Z, Tortop T. Dentofacial effects of a modified tandem traction bow appliance. Eur J Orthod 2010 December;32(6):655-61.

(68) Ngan P, Wei SH, Hagg U, Yiu CK, Merwin D, Stickel B. Effect of protraction headgear on Class III malocclusion. Quintessence Int 1992 March;23(3):197-207.

(69) da Silva Filho OG, Magro AC, Capelozza FL. Early treatment of the Class III malocclusion with rapid maxillary expansion and maxillary protraction. Am J Orthod Dentofacial Orthop 1998 February;113(2):196-203.

(70) Chong YH, Ive JC, Artun J. Changes following the use of protraction headgear for early correction of Class III malocclusion. Angle Orthod 1996;66(5):351-62.

(71) Nartallo-Turley PE, Turley PK. Cephalometric effects of combined palatal expansion and facemask therapy on Class III malocclusion. Angle Orthod 1998 June;68(3):217-24.

(72) Bjork A. The face in profile: An anthoropological x-ray investigation of Swedish children and conscripts. Lund: Berlingska Boktrycheriet 1947;40-58.

(73) Pancherz H. Vertical dentofacial changes during Herbst appliance treatment. A cephalometric investigation. Swed Dent J Suppl 1982;15:189-96.

(74) Baccetti T, McGill JS, Franchi L, McNamara JA, Jr., Tollaro I. Skeletal effects of early treatment of Class III malocclusion with maxillary expansion and face-mask therapy. Am J Orthod Dentofacial Orthop 1998 March;113(3):333-43.

(75) Baccetti T, Franchi L, McNamara JA, Jr. Treatment and posttreatment craniofacial changes after rapid maxillary expansion and facemask therapy. Am J Orthod Dentofacial Orthop 2000 October;118(4):404-13.

(76) Westwood PV, McNamara JA, Jr., Baccetti T, Franchi L, Sarver DM. Long-term effects of Class III treatment with rapid maxillary expansion and facemask therapy followed by fixed appliances. Am J Orthod Dentofacial Orthop 2003 March;123(3):306-20. 
(77) Del SM, Jr. Influence of occlusal plane inclination on ANB and Wits assessments of anteroposterior jaw relationships. Am J Orthod Dentofacial Orthop 2006 May;129(5):641-8.

(78) Hurmerinta K, Rahkamo A, Haavikko K. Comparison between cephalometric classification methods for sagittal jaw relationships. Eur J Oral Sci 1997 June;105(3):221-7.

(79) Rushton R, Cohen AM, Linney AD. The relationship and reproducibility of angle ANB and the Wits appraisal. Br J Orthod 1991 August;18(3):225-31.

(80) Liou EJ. Toothborne orthopedic maxillary protraction in Class III patients. J Clin Orthod 2005 February;39(2):68-75.

(81) Heymann GC, Cevidanes L, Cornelis M, De Clerck HJ, Tulloch JF. Three-dimensional analysis of maxillary protraction with intermaxillary elastics to miniplates. Am J Orthod Dentofacial Orthop 2010 February;137(2):274-84.

(82) De Clerck HJ, Cornelis MA, Cevidanes LH, Heymann GC, Tulloch CJ. Orthopedic traction of the maxilla with miniplates: a new perspective for treatment of midface deficiency. J Oral Maxillofac Surg 2009 October;67(10):2123-9.

(83) Williams MD, Sarver DM, Sadowsky PL, Bradley E. Combined rapid maxillary expansion and protraction facemask in the treatment of Class III malocclusions in growing children: a prospective long-term study. Semin Orthod 1997 December;3(4):265-74.

(84) Liou EJ. Effective maxillary orthopedic protraction for growing Class III patients: a clinical application simulates distraction osteogenesis. Prog Orthod 2005;6(2):154-71.

(85) Campbell PM. The dilemma of Class III treatment. Early or late? Angle Orthod 1983 July;53(3):175-91. 